Portland State University

PDXScholar

\title{
The Development and Testing of an Instrument to Measure Client Satisfaction of Child Protective Service Families
}

James Michael White

Portland State University

Follow this and additional works at: https://pdxscholar.library.pdx.edu/open_access_etds Let us know how access to this document benefits you.

\section{Recommended Citation}

White, James Michael, "The Development and Testing of an Instrument to Measure Client Satisfaction of Child Protective Service Families" (1991). Dissertations and Theses. Paper 1289.

https://doi.org/10.15760/etd.1288

This Dissertation is brought to you for free and open access. It has been accepted for inclusion in Dissertations and Theses by an authorized administrator of PDXScholar. Please contact us if we can make this document more accessible: pdxscholar@pdx.edu. 


\author{
THE DEVELOPMENT AND TESTING OF AN INSTRUMENT \\ TO MEASURE CLIENT SATISFACTION OF \\ CHILD PROTECTIVE SERVICE FAMILIES
}

by

JAMES MICHAEL WHITE

A dissertation submitted in partial fulfillment of the requirements for the degree of

DOCTOR OF PHILOSOPHY
in
URBAN STUDIES

Portland State University

1991 
TO THE OFFICE OF GRADUATE STUDIES:

The members of the Committee approve the dissertation of James Michael White presented May 6, 1991.
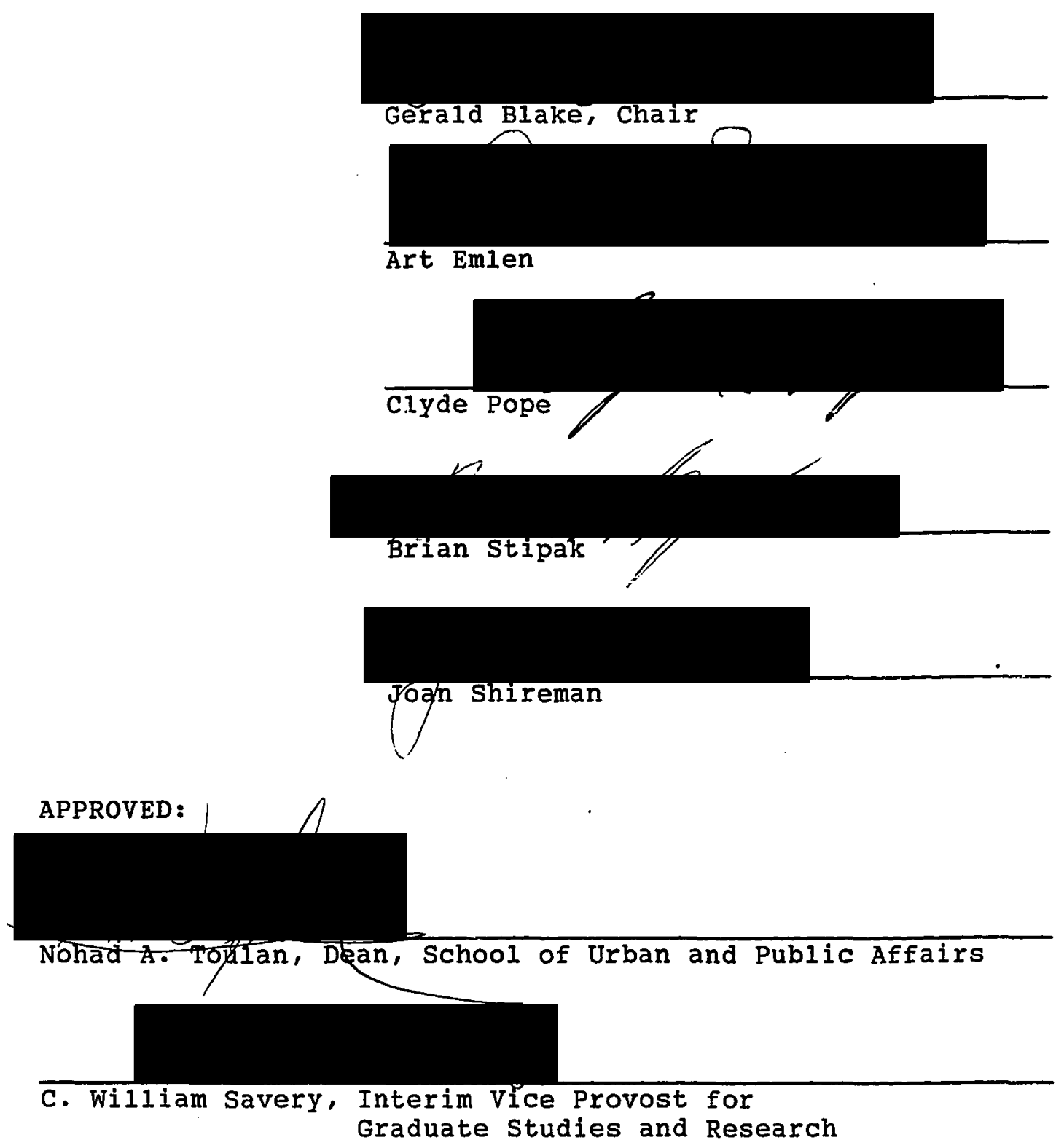
AN ABSTRACT OF THE DISSERTATION OF James Michael White for the Doctor of Philosophy in Urban Studies presented May 6 , 1991 .

Title: The Development and Testing of an Instrument to Measure Client Satisfaction of Child Protective Service Families.

APPROVED BY THE MEMBERS OF THE DISSERTATION COMMITTEE:

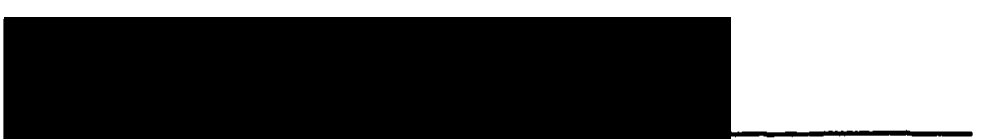

Dr. Gerald Blake, Chair

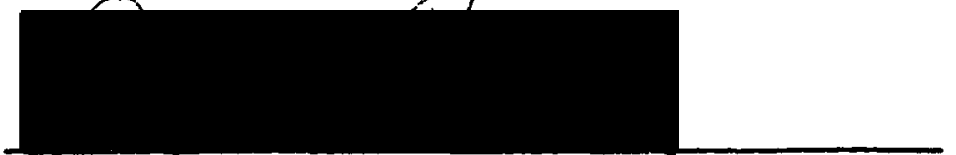

Dr. Art Emlen

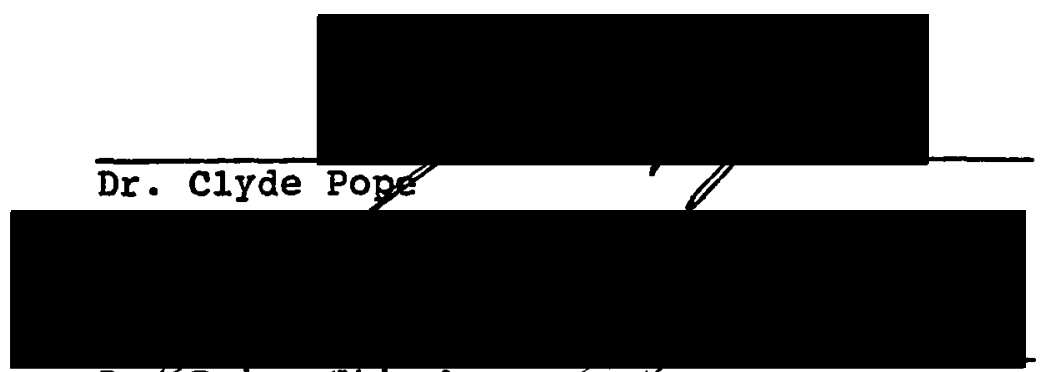

Dr. Brian Stipak

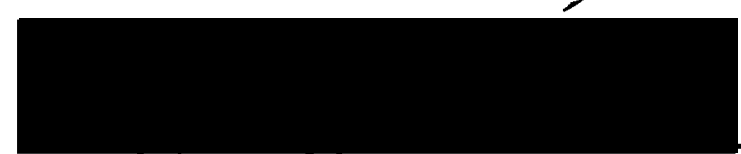

Drf Joan Shireman

The purpose of this study was to develop and test an instrument to measure client satisfaction among families who 
are clients of a child protective services agency.

With the growing numbers of families coming into contact

with CPS agencies, the burgeoning numbers of children in

foster care, and the increasing attention to the

effectiveness of services within this population, client

feedback is one approach that has been largely ignored by CSP

administrators. The basic problem this dissertation

addressed is the issue of obtaining feedback from the

involuntary client, such as the family in a child abuse case.

Specifically, this dissertation addressed the following

four research questions:

1. Can a client satisfaction instrument be developed for CPS clients largely through the input of the clients?

2. What are the domains of satisfaction that are applicable to CPS families?

3. How much involvement do the CPS families feel that they have in the planning and decision-making in their cases? What impact does this have on their overall level of satisfaction?

4. What are the relationships among the various domains of satisfaction and the overall level of satisfaction?

Two rounds of interviews were held with families who had been clients of the CPS agency serving. the state of oregon, Children's Services Division. These interviews served as the major source of information for the identification of 
satisfaction domains and for the development of a closed-ended instrument to measure these domains. The responses to the interviews were content analyzed and four specific domains of client satisfaction were identified. These were: (a) Helpfulness, (b) Partnership, (c) Choice, and (d) Information Sharing. Items were also developed to comprise a "General Satisfaction" domain.

A closed-ended instrument was constructed and pre-tested in two large Branch offices of the agency. This instrument included five items to address the interest of the agency in the issue of "convenience." It also included seven items to gather information concerning the opinions of clients on the agency mission and goals. Results of the pre-test were analyzed and the instrument revised. The final instrument was mailed to a population of 4,337 CPS families. Surveys were returned by 489 , or $11 \%$, of the families.

Analyses, including correlational analysis, factor analysis, and internal consistency reliability analysis, provided empirical support for the domains identified through the client interviews. Analysis provided very little support for the "convenience" domain. Satisfaction on the four scales measuring the four domains of satisfaction was positively correlated with measure of overall satisfaction.

The overall theme which ran through the entire client survey instrument was that of empowerment. Three of the four domains of satisfaction which were identified were: 
(a) "Partnership," (b) "Choice," and (c) "Information

Sharing." The challenge is for CPS agencies to incorporate these issues into their practice. 
TABLE OF CONTENTS

PAGE

LIST OF TABLES............................

LIST OF FIGURES...........................

CHAPTER

I STATEMENT OF THE PROBLEM.................

Child Protective Services: The Last Twenty

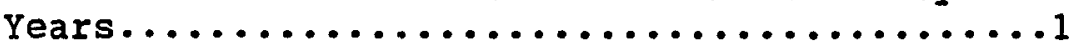

The Growth in Awareness of Child

Maltreatment

The Reaction to the Increase in Children in Foster Care

The Importance of Gathering Feedback in Child

Protective Services..................5

Social Service Consumerism

Parental Rights Advocacy

Increase in Child Abuse

Who Is the client in Child Protective Services?

Research Questions...................14

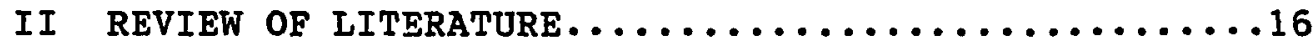

The Construct of Client Satisfaction.......16

Definition

Implications for Use

Measurement Issues

Findings from Prior Research with

Client Satisfaction Surveys...........27

State of Knowledge Regarding client

Satisfaction of Involuntary clients......30

Gaining Feedback from Involuntary

clients 
Client Satisfaction Surveys in Child Protective Services

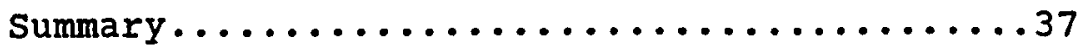

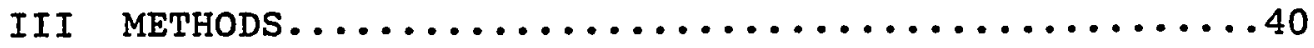

Development of the Instrument.........40

The Study Population: The Agency Context

Generating the Potential Dimensions.......45

The First Interviews

The second Interviews

Formulating the Closed-Ended Questionnaire

Items........................70

Initial Item Formulation

The Pre-Test and Instrument Refinement

The Final Survey Instrument............77

Satisfaction Statements

Caseworker Descriptions

List of Services

Implementation of the Instrument

Descriptive statistics..............96

Satisfaction statements

Caseworker Descriptors

List of Services

Scale Construction..................103

Analysis of Item Convergent Validity Analysis of Item Discriminant Validity Principle Components Analysis Internal Consistency Reliability of the Scale Scores

Relationships Among the Four Scales

Scales of Satisfaction and General 


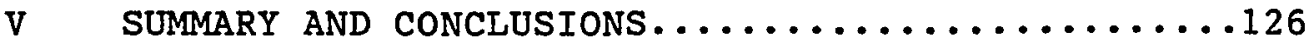

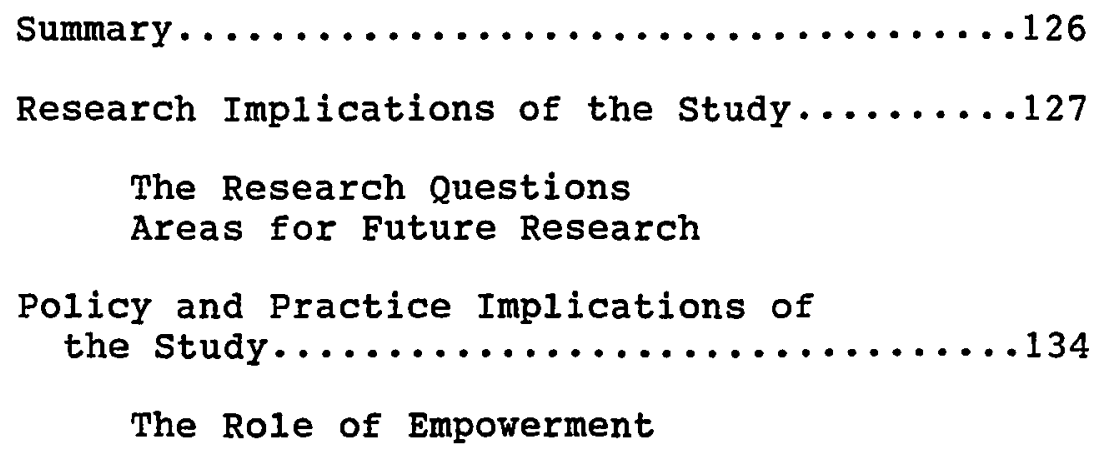

A DIMENSIONS OF SATISFACTION FROM LITERATURE

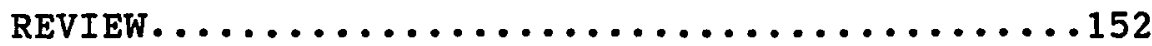

B CLIENT SATISFACTION INTERVIEW SCHEDULE.........154

C CLIENT SATISFACTION SURVEY PRE-TEST.........158

D CLIENT SATISFACTION SURVEY ITEMS LISTED

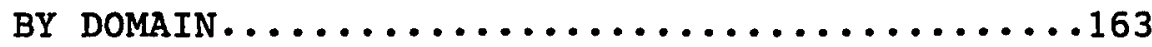

E CLIENT SATISFACTION SURVEY FINAI INSTRUMENT .....166

F CLIENT SATISFACTION SURVEY COVER LETTER.......171

G CORRELATIONS AMONG 22 CLIENT SATISFACTION ITEMS GROUPED BY DOMAIN....................... 


\section{LIST OF TABLES}

PAGE

List of Services Received by 17 Families Interviewed....................... 54 Descriptors of Caseworkers by 17 Families

Interviewed....................56

III Comparison of Pre-Test and Final Items......78

IV Caseworker Descriptors...............82

V Means and Standard Deviations for 39 Items

in Satisfaction statements..........98

VI Means and Standard Deviations for 22 Items

in Four Domains of Satisfaction........100

VII Means and Standard Deviations for the List

of 23 Caseworker Descriptors............101

VIII Means and Standard Deviations for the

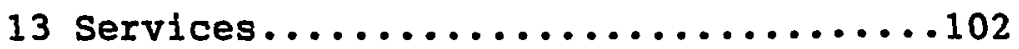

IX Correlations Among 22 client Satisfaction

Items Grouped by Domain................. 104

X Correlations Among the Six Items in the

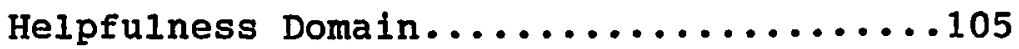

XI Correlations Among the Five Items in the

Partnership Domain................106 
XII Correlations Among the Five Items in the

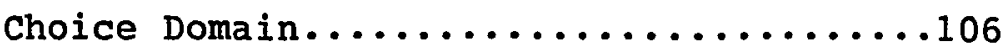

XIII Correlations Among the Six Items in the

Information Sharing Domain..........106

XIV Correlations Among Items and Proposed

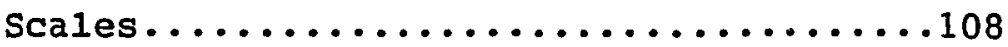

XV Correlations Among Items and Proposed

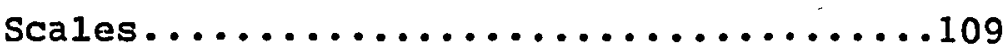

XVI Correlations Among 22 client Satisfaction

Items and Three Rotated Principle

Components........................111

XVII Correlations Among 22 client Satisfaction

Items and Four Rotated Principle

Components......................113

XVIII Reliability Analysis for the Helpfulness

Scale.. $(\mathrm{N}=433) \ldots \ldots \ldots \ldots \ldots \ldots \ldots \ldots \ldots$

XIX Reliability Analysis for the Partnership

scale.. $(\mathrm{N}=444) \ldots \ldots \ldots \ldots \ldots$...............

XX Reliability Analysis for the Choice

Scale.. $(\mathrm{N}=431) \ldots \ldots \ldots \ldots \ldots \ldots \ldots \ldots \ldots$

XXI Reliability Analysis for the Information

Sharing Scale.. $(\mathrm{N}=432) \ldots \ldots \ldots \ldots \ldots 16$

XXI Reliability Analysis for the Helpfulness

Scale After Correction.. (N=444) ......117

XXII Reliability Analysis for the Information

Sharing Scale After Correction.. ( $(\mathrm{N}=441) \ldots 117$ 
XXIV Reliability Estimates for Client Satisfaction scales................118

XXV Correlations Among the Four Scales

of client Satisfaction.............119

XXVI Domain Correlations Among the Four Scales

of Client Satisfaction.................

XXVII Shared Variance Explained Among the Four

Scales of Client Satisfaction.........120

XXVIII Reliability Analysis for the General

Satisfaction Scale..(N=443).........122

XXIX Reliability Analysis for the General

Satisfaction Scale After

Correction.. (N=464) ..................

Xxx Correlation Among the Three Measures of

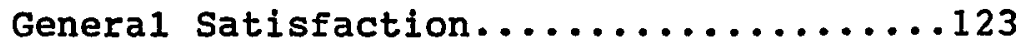

XXXI Correlations Among the Four Scales of

Satisfaction and Three Measures of

General Satisfaction...............124

XXXII Correlations Among the Four Scales of

Satisfaction and Three Measures of

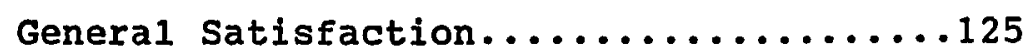




\section{LIST OF FIGURES}

PAGE

1. A Funnel of the Total Number of CPS Referrals

Which Were Assessed in Calendar Year 1988

to the Total Number of Families Who Were

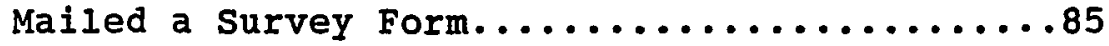


CHAPTER I

STATEMENT OF THE PROBLEM

CHILD PROTECTIVE SERVICES: THE LAST TWENTY YEARS

The last 20 years have been very tumultuous for child protective services agencies. Child protective services, or CPS, is a specialized area of social work within the broad field of child welfare concerned with protecting children from intrafamilial maltreatment.

The agencies that carry out this role perform a number of related tasks. Holder and Mohr (1981) state that CPS casework consists of seven basic steps: (a) intake, (b) initial assessment, (c) diagnostic assessment, (d) case planning, (e) service provision, (f) case plan evaluation, and (g) termination of the case plan.

Intake and initial assessment involve receiving and investigating allegations of child abuse and neglect. This responsibility is often shared with law enforcement. The next step involves assessing the risk of harm to the child. In instances in which the child is judged to be at high risk of harm, the child may be placed into protective custody by being removed from his family and placed into a shelter home 
or foster home.

The remaining tasks involve developing a service plan to provide services to the family to mitigate the circumstances resulting in the risk of harm to the child, providing those services, evaluating progress in meeting the service plan objectives, and closing the case at the point of successful achievement of these objectives.

The Growth in Awareness of Child Maltreatment

Concerns over the increasing numbers of child abuse and neglect victims during the 1950's and early 1960's led to the strengthening of child abuse laws and policies that stressed removal and placement as a means of protection. The decade of the 1970's saw an expanded awareness among the general public of the problem of abused and neglected children. During this decade, Congress enacted the Child Abuse Prevention and Treatment Act (Public Law 93-247) that mandated the reporting and the investigation of reports of possible cases of child abuse and neglect. It also required the establishment of state central registries to serve as the official clearinghouse of statistics regarding numbers of investigations and victims of abuse.

During the 1970's, the National Center on Child Abuse and Neglect was established. A network of national organizations attempting to advance services was also developed. 
These included the National Center for the Prevention and Treatment of Child Abuse and Neglect in Denver, the Child Protection Division of the American Humane Association in Denver, and the Chicago-based National Committee for the Prevention of Child Abuse.

This growth in public awareness continued into the 1980 's and was a major contributing factor in the tremendous increases during this period in the numbers of reports of child abuse and neglect. The laws enacted a decade earlier required that all such reports be investigated and that services be provided when deemed appropriate.

One major consequence of this growth in reporting was an expanding population of children who were removed from their parents or caretakers and placed into protective custody. By the early 1980's, one result of the response to the crisis of child maltreatment was a new crisis in foster care. Some were beginning to question the wisdom of the removal of children from their homes as the answer to child protection (Fanshe1, 1971; Gruber, 1978; Mass \& Engler, 1959). Disturbing findings were reported about the negative effects of long-term placement of children in out-of-home care, the consequences of multiple movements of children among different foster homes, and the difficulties of reuniting children with their natural families after lengthy periods in care. 
The Reaction to the Increase in Children in Foster Care

By the late 1960's and into the 1970's, the concern of many had shifted to the growing numbers of children in foster care. This led to the enactment of Public Law 96-272 (the Adoption Assistance and Child Welfare Act of 1980). This 1aw requires states to see that "reasonable" efforts are made to prevent out-of-home placement, to reunite families when placement has been necessary, and to provide permanent alternative homes for children for whom reunification with their own families has not been possible. This legislation gave a mandate to the concept of a child-centered and family-focused approach to reunification and permanence.

This concern also led to the development of services and an approach, termed family-based placement prevention, to prevent removal of children from their own homes. This approach is based on the principle that the first and greatest investment, both to prevent the removal of children and to hasten their return, should be made in services that support and strengthen families in their role as primary caretakers of their children. Most of the models of these programs subscribe to either a family systems or to a behavioral approach.

The 1980's witnessed a dramatic increase in the development of these services. This increase was due, in part, to the fact that family preservation services are consistent with the prevailing public policies pertaining to 
prevention of placement and the treatment of children in the least restrictive environment possible. It is also consistent with the societal values pertaining to the importance of families in providing the primary nurturance and socialization of children. Finally, this approach emphasizes client empowerment and client competence.

The initial success of PL 96-292 in keeping children at home and returning them to their parents may have slowed. The numbers of chilaren in foster care, which appeared to be moving downward during the mid-1980's, have again turned up at alarming rates. In its first five years, it is estimated that the federal law helped cut the number of children in foster care by nearly half, from 500,000 to 270,000. But, since 1985, the number has grown steadily. It is estimated that there are 360,000 children currently in foster care.

\section{THE IMPORTANCE OF GATHERING FEEDBACK IN CHILD PROTECTIVE SERVICES}

Few attempts have been made to gain systematically an understanding of how the families who are involved in child abuse cases, or child protective services (CPS), view their participation in the decisions affecting them. Little is known about what constitutes client satisfaction among this group of clients. Policy-makers and decision-makers in other areas of human services have begun to understand the 
importance of client feedback. This is particularly true in the health and mental health fields where client feedback has been used both as a measure of service effectiveness in outcome evaluations and as a predictor of future behavior. Three trends which have occurred in the past 15 years point to the importance of gathering such feedback among CSP clients: social service consumerism, parental rights advocacy, and increases in child abuse.

\section{Social Service Consumerism}

The first trend is the increase in the emphasis upon client satisfaction with services as evidenced by the growing number of publications regarding satisfaction in the last 10 to 15 years. This phenomenon seems to be part of a nationwide trend toward holding those who provide services more accountable to the consumers of those services. Additionally, those who hold the purse-strings over the ever-shrinking public resources are increasingly demanding that social service agencies be held accountable for demonstrating the effectiveness of the services that are being purchased. Agencies are being asked to establish measurable outcomes and to target their resources toward those areas and clients who have the greatest potential for benefiting from these services.

For example, in the state of oregon, during the 1989-91 Legislative session, legislation was passed which required 
that an existing state commission, the Oregon Youth Services Commission, evaluate the efficiency and effectiveness of programs administered by Children's Services Division.

\section{Parental Rights Advocacy}

A second trend paralleling this rise in social service consumerism has been a growing, more specific concern among clients and their advocates regarding the rights of parents in the child welfare system. These individuals have raised many issues, including the termination of parental rights, foster care drift, cross-cultural/ethnic adoption and placement of children, visitation, "voluntary" service agreements, home visits, removal and placement of children in foster and shelter care, permanency planning, and child abuse investigations.

In recent years, citizen and client advocacy groups, such as the Committee for oregon Families and the national organization VOCAL (Victims of Child Abuse Laws), have raised questions concerning both the general decision-making process in CPS agencies and specific decisions that have been made with respect to some of these issues.

Across the nation, the child welfare agency that encompasses many of these areas of contention and has most clearly focused the debate of the rights of the child versus the rights of the parents is Child Protective Services. CPS agencies are called upon to investigate reports of possible 
child abuse and neglect and to provide services to those children and families affected. CPS staff state that the protection of the child is their paramount concern, yet they will generally add that the ultimate goal is to keep families intact whenever possible, supporting the concept of "child-centered and family-focused."

The potential conflict inherent in this mission is illustrated by two roles that CPS staff typically are asked to perform:

1. To investigate a report of possible child abuse (including the assessment of possible future harm to the child and a potential decision to place a child into protective custody) and

2. To engage the family in a therapeutic social service partnership to restore the family or to keep the family together by improving the family functioning and parenting skills.

\section{Increase in Child Abuse}

As mentioned earlier, the third trend has been a dramatic rise nationally in the numbers of child abuse investigations and victims of abuse and neglect. These increases have continued to stretch resources needed to conduct these investigations and provide services to these families.

Two separate national studies both indicated such 
increases. First, the purpose of the second National Incidence Study (1988) commissioned by the National Center on Child Abuse and Neglect was to assess the current national incidence of child abuse and neglect and to determine what changes had taken place since the first study completed in 1980. Data from 1986 showed an increase from 9.8 to 16.3 children per 1,000 (a $66 \%$ increase) in the previous six years in the incidence of children who experienced abuse or neglect.

Second, in 1989, the American Association for Protecting Children published its fourteenth annual report representing a profile of officially reported child abuse and neglect in the United States and participating jurisdictions. Like the study of child victims, this study of reports also showed a large increase. Data from 1987 showed an increase from 19.4 to 34.0 children per 1,000 (a $75 \%$ increase) in the previous six years in the incidence of children who were reported as possible victims of abuse or neglect. In the eleven years since 1976 , this increase was $237 \%$.

In Oregon, data from 1989 showed that the number of victims had increased from 10.4 to 12.3 children per 1,000 (an 18\% increase) in the previous five years and that the number of total reports had increased from 16,731 to 25,018 (a $50 \%$ increase) during the same period. Since 1981 , the total number of reports had increased from 10,621, a $136 \%$ increase. 
Two of the major conclusions of a study of foster care by CSD (CSD Research Unit, 1989) relate directly to the potential importance of client feedback. First, a growing percentage of CSD clients, including those families who experience foster care, have had some contact with the CPS role of the agency. While as recently as $1985,40 \%$ of children in foster care had CPS involvement, that figure had increased to $60 \%$ by 1987 . In the foster care study, more than $80 \%$ of the children in the sample were in care due to a protective service issue. Among the general client population of the agency in 1989, over two-thirds of the families receiving services had a protective service referral.

Secondly, a major finding in the study was the lack of compliance with case plan requirements. Findings suggest that this lack of compliance was a major factor contributing to the growing number of placements, children remaining in care, and an estimate that $50 \%$ of the foster care population would not return to their families.

Nationally, these burgeoning numbers have added tremendous strains and placed increasing pressure on the public child welfare and CPS agencies at the same time that the public, the state legislatures, and the clients are demanding that these agencies be more accountable, responsible, and effective. Agencies are also being asked to rethink their broad child welfare mission and to consider 
focusing exclusively either on the issues of child maltreatment or on the preventive family service component.

The argument can be made that one of the key ingredients to a "successful outcome" in a protective services case lies in the ability to engage the client in the treatment process which includes problem identification, case plan development, and participation in services to successfully complete the plan (Maluccio, 1979; Oxley, 1966). Yet, despite the growing interest in the potential benefits of client feedback by some in various social service arenas, and also among those within CPS agencies who advocate the family-based approach to the issues of child protection and the placement of children in protective custody, this source of information has remained relatively untapped by child protective service agencies.

One possible explanation for failure to seek this information from families is that most CPS agencies are included in large public child welfare agencies and do not have established systems for evaluating their programs and services.

Second, even for those agencies which have or are discussing adding such evaluation systems, the idea of including client feedback as a component of such a system raises logistical, resource, and workload questions that are often left unaddressed.

Third, many caseworkers are reluctant to be a part of any systematic, centralized effort of evaluating services 
because they are sensitive to the possibilities of such efforts being used to evaluate their individual performances. In addition, many of the families involved with CPS agencies are often viewed as less than ideal service recipients from whom to elicit opinions concerning their view of the CPS agency. They often include the perpetrator and an enabling or denying adult; are seen as inarticulate, lacking in objectivity, and uncooperative, and may be resisting the efforts of the agency to assess and offer services to ameliorate the situation.

In sum, with the growing numbers of families coming into contact with CPS agencies, the burgeoning numbers of children in foster care, and the increasing attention to the effectiveness of services with this population, client feedback is one approach that has been largely ignored by CSP administrators. The basic problem this dissertation will address is the issue of obtaining feedback from the involuntary client, such as the family in a child abuse case. Specifically, the goal of this dissertation is to develop and test a client satisfaction instrument that can be applied to CPS families.

\section{Who is the Client in Child Protective Services?}

Unlike other social service programs and agencies, a discussion of the use of clients in evaluating child protective services must address the question of who is the 
client. At least four possible "clients" have been identified.

First, the person who initiates the agency response by making the protective service referral is in some respects the client. This individual felt enough concern for the safety or well-being of a child to report that concern officially. It is logical to argue that such persons would be interested in, and even deserve to be informed of, the outcome of a specific case or in general about the services and outcomes of the agency to which they reported.

Second, some would also argue that, as a tax-supported public agency, the services are being provided by the public and ultimately for the public. Shouldn't the opinion of the general public be included in any such discussion?

Third, most child protective services workers will echo agency statements that the purpose of their services is to insure that children are protected and that risks are minimized. Doesn't this make the abused or neglected child the obvious primary client of these services?

Finally, however, as mentioned earlier, the family is very often the focus of the services and case planning. Isn't the family the client to be studied?

For purposes of this study, the focus is upon the family. Choosing more than one type of client would have meant the development of multiple instruments, the generation of different groups of research questions, and the analysis 
of multiple groups of data. Future studies may want to study the satisfaction of the other client groups. This study will focus upon the family as the client to be studied. The child protective service investigation is generally directed toward one or more family members. The services and case planning are normally directed toward the family. Additionally, focusing the study upon the child would have presented ethical and logistical problems. At what age is a child old enough to be included in the interviews? In the mail-out survey? How does one insure that the child is completing a mail-cut questionnaire? Is a child placed in some danger by participating in such a study?

\section{RESEARCH QUESTIONS}

Specifically, this dissertation will address the following research questions:

1. Can a client satisfaction instrument be developed for cPS clients largely through the input of the clients?

2. What are the domains of satisfaction that are applicable to CPS families?

3. How much involvement do the cPs clients feel that they have in the planning and decision-making in their cases? What impact does this have on their overall level of satisfaction? 
4. What are the relationships among the various domains of satisfaction and the overall level of satisfaction? 
CHAPTER II

REVIEW OF LITERATURE

THE CONSTRUCT OF CLIENT SATISFACTION

Definition

If one is attempting to articulate "client satisfaction" as one important outcome measure as a way of evaluating social services, then some thought needs to be given to the construct of "client satisfaction." Does there exist a clear, consistent definition of what it means? Like any other construct, satisfaction is at a level of abstraction that requires the application of measurement techniques to provide useful inferences concerning the qualities and relationships of the construct.

In their study, The Quality of American Life (1976), Campbe11, Converse, and Rodgers were concerned with measuring the individual's sense of well-being. At that time, work had been done using various social indicators as measures of objective conditions of life. These were used as proxies for the more subjective aspects and experiences of life. The authors were concerned with the lack of knowledge regarding the degree to which such measures actually 
represent the underlying psychological states. Their research grew out of the conviction that since this relationship was imperfect, research attempting to measure the quality of life needed to go directly to individuals for their descriptions of their feelings.

One of their first decisions concerned which basic construct to use to represent quality of life. They felt the choice was between two constructs: "happiness" or "satisfaction." Important prior work had been done with both.

"Happiness" had been used by Bradbury and Caplovitz (1965) in their study to establish norms for mental health related behavior of the American public. The item they used was, "Taking all things together, how would you say things are these days - would you say you are very happy, pretty happy, or not too happy these days." Their "affect-balance" theory states that happiness is the product of the presence of positive feelings and the absence of negative feelings.

"Satisfaction" was used by Cantril (1965) in a similar study. He used a "self-anchoring scale" to examine satisfaction. Individuals were first asked to think of "the best life" and "the worst life" that they could imagine and to then place themselves at the point they presently stood between these extremes. Later, respondents were asked to suppose that those who were entirely satisfied with their lives were at the top of a ladder and those who were 
extremely dissatisfied with their lives were at the bottom of a ladder. They were then asked again to place themselves at the point where they presently stood between these extremes.

Campbell, Converse, and Rodgers chose "satisfaction" for many reasons. A major one was that "happiness" carried a short-term connotation and was viewed as a measure of affect. "Satisfaction," on the other hand, implied a cognitive or judgmental experience. Additionally, they thought that "satisfaction" had more of a public policy relevance than measures of positive or negative affect. It was vịewed as a more powerful construct that was somewhat more stable. It also could be used to answer questions such as what variables contribute to its change over time. It was also more adaptable to their basic study design which called for using a series of scores from separate life domains to measure the quality of life instead of using a single global measure.

From the analytical standpoint, they argued that there were three basic reasons for choosing the construct "satisfaction." Quality of life was viewed as being comprised of specific elements that could elicit differing degrees of reward. Using a construct that was more applicable for multiple measures would provide more detailed information. Finally, it would permit the examination of the patterns of relationships among the specific measures and the contribution of each to an overall measure of quality of 
1ife. As one moves from interest in more global feelings to more specific assessments, therefore, the concept of "happiness" begins to lose its value and the concept of "satisfaction" begins to appear more appropriate.

Linder-Petz (1982) argued that, despite widespread concern with patient satisfaction in the health care literature, very little work had been done in the areas of defining the concept or in building a theory of patient satisfaction. For the purposes of this study, client satisfaction is defined as the overall judgment of the value which someone who has received services places in the interaction and experiences with the provider of the services. The overall level of satisfaction is comprised of a combination of experiences, or domains, of more specific judgments and the set of criteria or requirements applied by the individual to these experiences.

client satisfaction is, therefore, viewed as one important aspect of an individual client's relationship with the agency or individual providing the service. It is seen both as one basic source of information with which to evaluate the services received and as a source of motivation which can serve to underlie and shape future behavior.

\section{Implications for Use}

Client feedback can be used for a number of purposes by organizations that provide services (Millar \& Millar, 1981). 
These include agency accountability, budget preparation and justification, worker motivation, and worker assessment. Two other uses are of particular importance, measuring effectiveness of services and predicting future behavior. Measuring Effectiveness of Services. A number of authors have discussed the advantages of involving clients in the evaluation and assessment of various social welfare services and agencies (Lebow, 1983; Magura \& Moses, 1986; Ware, Davies-Avery, \& Stewart, 1978). Bush, Gordon, and LeBailly (1977) interviewed a sample of children placed in foster care in order to describe characteristics of caretaking that a child finds supportive. They argue that not to include information from the children might ignore some concerns that are vital to the success of individual placements. They add that their approach is not an argument for diminishing the need for other criteria for effective care but is merely intended to add another set of criteria. The appropriateness of including client input in evaluating programs becomes a necessity if the client feedback is being used specifically to provide information on client satisfaction. Bush and Gordon (1977) refer to clients as "prime witnesses" and as the most effective reporters of the impact of programs when the question is whether or not the clients are satisfied with the services rendered. Magura and Moses (1986) describe three major types of outcome variables used to evaluate the effectiveness of 
child welfare services. These are case status variables, client status variables, and client satisfaction. Client satisfaction is used in two different ways. The first is as a direct measure of service effectiveness, in other words, it is a desired service outcome in and of itself. The second use of client satisfaction is as a proxy measure of other measures of case outcome. The assumption is that in those situations in which clients express satisfaction with services, this satisfaction is assumed to be evidence that the service was effective.

Predicting Future Behavior. A second use of client feedback is as an independent variable to predict future behavior. This use assumes that differences in satisfaction influence what people do. For example, in the health arena, studies have found that patients who are satisfied use more services than patients who are less satisfied. Studies have indicated that satisfaction is related to choice of care, location, and use of specific facilities (Elling, Whitemore \& Green, 1960; Hurtado, Greenlick \& Colombo, 1973).

of most relevance to this dissertation are studies which relate satisfaction to participation in specific treatment programs and to compliance with specific medical regimens. Evidence is accumulating that satisfied patients are more likely to comply with medical regimens (Becker, 1972; Korsch, 1968). These studies have related patient satisfaction to increased appointment-keeping, taking 
medication, intent to follow physician advice and instructions, use of services in the future, understanding and retention of medical information, and continuity of care.

In a study by Zimmerman (1988), patient satisfaction was an independent predictor of both reported behavior change and objective improvement in dental health.

Giordano (1977) states that one reason for the increased use of client feedback is the growing awareness in organizations that the successful attainment of their goals is facilitated by positive organization-client relations. More specifically, it has been argued that the effectiveness of various services and treatment is affected by the degree to which a good relationship can be established with the client. Additionally, she argues that since the goals of the organization are usually defined by the organization itself, that for evaluations to be truly reflective of the client's perspective, the clients need to be involved early in the evaluation process. This is to insure that the questions being asked actually reflect the client's perspective as well as that of the organization.

\section{Measurement Issues}

Two interrelated issues need to be considered in measuring the construct of client satisfaction. Both of these issues relate directly to the potential utility of the information derived from the instrument. The first issue 
concerns whether or not client satisfaction is viewed as a single entity or as comprised of multiple aspects, or domains. The second issue concerns whether or not client satisfaction is being measured at a general, global level or at a specific level.

Single versus Multiple Domains. One approach treats client satisfaction as a construct composed of a single entity. The definition of client satisfaction is viewed as the response to the specific item or items asked, such as, "How satisfied were you with the counseling services which you received?" Probably the best known and most wịdely used unidimensional scale of client satisfaction is a version of the Client Satisfaction Questionnaire (CSQ) originally proposed by Larsen, Attkisson, Hargreaves, and Nguyen (1979). Since then, different versions of the CSQ have been developed including parallel, more specific versions of the 18-item scale and a short, eight-item version (CSQ-8). Two major problems are associated with this approach: First, there is more possibility for the tendency for those who respond by providing socially acceptable responses. The second difficulty associated with general satisfaction instruments is that the utility of the information they provide is limited because it is general. Such surveys yield very little specific information that can be used to suggest improvements in services or changes in procedures. The second approach presumes more than one domain 
underlies a set of observations. Thus, it views client satisfaction as a complex, multifactorial construct which is comprised of a number of underlying aspects.

In a review of 111 theoretical and empirical articles concerning patient satisfaction published in the 25 years prior to 1976, Ware, Davies-Avery, and stewart (1978) conducted a content analysis of over 200 items and over 700 responses to open-ended questions. They concluded that eight distinguishable dimensions emerged from their review. These were: (a) art of care/concern, (b) technical quality of care/competence, (c) accessibility/convenience, (d) finances, (e) physical environment, (f) availability in terms of number, (g) continuity/regularity, and (h) efficacy/outcomes. An earlier review of studies of patient attitudes had identified four major dimensions: attitude toward doctor conduct (humaneness and quality); availability of services; continuity/convenience of care; and access mechanisms (Ware \& Snyder, 1975). A third study of patient attitudes had identified three major dimensions: professional competence; personal relationship; and cost-convenience (Stamps \& Finkelstein, 1981).

In the social service arena, there has yet to develop a consensus with respect to the specific domains which comprise client satisfaction with social services. A review of ten scales developed for use in the social service field, however, did identify a group of common themes (Poertner \& 
Wintersteen, undated). These included: (a) generalized satisfaction with the agency or its services, (b) perception of staff helpfulness and understanding, (c) perception of goal attainment, (d) quality of staff-client cooperation/interaction, and (e) agency amenities. Appendix A contains other examples of dimensions of satisfaction which have been identified by other researchers.

General versus Specific Focus. The second measurement issue concerns whether or not client satisfaction is being measured at a general, global level or at a specific level. A unidimensional client satisfaction scale could be developed which was either very general or very specific. A scale which was both unidimensional and general would be less likely to provide information which could be used by policy-makers in making program changes.

client satisfaction scales that are specific tend to have higher reliability than measures that are more general (Campbell et al., 1976). Stipak (1980) concluded that scales which are more specific are more likely to elicit responses which are based upon actual experiences and thus have higher reliability. Specific scales also provide policy-makers and administrators with information of more practical value than general scales. Low ratings from a general scale do not give direction to administrators concerning what corrective actions to take.

Other Measurement Issues. Unfortunately, the increasing 
use of satisfaction surveys seems to have occurred, to a large extent, without regard for the state-of-the-art of measurement practices. Given that critical reviews of the literature on the conceptualization and measurement of satisfaction are rare, the most appropriate uses and potential abuses of satisfaction survey data are not widely known.

Ware (1976) raised issues concerning the conceptualization and measurement of satisfaction. These include:

1. What proportion of people are actually dissatisfied with services?

2. Are there various dimensions of satisfaction with services and, if so, what are they?

3. Do satisfaction surveys measure anything/how reliable are the scores?

4. What do satisfaction scores mean/are they valid in terms of their intended uses?

5. Is satisfaction a simple dichotomy or can individuals be placed along a continuum of satisfaction?

6. What are the best methodologies for designing and conducting a satisfaction survey? Addressing the question of the validity of patient satisfaction scores, Ware, Davies-Avery, and Stewart (1978) stated what to them were the key remaining questions in 
using these scores as independent and dependent variables. They first examined the area of using scores as dependent variables to evaluate programs. The key issue was whether or not measures of specific satisfaction dimensions are able to differentiate between specific characteristics of providers and services. This is particularly important if the information is to be used for making changes in programmatic and practice areas.

In the area of predicting behavior, they again stated issues that related to the utility of specific dimensions. "Which satisfaction dimensions best predict what people do? ...How much does satisfaction influence health and illness behavior? Which are the most important dimensions of satisfaction in influencing behavior?" (p. 9)

\section{FINDINGS FROM PRIOR RESEARCH WITH \\ CLIENT SATISFACTION SURVEYS}

The major application of client satisfaction surveys, outside of the strictly market research area, has been in the area of patient satisfaction. As the costs of health care have soared in recent years, and as the consumer of health services has become a more educated and discriminating purchaser of those services, the health care industry has become more interested in knowing what the consumer values. While most of the client satisfaction surveys developed 
and used in the last twenty years have involved the medical community, there also has been a growing discussion of their use beyond the patient context. Users of public facilities and services, including parks, roads, crime control, and neighborhood livability have been surveyed to elicit their feedback. More germane to this study are the studies that have included clients of human service programs and social welfare programs in the evaluation or assessment of these services (Bush \& Gordon, 1978; Bush, Gordon, \& LeBailly, 1977; Giordano, 1977; Gottesfeld, 1965; Magura, 1982; Mayer \& Timms, 1970; Tanner, 1982).

As with client feedback in general, client satisfaction surveys have also been used for multiple purposes. One patient satisfaction study (Ware, 1976) included an extensive review of the literature to determine how patient satisfaction data were used. This review of 73 studies found the following five uses:

1. to evaluate health care (29 studies);

2. to explain why and when services are used (19);

3. to describe satisfaction levels of different groups (13);

4. to conduct methodological research - including questionnaire development (4); and

5. to explain health and illness behaviors (3). In addition to these uses, social service agencies have used survey results to promote public awareness and 
education, and for a variety of management purposes. These include internal accountability, motivating staff, aiding in budget preparation and justification, and self-improvement (Millar \& Millar, 1981).

In care of the aged, Spector and Drugovich (1989) report that the federal government recently revised its methodology for its mandated nursing home quality survey and certification process. The process had been criticized for focusing too much on the potential for the provision of quality care and not enough on the actual care delivered and the current patient outcomes. It was also felt that these annual surveys, used to determine individual nursing home compliance with federal standards of care, spent too much time reviewing issues of documentation, policies, and procedures and not enough on directly assessing patient care. To address these concerns, the Health Care Financing Administration (HCFA) financed a number of state evaluations of demonstrations that modified the survey process during the early 1980 's. The result was a revised federal nursing home survey process entitled Patient Care and Services (Pacs). As a part of this revision, in-depth patient care assessment, which included interviews with patients, was mandated as part of the survey process.

It was felt that these changes would result in the citation of more patient-oriented deficiencies to which the providers would respond. It was anticipated that the 
ultimate result would be better quality care and improved resident outcomes as the providers made changes to correct the deficiencies.

\author{
STATE OF KNOWLEDGE REGARDING \\ CLIENT SATISFACTION OF INVOLUNTARY CLIENTS
}

Gaining Feedback from Involuntary Clients

The discussion to this point, and the majority of the literature on consumer or client satisfaction, has focused upon groups who have some major degree of autonomy with respect to the services involved. While patients generally don't opt to be ill or in need of medical service, many times they do have some control over when to seek out such services, where to seek them, and how closely to follow the medical advice.

Consumers of many social services, while possibly preferring not to be in a situation where they require such services, still voluntarily seek out and choose to avail themselves of the service. Other clients, while possibly being referred by others, are still accepting of the service and are not reluctant to participate.

In her discussion of how to promote competence in involuntary clients (1981), Oxley describes the involuntary client as one who "...has suffered some loss of competence but has not demonstrated recognition of a problem or capacity 
to find a possible resource for help." (p. 290) Involuntary clients are classified into five general groups. These groups are:

1. Clients from low status groups

a) often members of minority and low socioeconomic status groups

2. In-patient clients

a) in settings such as hospitals, psychiatric centers, and detention facilities

3. Parents of the identified patient child

a) parents who seek or have forced upon them child care or child protective services

4. Child clients

a) the child who is brought to the agency by the parent

5. Crisis-immobilized clients

a) the individual in crisis who is brought to the agency by a relative or friend

Attempting to elicit feedback from these groups of involuntary clients exacerbates methodological problems associated with the construction and testing of such instruments, including low response rate, the representativeness of those responding, and potential negative response bias.

As mentioned earlier, most of the client feedback studies have been concerned with patient satisfaction with 
health care programs (Ware, 1976) and, to a lesser degree, with client satisfaction with social services including mental health services (Ellsworth, 1975; Springer, 1977; Tanner, 1982) and various social welfare programs (Bush, 1976). Rarely have client satisfaction surveys been attempted with the involuntary clients mentioned earlier. Protective Service clients have been surveyed only a few times as a means of evaluating services (Bush et al., 1977; Giordano, 1977; Magura, 1982; Maluccio, 1979). Only recent studies by Magura and Moses (1984) and Fryer, Bross, Krugman, Denson, and Baird (1990) included a client satisfaction component. Based on this paucity of previous studies with this involuntary type of client, and the goal of the child protective service agencies to keep families together whenever possible, the development of such a satisfaction measure seems to fill a needed social service gap.

\section{Client Satisfaction Surveys in Child Protective Services}

Magura and Moses (1984) conducted a study in which 250 Child Protective Service client families were interviewed. The instrument used was the Parent Outcome Interview which evaluates the status of the family in 11 specific areas related to child well-being: discipline of children, supervision of children, living conditions, financial situation, physical child care, emotional child care, school adjustment, children's conduct, children's symptomatic 
behavior, sexual abuse, and parental coping. In each of these areas, the families were asked to rate problem change, describe improvement or deterioration, note unresolved problems, and describe services received and help still needed.

Additionally, the interviews also addressed the issue of the family's satisfaction and dissatisfaction with its contact with the caseworkers and the agency. The Parent Outcome Interview included two sections of questions referencing client satisfaction issues.

Section 1, Referral Situation, asks the family to describe the problem or the situation that first brought the family into contact with the agency. It continues by asking the family whether or not it agreed with the worker concerning the problem or situation, whether or not there has been a recurrence or continuation of the problem, why it feels that it has or hasn't improved, and whether or not it feels that the problem has gotten better or worse since the initial contact. It continues by asking the family to describe any services received to help with the situation, to describe the relationship between any services and any changes in the situation, to rate its overall feeling of satisfaction with services and caseworker, and to indicate what it liked and didn't like about the agency. A mix of open-ended and close-ended response items were used throughout this section. 
Section 11, Relationship with Social Worker, contained a list of 17 items with a 4-point likert scale response choice and contained such issues as the worker's availability, reliability, accessibility, empathy, openness, and skill. This was followed by a series of questions on the family's satisfaction with the worker, what it did and didn't like about the worker, and questions about the case closing process.

The authors found that about $70 \%$ of the families expressed at least mild overall satisfaction with the "services or help" they received from the agency. They were also asked to describe the most important thing that dissatisfied them concerning their involvement with the agency. Sixty percent of the families responded by mentioning at least one issue. The issues noted in the study included:

1. family did not agree with caseworker's ideas on how to handle problems in case (23\%);

2. family disliked the attitude of the caseworker including being condemning, pushy, threatening, impersonal, biased (13\%);

3. family believed the agency did not provide help needed in financial problems (9\%);

4. family believed the agency did not provide help needed with parental mental, emotional, or health problems $(8 \%)$; 
5. family did not feel that enough services were offered (9\%);

6. family felt that the service provided either did not benefit or actually hurt the family (6\%);

7. family felt that the caseworker was inexperienced or incompetent $(5 \%)$;

8. family did not feel that their problems were serious enough to justify agency involvement (3\%); and

9. other $(5 \%)$.

Magura and Moses (1984) summarized the data from these sections with the finding that $25 \%$ of the clients interviewed reported basic disagreement with the agency over the circumstances surrounding the referral and $60 \%$ of them volunteered at least one important criticism of the agency.

The validity of the clients' perceptions may be a lesser issue than the mechanism for dealing with sincere disaffection and resentment. What recourse do clients have when they perceive the caseworker or the agency to be unresponsive, unfair, or ineffectual? How successful can casework be under such circumstances? (p. 110)

Fryer and his colleagues (1990) sent a questionnaire to a sample of 661 families who had been reported for abuse or neglect in the State of Iowa. The sample was divided between. cases still open and those that had recently closed (within 60 days of the survey). The sample was also divided between cases where abuse had been substantiated and those where the 
report had been unsubstantiated. A final distinction was between cases with records of previous substantiated abuse and those with no prior record.

The survey insirument contained two seven-item summated rating scales and two additional items. One of the scales contained seven qualities of the worker and respondents were asked to rate their worker using a 10-point semantic differential format. The second scale was a likert scale and rated the performance of the worker. The first additional item asked respondents to rate the quality of the services they received on a four-point scale. The final item asked whether the client's family life had been made better or worse by the contact with the agency.

Overall, the results of the survey were generally positive. Twenty-seven percent of those surveyed responded to the questionnaire. In the area of worker qualities, over half of the respondents rated their worker at the highest point on the ten-point scale and over $80 \%$ rated the worker favorably for each attribute. The quality rated most favorably was "Concerned - Not Interested" and the one rated most unfavorably was "Efficient - Not Organized."

Respondents were also positive when they were evaluating the performance of the workers. The lowest-rated item, at $61 \%$ positive, was "accurate in judgements about our possible parenting problems." For the remaining six items, at least two-thirds of the respondents rated workers favorably. 
Thirty-eight percent of the respondents rated the services they received as excellent, $36 \%$ as good, $15 \%$ fair, and

$11 \%$ as poor. Fifty-nine percent of the respondents felt that their family lives were better as a result of the worker, $19 \%$ noted no change, and $23 \%$ indicated that family life had gotten worse.

Generally, the responses were not affected by any of the three respondent categories. The exception was that those families with prior substantiated cases rated worker listening and answering questions much more negatively.

\section{SUMMARY}

client satisfaction has been used extensively in the area of health services. Patient satisfaction has been used as an outcome measure to evaluate medical services and providers. It has also been used as an independent variable to predict future health-related behaviors. Studies have indicated that patient satisfaction is directly related to issues of compliance with medical regimens.

Among the social services, client satisfaction has been used most extensively in the mental health arena and less so in the public welfare and child welfare areas. Its use with involuntary clients, and specifically with CPS clients, has been very limited.

The construct of "satisfaction" has been used much more 
extensively in examining the relationship between clients and service providers than an alternative construct, "happiness." "Satisfaction" is generally viewed as a more focused, cognitive construct which is more applicable to this use.

One of the major measurement issues to consider in constructing a client satisfaction scale concerns the degree of specificity required of the use of the data. Scaies that are more specific and that measure more than one aspect of client satisfaction are generally more reliable. They are also more likely to provide useful information to administrators in reviewing agency policies and procedures.

A number of trends highlight the importance of gathering feedback from families who are involved with child protective services. The number of abused and neglected children has increased dramatically in the past 20 years. This has led to a parallel increase in the number of children being placed into protective custody and into foster care: Additionally, the age range of these children has declined steadily during the last seven years. The themes of client empowerment, agency accountability, and parental rights, while not necessarily compatible, are, nonetheless, coalescing into a critical mass focusing attention upon the effectiveness of CPS agencies.

The development of new client satisfaction scales should be undertaken with caution. In the instance of examining 
the level and specific aspects of satisfaction among CPS families, there is very little empirical work upon which to draw. Interviews with families who have been clients of a CPS agency should be a rich source of information from which to generate an item pool for the development of a client satisfaction instrument for CPS clients. 
CHAPTER III

METHODS

DEVELOPMENT OF THE INSTRUMENT

When this study was originally being contemplated, the initial literature review indicated that the area of client feedback with cPS clients, either satisfaction surveys or interviews, was one that had not been extensively researched. Additionally, initial discussions with CPS staff in oregon, including program managers, field caseworkers, and supervisors, provided only some general ideas as to what issues and concerns should be included in such a survey. Both of these results helped to solidify the initial thoughts that the clients should be a major source for the items and language in the instrument.

The generation of items in scale construction involves an examination of the applicable literature and appropriate tested scales, interviews with the applied personnel and other experts in the field, and discussions with members of the population to be surveyed. In constructing a client satisfaction scale, clients should be among the sources for the original items in the item pool. The inclusion of 
clients enhances the possibility of including items which cover more specific concerns with service delivery. In addition, it also increases the possibility of including issues of dissatisfaction.

The value of including the client in the development of the instrument, however, has been questioned in some situations. Concerns have been raised about client surveys of involuntary clients. The general concern is whether or not such clients are able to separate their feelings about their involuntary involvement in a program from an objective assessment of the program.

With respect to the development of this satisfaction survey for CPS clients, one of the questions being examined is precisely that of the value of client feedback in the construction of the instrument. (This same concern has been applied to the question of the most appropriate respondent to a client survey. When discussing the use of client feedback among clients with diminished capacities, such as the developmentally disabled and the mentally impaired, many times those surveyed are individuals who are close to the client, such as a parent, guardian, or advocate.)

The instrument to be used in this study was developed through a two-stage process. The first stage was the generation of the potential dimensions of satisfaction and the exploration of possible items and their phrasing. This was accomplished through two structured, open-ended 
interviews and the content analysis of the responses from the interviews. The second stage was the formulation of the closed-ended questionnaire items for the dimensions identified. This was accomplished through a review of the content analyses and the pre-testing of the closed-ended instrument. The final instrument resulted from the analysis of the results of the pre-test.

\section{The Study Population: The Agency Context}

The site where the client satisfaction instrument was developed and tested was at Children's Services Division (CSD). CSD is one of the Divisions of the state of Oregon's Department of Human Resources. Other divisions include Adult \& Family Services Division, Health Division, Mental Health and Developmental Disability Services Division, Corrections Division, Senior and Disabled Services Division, Employment Division, and Vocational Rehabilitation Division. CSD is a diverse child welfare agency with a variety of programs including:

1. the administration of the juvenile correctional facilities and community alternative programs;

2. recruitment, training, and certification of foster homes ;

3. provision of supportive and remedial day care services;

4. certification and registration of day care centers 
and family day care homes;

5. conducting independent adoptive home studies;

6. recruitment of homes and the placement of hard-toplace, special needs adoptive children;

7. out-of-home placements of children in foster homes, group homes, and residential facilities; and

8. the provision of a number of in-home, preventiverestorative services to families including counseling, parent training, homemaker, and housekeeping services.

While CSD provides a number of services, the core services that CSD provides to the state are the investigation and provision of child protective social services in response to reports of possible child abuse. In calendar year 1990 , CSD received 23,820 child protective services referrals. 1

Every referral is investigated either by the Division, by a law enforcement agency, or by both in a joint investigation. These investigations are concluded with a determination as to whether abuse did or did not occur, an assessment of current and future risk to the child(ren), and an assessment as to whether and then which protective social

\footnotetext{
1 This number does not include those phone calls that the Division receives in which the discussion does not provide sufficient information to conduct an investigation, and those in which the discussion and clarification lead to a conclusion that the "incident" is not abuse. This number of "non-referral" phone calls has been estimated to include another $70 \%$ above the figure cited.
} 
services should be either offered or recommended be mandated through a juvenile court proceeding. Of the 21,822 referrals assessed in $1988,7,515$, or $34.4 \%$ were "Founded." Another $7,034,32.2 \%$, were termed "Unfounded" and 7,273 , or $33.3 \%$, were deemed "Unable to Determine." Many cases are closed during an initial 30-day assessment period with no or minimal direct service provision. During $1988,64 \%$ of the cases were closed upon completion of the assessment of the CPS referral. Other cases are opened for more extensive services and service plans. These services are either offered and accepted voluntarily by the family or are mandated in a juvenile court proceeding. In a minority of cases (18-19\%), the abused or neglected child is removed from the home and placed into protective custody by the police and may remain there for a period of time via a juvenile court proceeding. Referrals may be received for families that have never had official contact with the agency, for families with prior contact, and for families who have a current open case. In $1988,40 \%$ of the referrals were for new cases, $46 \%$ for prior cases, and $14 \%$ for cases open at the time of the referral. 
GENERATING THE POTENTIAL DIMENSIONS

\section{The First Interviews}

Sample: Rationale for Sampling Technique and Sample Characteristics. The sampling approach used in selecting families to be included in the interviews was a purposive approach. The purpose of the interviews was to discover the range of issues and concerns, likes and dislikes, among families who had been involved with an agency providing child protective services.

A random selection technique was not used in selecting families to be interviewed for three major reasons. First, the purpose was to identify domains of satisfaction and not to test any hypotheses or use any inferential statistics. The intent of the sampling procedure, therefore, was to maximize the amount of diversity in the case situations and the issues of satisfaction and dissatisfaction that individuals brought to the interviews. A range of client types and experiences was necessary in order to identify the entire spectrum of experiences and issues to include in the survey instrument. A random selection process to identify 17 cases out of such a large potential population would do a much poorer job of obtaining the needed range of clients and experiences.

A second reason for the purposive sampling approach was confidence that the staff making the selections would choose 
the range of clients required. The Branch Managers who volunteered to participate understood the purpose of the interview stage. They also understood that to accomplish this would require their assistance in identifying such clients.

The third consideration was sensitivity to the possible impact on a family of this initial contact. A random selection process had the potential of identifying interviewees who might consent to the interview only to be hurt by the experience. Involving the Managers in these selections minimized this possibility.

The first interview was administered to $17 \mathrm{child}$ protective service families. Families were selected by Branch office staff after discussions with the researcher concerning the purpose of the interviews and the types of families to be included. Care was taken to select a range of families across key areas including length of involvement with the agency, voluntary nature or cooperativeness of client, type of abuse, and verbal skills. The Branch offices participating in this set of interviews were: Multnomah, Benton, Hood River, Wasco, and Deschutes. Branch offices were selected to participate based upon their willingness to participate, geographical location and size.

Families selected represented the three major, general types of abuse: neglect, physical abuse, and sexual abuse. of the 17 families, four families represented a neglectful 
situation, six represented issues around an incident of physical abuse, and seven of the families represented situations involving sexual abuse. The initial referral to either CSD or law enforcement that brought these families into contact with the agency had come from a variety of sources. Four of the families had been referred by health professionals, three by other family members, three by the victim, and seven by the non-offending spouse. Seven of the families had voluntarily sought the assistance of the agency, five had been referred by others and were very upset by this referral, and five had been referred by others but were grateful for this disclosure of the problem or situation.

Typically, the mother was the only adult who participated in the interview. In ten interviews, the mother was the only person responding. (Small children were present during a number of these interviews.) In four of the interviews, both the mother and the father participated. In one of the interviews, the four children were included with both parents. Two of the interviews involved the mother and victim/daughter.

Procedure. Staff from the Branch office made an initial contact with the family to see if they were willing to describe their experiences with the agency. The following points were emphasized:

1. Their willingness or lack of willingness to participate in the interview would have no bearing 
on their case - participation was entirely

voluntary

2. The information they provided would be held in strict confidence - none of the information would be shared with anyone from CSD or any other agency that might be involved with the family.

3. The purpose of the interviews was not to investigate or review individual cases and therefore, while the interview provided a forum to express concerns, there would not be any follow-up on individual case concerns.

4. The family could decide which family members to include in the interview and could terminate the interview at any time and request that the information provided not be used.

If a family expressed interest in participating in the interviews or had questions about the study, they were told that the researcher conducting the study would be calling them to discuss the interview further and to schedule a time for the interview. For these families, names, telephone numbers, and best times to be contacted were given to the researcher by the Branch staff. The researcher then telephoned each family and explained the purpose of the study and what would be involved in the interview. Both the voluntary nature of the interview and the confidentiality of the information that the family provided to the researcher 
were emphasized. Other aspects of the interview were discussed, including: (a) the general types of questions that would be included, (b) the fact that it would likely be emotional for them to "relive" some of these very personal issues with a stranger, and (c) the fact that the researcher could not influence their individual case situation.

Families were told that it was totally their decision whether or not to participate, who to include in the interview, and whether or not to terminate the interview at any time. For those families who wanted to pursue the interview, the researcher scheduled a time and place most convenient for them. All families contacted by the researcher agreed to participate. All except one of the families wanted the interview to take place in their home. That family wanted to be interviewed at the local CSD office. Initial contact was followed up with a letter to each family confirming the discussion and the time and place of the interview.

Upon first meeting, the researcher introduced himself and provided identification. Care was taken to again discuss the purpose, confidentiality, and voluntary nature of the interview. The possibility of discussing some painful and hurtful memories was discussed with the families. The families were then asked to read an Informed Consent statement. This statement was discussed with the family. They were asked to sign the statement if they were still 
willing to be interviewed. The researcher then answered any questions and summarized what they were signing. None of the families declined to be interviewed after these discussions.

The interview began by asking each family how they had initially become involved with the agency. (See Appendix B for the initial interview schedule.) The next series of questions concerned service provision. Specific areas covered included discussions of the services that the family received directly from CSD or from an agency to which they had been referred, whether or not they felt that the services were being offered to the family voluntarily or mandated to the family, which services they felt were helpful, which services they felt were not helpful, what additional services should have been offered or available, and their overall evaluation of the services.

The next general area covered was the relationship between the family and the caseworker. Families were asked to describe the things about their caseworker they found helpful and useful, not helpful and not useful, what they liked most about their caseworker, what they liked least, and what changes they would make in the relationship.

The next part of the interview consisted of a series of questions concerning the issue of communication with the agency. The specific areas covered included what the family liked and found helpful in the area of information, what they did not like and did not find helpful, how well they felt 
they were kept informed, and any suggestions that they might have for improving communication. The discussion then shifted to an overall discussion of what things the family found most helpful and liked the most and what things they found least helpful.

The interview concluded with a series of broad questions concerning any recommendations that the family had on what should change, what should remain the same, any other concerns, any further comments, and a general satisfaction summary statement.

The first set of interviews occurred over a two-month period of time. These initial interviews ranged in length from 40 minutes to four hours, with most of them taking approximately 90 minutes. These interviews were emotional for most of the families and some time was always devoted to assuring that the interview ended under the best possible circumstances.

Data Analysis and Preliminary Findings. Responses to the interview questions were content analyzed to identify and. group the clients' responses to the questions. Immediately after an interview was completed, or as soon as feasible, the interview notes were reviewed for completeness and clarity. The revised notes were typed and again reviewed. They were then reviewed independently by a second researcher who noted any questions or inconsistencies. The two researchers then met and reviewed the interview notes to expand and clarify 
any areas of confusion. The interview notes were retyped to reflect these changes.

The next step was to code the individual responses. Every word, phrase, or statement which contained meaningful information was listed. These were grouped together on separate sheets of paper. Individual phrases were combined with other words and phrases judged to contain the same meaning. Care was taken to retain exact words and phrases whenever possible when summarizing and collapsing statements. The next step was to group these words and statements into areas of similar general content. Key words and phrases were identified and grouped together.

1) Initial Agency Contact

The interview began by asking each family how they had initially become involved with the agency. Four families described a neglectful situation, six described issues around an incident of physical abuse, and seven of the families described situations involving sexual abuse. The initial referral to either CSD or law enforcement which brought these families into contact with the agency had come from a variety of sources. Four of the families had been referred by health professionals, three by other family members, three by the victim, and seven by the non-offending spouse.

Situations leading to contact with the agency included: (a) an adopted boy being sexually molested by an older adopted boy, (b) a handicapped foster child going to the 
hospital after breaking a hip at home while being carried by two daughters, (c) a mother and boyfriend being accused by her ex-husband and new wife of physical and sexual abuse of her two young children, (d) the removal and placement of three children into foster care because of neglect and a continuing alcohol problem, (e) a mother who broke the leg of her young son attempting to get his leg unstuck from a crib, (f) a boyfriend physically abusing the young son over an extended period of time, and (g) a daughter taken to the doctor with bruises of an undetermined nature.

2) Services

The families offered a broad range of opinions concerning services received (Table I). As expected, some of the families described situations in which they requested services, some where services were offered, some where services were mandated by the courts, and some where services were required by the CSD office.

The most negative comments expressed by families concerning services were about the following types of situations:

1. Situations in which the family felt that they had been promised or told something which did not happen.

2. Situations in which the family felt forced to participate in services with either a vague or an explicit threat. 
TABLE I

LIST OF SERVICES RECEIVED BY 17 FAMILIES INTERVIEWED

Victim's sex abuse counseling

Sexual victims' group for moms

Counseling with county MHD

Alcohol counseling

Psychological evaluation

Therapeutic day care

State hospital

Shelter for battered women

Transportation services
Homemaker services

Sexual offenders' program

Parent training

Foster care

Drug and alcohol counseling Shelter evaluation center Family therapy (IFS)

Nurse to instruct baby care

3. Situations where CSD required the specific CSD- . sponsored version of the service, even when this meant dropping out of a private relationship which the family felt was beneficial.

4. Situations where CSD mandated a service even when the family questioned its need, causing the family to feel they were on a service conveyor belt.

The most positive comments by families concerning services occurred in the following situations:

1. Parent training as a specific service was the most frequently mentioned with positive comments.

2. Situations where the family agreed with the need for the service.

3. Situations where the family felt they had a part in the decision to participate in the service.

In response to the question about whether or not there were services which CSD should offer but didn't, families gave three major answers. The type of service most often mentioned by families was financial assistance of one 
kind or another, including adoption subsidies, consistent SSI payments, money/equipment for medical problems, jobs, and places to live.

The next most frequently mentioned service issue was that there needed to be more compatibility and coordination among various agencies. The final service issue mentioned was the need to offer and provide services to everyone in the family and not just to the obvious victims. One mother stated, "I can't even think of a service that CSD couldn't get for me if I asked for it. Joanne [her caseworker] is now filling out papers to get speech therapy for Tommy. There is a lot of paperwork and she is really good at staying at it."

3) Relationship with the Caseworker

Throughout the discussions with the families concerning their caseworkers, the same descriptive words and phrases were used again and again. Table II contains a listing of the positive and negative descriptors used by the families.

One mother described how the worker went out of her way to make sure that the mother didn't feel left out by calling her at Christmas when her children were in foster care. She stated that the worker made her feel that the worker worried about her as well as the children.

Another mother described her worker as someone who was always thinking of the best interests of the client. A third mother described her worker as real helpful; as one 
TABLE II

DESCRIPTORS OF CASEWORKERS BY 17 FAMILIES INTERVIEWED

\author{
Positive \\ Good listener \\ Supportive \\ Knowledgeable \\ Honest \\ Non-threatening \\ Understanding \\ Always there \\ Concerned \\ Open-minded \\ Complimentary \\ Responsive \\ Trusting \\ Helpful
}

\author{
Negative \\ Dishonest \\ Not supportive \\ Lack of understanding \\ No follow-through on promises \\ Inexperienced \\ Impersonal \\ Won't listen \\ close-minded \\ Not forthcoming \\ Judgmenta 1 \\ Inconsistent \\ Negative \\ Controlling
}

who she could always call on if she had a problem and that would take the time to track down answers to questions if he didn't have the information himself. The mother of a daughter who had been sexually abused by a neighbor said that she could not have gotten through the situation without the support of her worker: "CSD was a Godsend. I am thankful that there is an agency there to give you support and help when you need it."

on the other hand, one mother felt betrayed by the worker since she had turned to CSD for help and the worker "...stormed in and took over." The worker immediately took custody of the child, stating simply that this is the "way we do it." Another mother always felt unsure of her status since the worker continually changed the expectations, "...kept moving back the goal posts." one mother said that her first worker told her that the 
only way that she would get her daughter back would be to leave her husband. The next worker told her that the only way she would get her daughter back would be to admit the abuse, then things would go faster. That same mother said that, as long as CSD has legal custody, she lives in fear that CSD can come and take her child at any time without any reason or explanation.

4) Communication

The most positive comments made concerning communication included feeling that nothing was being hidden from them, that they were actively involved, that they received numerous phone calls from the worker to keep them updated, that they never wondered what was going on, that the worker continually asked if they had any questions or concerns, that the worker was very supportive and thorough in explaining the court process, and that the worker took the time to explain things in a way that the client could understand.

One mother especially appreciated that her worker initiated conversations, kept her informed of what to expect, explained the various "possibilities" from which she could choose and stated that he would support whatever she decided to do. Overall, what seemed to be most valued was basic openness and honesty and the feeling that the worker and the family were working together to make decisions.

on the negative side, comments were made that the worker and the office didn't seem to know basic information 
concerning process and that the family would be informed of important events after they had already occurred. Moving children from one foster home to another is one example. The most common complaint was that they often felt they didn't know what was expected of them or specifically what they needed to do in order to regain the custody of their children.

One mother was very frustrated that the issue seemed to be something about housework but she could never get any specifics. Another mother described being generally confused about the entire situation and being frustrated that, when she would inquire how her son was doing in foster care, she would always be told "fine" with no details.

Two suggestions for improvement in the area of communications emerged. The first was to clearly state the expectations to the family; exactly what did they need to do, in what period of time, and how would they know when it had been completed satisfactorily. The second suggestion was to be consistent in the expectations. Too often, respondents felt the evidence for compliance with the initial requirements was shifted or that requirements were expanded.

5) Overa11 Most/Least Helpful

Families were asked to discuss things they liked the most and found most helpful in their contact with CSD and things they liked the least. A few families mentioned specific services, such as parent training, when asked what 
was the most helpful. Generally, however, the families described positive aspects of their relationship with their caseworker as the most helpful and most liked aspect of their contact with the agency. They reiterated the terms listed in Table II: openness, empathy, encouragement, honesty, understanding, moral support, communication.

When describing the negatives, some families mentioned negative attributes of their caseworker but more discussed specific issues such as:

1. Continual reviewing of the case by revolving groups of outsiders.

2. Frustration over not being able to mandate counseling for the abuser.

3. General unfairness of system - knowing of families who provide much worse care but have their kids returned.

4. Worker "lied" to her and her daughter by saying "nothing bad will happen if you tell me the truth."

5. Lack of support - seemed to alienate the agency by asking for help.

6. Feeling that families are condemned from the start "Kids don't lie."

7. General feeling that she wasn't in charge anymore not in control.

8. Basic attitude of intimidation - they [CSD] feel they can walk in and do anything that they want - 
"Sign this paper or we take your kids."

9. Not making expectations clear.

one father said, "There is nowhere to go to question

CSD decisions. We just got shuffled from the top to the

bottom. The total control that they have is frightening. If

they had just taken a few minutes and listened objectively to

what we had to say."

6) General Recommendations and Comments

The last questions asked families for any

recommendations or final comments. Much of the information

that the families provided had, by this time in the

interview, become redundant. Below are some additional

comments families made during the final part of the

interview:

1. CSD needs to operate by set policy and procedures there is too much inconsistency.

2. CSD should always remove the offender - not the victim.

3. CSD needs separate programs and procedures for clients who cooperate and those who resist - yet both are treated the same.

4. CSD needs to keep information confidential.

5. It is frustrating that it seems you just start all over again anytime that you get a new worker.

6. CSD should be an agency where you go to get help not get investigated. 
7. The worker should serve in a supervisory or supportive role - not a controlling one.

8. CSD needs to see juvenile offenders not just as abusers but also as victims who need help.

9. All staff in an office should know something about every case so you don't have to try to connect with specific worker every time.

10. No matter how you enter the system, you still feel like you are just being processed.

Summary of First Interviews for Instrument Development. The first round of interviews provided clear direction for the construction of the closed-ended instrument. Consistent patterns, both within the general topic areas covered in the interview and across these topics emerged from the responses. Families expressed both concerns and compliments during the interviews about their contact with the agency. These fell into four major categories:

1. Issues of communication and keeping the family informed.

2. Issues concerning the basic nature of the relationship with the agency - whether it was viewed as voluntary or coerced.

3. Issues concerning the basic nature of the relationship with the caseworker - involvement or lack of involvement of the family in decisions.

4. Issues concerning the helpfulness of the contact 
with the agency.

In the area of services, the basis of all of the

families' comments related directly to how helpful/beneficial

they felt the services were in dealing with the problems or the agency expectations.

In the area of the relationship of the family with the caseworker, families consistently used the same words and phrases to describe why they did or did not like their caseworker; why they did or did not find them helpful.

\section{The Second Interviews}

As beneficial as the interviews ware in providing information, a second round of interviews was planned. The purpose of a second round of interviewing was to determine if information obtained during the first interviews could be confirmed or if changes needed to be made. A second round of interviews would add confidence that the conclusions from the first round had validity among families who had contact with a different Branch office. Additionally, the second round, while still open-ended, could provide focus in specific areas. It would be possible to probe to obtain explanation and clarification of the general comments.

Sample: Rationale for Sampling Technigue and Sample Characteristics. The same purposive sampling technique was employed in the second round of interviewing. The Branches participating in this second round of interviews were asked 
to involve more families with participation from the father. The clients for this second phase of interviewing were again selected by the Branch office staff.

The second interview was administered to ten Child Protective Service families. These families were served by three Branch offices: Marion, Lincoln, and Crook. Four families were involved with the Division because of neglect, three because of physical abuse, and three because of sexual abuse. Thus, across both sets of interviews, the 27 families involved eight neglectful situations, nine of physical abuse, and ten of sexual abuse.

The referral for four of the families had come from relatives or friends of the family, two came from the victim, three from a professional, and one from a stranger who witnessed an incident. Five families could be broadly termed as glad that the situation had been reported and five as not glad. Four of the interviews involved only the mother, three only the father, and three included both.

Data Analysis and Preliminary Findings. The procedures followed for the content analysis of the second set of interviews were the same as followed with the first set. Responses to the interview questions were content analyzed to identify and group the clients' responses to the questions. Immediately after an interview was completed, or as soon as feasible, the interview notes were reviewed for completeness and clarity. The revised notes were typed and 
again reviewed. They were then reviewed independently by a second researcher who noted any questions or inconsistencies. The two researchers met and reviewed the interview notes to expand and clarify any areas of confusion. The interview notes were then retyped to reflect these changes.

The next step was to code the individual responses. Every word, phrase or statement which contained meaningful information was 1 isted. These were then grouped together on separate sheets of paper. Individual phrases were combined with other words and phrases which clearly contained the same meaning. Care was taken to retain exact words and phrases whenever possible when summarizing and collapsing statements. The next step was to group these words and statements into areas of similar general content. Key words and phrases were identified and grouped together.

1) Initial Agency Contact

As in the first interviews, families were asked how they had come into contact with CSD. The range of situations included the following:

1. A father was seen in the parking lot of a shopping center striking his son in the mouth.

2. A father received a phone call while in Georgia in a training session that his wife had just turned their three children into CSD because she could no longer care for them.

3. A public health nurse reported that the infant child 
of an alcohol-abusing couple was not being adequately cared for.

4. A mother was reported for numerous injuries to her young child.

The results from the responses to the remaining questions in the second set of interviews are discussed below by general content area.

2) Basic Approach by the Agency

A number of comments which were made during these interviews could be termed as basic critiques of the approach of the agency.

One mother was frustrated by the following scenario. The worker had the mother sign a service agreement. The mother felt, however, that the worker did not provide any assistance to her in getting started on the program. The mother decided to begin on her own but then received an "angry" letter from her caseworker who was upset by her action. This mother also disliked the approach to parenting services that provided services to parents and children separately but did not include classes in which parents and children could participate together.

A second mother, who had reported the sexual abuse in her family, felt somewhat cheated after her honesty. She felt that it had no effect on how they were treated; the family was "...still pegged and placed into a pigeonhole." All of the guidelines seemed to be set. "This is our 
policy." She felt that CSD was reluctant to individualize situations. She felt that seeking help should have resulted in adjustment in how they were treated.

3) Relationship with Caseworker

The relationship with the caseworker was also of major importance in these interviews. The same terms heard in the first interviews were also repeated here. Below are vignettes of these relationships.

One interview was with a father who had hit his son out of frustration after a dash across a shopping center parking 1ot. The father remembered the personal interest the worker had in him as a client. "She treated everyone with dignity and trust. She was both professionally interested and genuinely concerned with our family. She showed concern for us as individuals. She recognized that everyone makes mistakes. Trust people and they will respond accordingly."

A second interview was with a mother and father who were involved with the placement of their five-month-old daughter in foster care because of neglect. They expressed the same sentiments. "The small things that (she) did added up and showed that she cared. She hugged us when we got our baby back. She took a picture of us. She seemed more like a friend than a counselor. She trusted us and that made us want to do better. She cares for the people." They said it didn't feel like they were being supervised but more like the worker was there for them if they wanted or needed anything. 
They were told to call her if they had any problems and they felt supported because the worker believed they could do what was required.

4) Communications

One father was not sure of the exact status of his case or records. He asked if he had access to his case record. He felt that someone from the agency should explain procedures. "If someone came out to see us this evening, I wouldn't be surprised, but I don't expect it." Another couple simply stated that they became much more relaxed once they knew what they had to do.

A third mother felt that the status of her case was open-ended with respect to how long it would take to meet the requirements. She was unsure how long her family would be under the supervision of the agency. "Not knowing what was happening was the problem. It was just too vague. They should have a form telling us our rights."

One mother also stated that she didn't ever really understand her case status. She said she kept asking and was always told that the case would close when it was felt that the children were no longer at risk. The mother would have preferred more specifics.

Another mother felt that the communication was very good. She was told the procedures, why things were happening, and what to expect. Her worker was good about calling her ahead of time and keeping her informed of what 
was going on. "They listen to you and involve you. I understand that the final decisions are theirs, but they do involve you."

A father felt that the expectations were very clear but felt "dehumanized" since there was absolutely no choice involved.

5) Participation

One mother indicated that, even though the services were mandated, they didn't feel forced. She stated that she was pleased to have the opportunity to participate. The worker initially asked her what family situation she wanted: the father to move out of the home or the daughter to go into protective custody. Later, she was asked if she felt that it was time for her daughter to return home.

One mother said, "It would have been better if it had been voluntary; I sought help and then felt it was forced. I didn't like this aspect of it." She said she was told to sign her children over as wards of the court and then CSD' would help her get them back. They remained wards for four and a half years. She had been told that the wardship was a "hatchet over your head" to protect her children. Another mother said that she was told the results of a psychological evaluation indicated that CSD should pursue the adoption of her children if she didn't change in three months. She had signed a service agreement but felt that it had been forced since CSD was going to keep her daughter if 
she didn't participate.

Another mom was given the "choice" to participate in parenting classes or have her child taken away. Another indicated that the general feeling she had was that, if she fought them over anything, they would find some reason to take her children.

Summary of Second Interviews for Instrument Development. The concerns and praise which families discussed during this round of interviews were very similar to those raised during the first round. The four major themes which emerged during the second round were:

1. Communication

Families returned again and again to issues of the status of their case, agency expectations of them, and their level of understanding of the process.

2. Relationship with Caseworker one of the pivotal issues to all of the families was the relationship which they had with their caseworker.

3. Level of Participation Perhaps the key issue to the families, other than the relationship with their caseworker, was their feeling of involvement in the planning and decisions. Words which were used again and again were: "threats," "force," "choice," "opinion," 
and "voluntary."

4. General Agency Approach

A very broad area which received many comments could be termed the general approach which the families felt the agency took in working with the family.

In summary, the second set of interviews supported the basic themes which were identified in the analysis of the first set of interviews. Additionally, a new issue emerged more clearly after these second interviews which seemed to cut across the areas of communication, relationship with the caseworker, general relationship with the agency, and even services. This was the issue of participation. Being involved and included in the decision-making and planning appeared to be a key component to the family's general feeling of satisfaction, or lack of satisfaction, in their contact with the agency.

FORMULATING THE CLOSED-ENDED QUESTIONNAIRE ITEMS

The second stage of instrument development involved the construction of a closed-ended questionnaire based upon the analyses of the responses from both sets of interviews. The results from the content analyses, along with some additional items from the literature and agency interests, were used to develop a client satisfaction questionnaire. This 
closed-ended instrument was then pre-tested. The results of the pre-test were analyzed and the instrument was further refined.

\section{Initial Item Formulation}

During the course of the questionnaire construction, three distinct sections were developed: (a) satisfaction statements, (b) caseworker descriptions, and (c) list of services.

Satisfaction Statements. The first step was to write the phrases from the content analyses statements with Likert-type response categories ranging from "strongly agree" to "strongly disagree." Many times, statements were written both in positive and negative terms. Later, one of these pairs was removed, keeping a balance of positive and negative statements.

After a list of 30 to 35 items was developed, the researcher went back to the client and patient satisfaction literature to examine the issue of the domains covered.

Following the content analysis of the interviews, the literature was re-examined to compare the basic issues which were dominant in the interviews with the dimensions which are generally identified in the client satisfaction studies.

One general area that appears in the literature but had not been clearly articulated in the interviews was the area of convenience. CSD was interested in including some items 
addressing this issue. A number of items were developed for this area and included in the pre-test. (These are items \#23，24，25，26, and 27.)

The first section, the satisfaction statements, contained 27 items. These items composed a Likert-type scale; each with five response choices. These response choices were: (a) "strongly agree," (b) "agree," (c) "no opinion," (d) "disagree," and (e) "strongly disagree." An additional response category of "not applicable" was included, mainly to address the statements concerning office visits.

After the satisfaction statements were developed, it appeared that two of the major content areas from the interviews were not covered adequately. These were the areas of services and caseworker attitudes. In reviewing the coding from the interviews, it seemed that a different approach would be more appropriate for these areas.

Caseworker Descriptions. The coding of the perception of caseworker attitudes first was examined for the possibility of developing a semantic differential scale. This was rejected for three reasons. It would make the survey form and analysis overly complicated by adding a different coding method. It is a complex task to generate true pairs of opposite statements. Third, while many of the actual phrases from the interviews appeared to form such pairs, many did not. 
Instead of statements, a 1ist of 13 descriptive words and phrases about caseworkers mentioned in the interviews was included. Respondents were asked to indicate whether or not the words described their worker, using a five-point scale from "strongly agree" to "strongly disagree." These response choices were: (a) "strongly agree," (b) "agree," (c) "no opinion," (d) "disagree," and (e) "strongly disagree." Even though the format for these items differed from the 27 satisfaction statements, the response format remained consistent.

List of Services. A list of 17 services was developed using information from the interview responses and the list of services provided by the agency. The response choices most appropriate for this list of services was a "helpfulness" scale. A five-point scale was developed with response choices of "very helpful, "helpful," "neutral," "not helpful," and "harmful." An additional response category of "didn't receive" was also included.

The instrument to be pre-tested thus consisted of three sections. (See Appendix C for a copy of the Pre-test client Satisfaction Instrument.)

The Pre-Test and Instrument Refinement

Sample. The sample for the pre-test was composed of two non-randomly selected groups of respondents. The first consisted of any client who visited one of two specified CSD 
Branch offices during a two-week period and volunteered to complete the survey instrument. The second sample was a group of parents who were participating in a CSD parent training class. The total sample size was 53 and consisted of the following distribution: (a) 34 individuals who visited the Multnomah Branch office, (b) seven individuals who visited the Clackamas Branch office, and (c) 12 individuals who attended a parent training class offered at the Multnomah Branch office.

Procedure. The instrument was pre-tested during a two-week period of time during June 1988. The survey instrument was left in the reception area of two of the largest Branch offices of CSD (Multnomah and Clackamas). Staff in the reception areas were instructed to ask each client who entered the building, either for a scheduled appointment or as a walk-in, if they wished to complete a client satisfaction survey.

Clients who completed surveys were instructed to leave them in a bin located in the reception area. Staff was instructed to gather the completed surveys at the end of each day and keep them in a secure area. Batches of completed forms were sent to the researcher at the end of the first week and at the end of the pre-test.

The second group of respondents was asked by their instructor to complete the survey at the end of one of their parent training classes. The instructor emphasized that 
participation was voluntary. Completed surveys were placed in a manila envelope, sealed, and sent to the researcher. Data Analysis and Findings. While the methodology for the pre-test was somewhat restricted by practical considerations of the agency, it did allow for the testing of many of the major issues that were of concern.

1) Client Acceptance of a Written Survey to Complete The two groups of clients who participated in the pre-test were open to the idea of providing feedback to the Division. The receptionists in the two offices noted only a few instances of what they considered to be hostility toward the idea. The parent trainer received $100 \%$ participation of his class in completing the surveys. It could be argued that this second group might have felt intimidated, or subtle pressure, to participate. The instructor did not think that very likely.

More specifically, no comments were made to the staff or included on the survey forms to indicate any reluctance to complete the survey. There were no obvious attempts to subvert the study by responding to the survey in a rote method.

2) Client Understanding of the Protections Discussed in the Cover Letter

None of the individuals responding to the survey raised any questions or expressed any concerns about the voluntary nature of the survey. Neither were any questions or 
concerns expressed with respect to the anonymous nature of the information provided.

3) Client Ability to Understand the Required Response Pattern and the Language Used in the Survey

None of the individuals responding to the survey raised any questions or expressed any concerns about not understanding how to complete the survey. No one asked for any assistance in reading or understanding any individual items. Only three of the 27 items received as many as four "no responses." These three statements were among the shortest and least complex of the survey.

4) Client Ability and Willingness to Respond to the Items in a Thoughtful and Careful Manner

A major concern prior to the pre-test was the possibility that this group of respondents might exhibit a tendency to respond to the survey items in a careless manner, simply responding either randomly or in a totally rote manner. Neither the examination of the survey forms nor the statistical analysis of the responses supported that fear.

5) Positive or Negative Response Bias

Another concern was the possibility that this group of clients would have a tendency to respond with a one-sided, negative response set. Again, neither the examination of the survey forms nor the statistical analysis of the responses supported that fear.

After this broad review of responses to the survey, a 
limited statistical analysis was performed on the pre-test data. The small sample size resulted in a poor sample-to-item ratio of two to one, which negated the possibility of performing factor analysis on the scale. Although questionable because of the small sample size, correlational analysis was performed to examine the structure of the first two sections and to help determine which items should be eliminated, reworded, or added to the final instrument.

The correlational analysis provided some evidence for the domain of "communication and information" and the choice component of the empowerment domain. A larger group of items, that cut across the "service helpfulness and satisfaction," "partnership," and "choice" areas, contained the strongest set of correlations.

\section{THE FINAL SURVEY INSTRUMENT}

Five criteria were used to revise the pre-test instrument. These were: (a) intrinsic value of the item, (b) a final examination of the possible domains to be included, (c) item wording, (d) response variability, and (e) correlational matrix.

\section{Satisfaction Statements}

of the original 27 items from the pre-test, 22 were 
retained. Of these, eight remained unchanged, three were reworded into the negative, and 11 were reworded. Table III displays these items and the changes made.

TABLE III

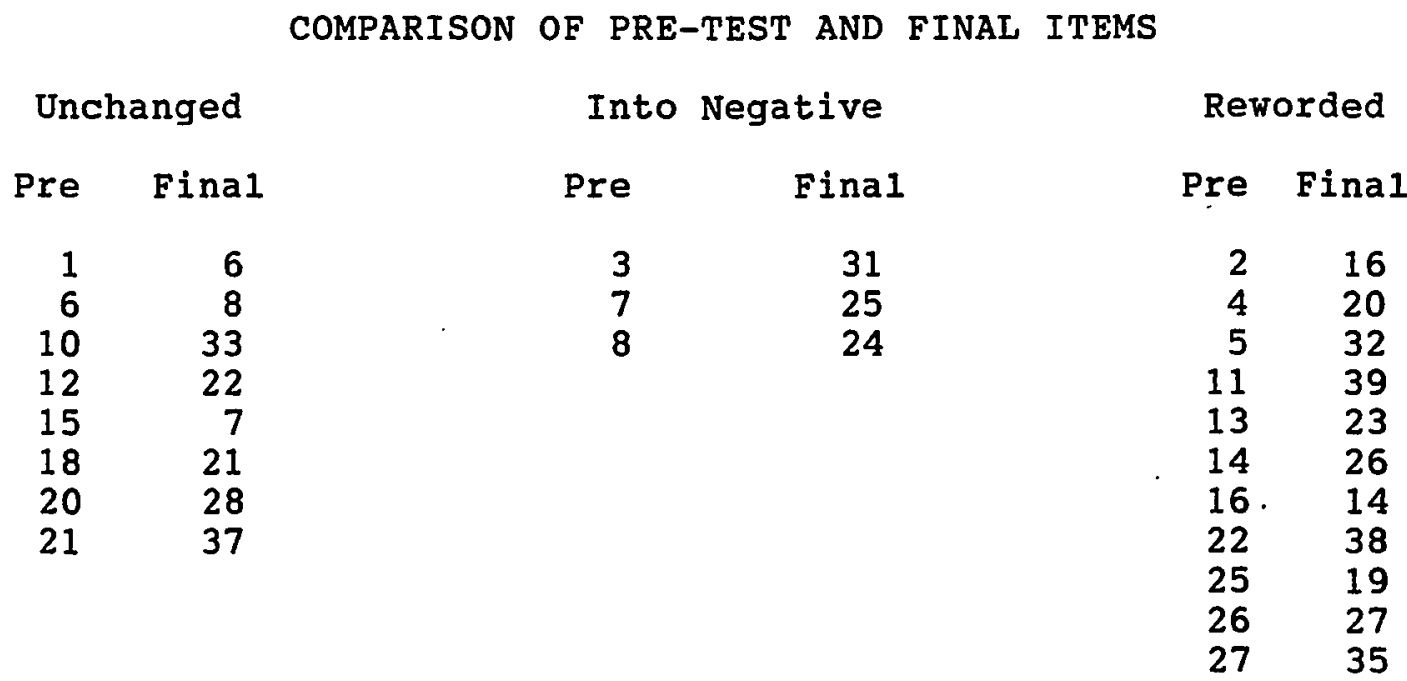

Based upon the considerations mentioned above, five of the 27 items from the pre-test instrument were deleted from the first section of the final client satisfaction instrument. These were items number $9,17,19,23$, and 24 . Three of the five items deleted, items numbers 19, 23, and 24, were among the lowest correlated items with any other items (ranking 27th, 26th, and 22nd). Additional1y, item number 24 was specifically added to the pre-test based on agency interest and was not an item which had been identified during the interviews. (This item was, "I had to wait too long for my appointment.")

Another item which was deleted, number 17, was poorly 
worded. Also, it contained the problem of double-barreling; containing more than one issue within the single item. Its range of variability was also limited with the lowest number and percent of "negative" judgment. Only three out of the 48 valid responses were aither "disagree" or "strongly disagree."

The final item that was deleted, number 9, also suffered from limited range, containing the highest single response category number and percent. Twenty-six of the $50^{\circ}$ valid responses were "agree." Additionally, it was an item judged to be poorly worded and vague ("I understood what was going on.").

Sixteen new items were added to the scale to reflect a rethinking on the domains of satisfaction. Three additional items were added to one of the domains (partnership) and four were added to each of two others (general satisfaction and helpfulness). One item was added to the "choice" domain.

Items were added because two general domains were split into two subdomains each. "Services" was divided into "General Satisfaction" and Helpfulness." "Empowerment" was divided into "Choice" and "Partnership in Decisions."

Four items were added to the two which remained in "Information Sharing" to be more specific and focus on the issue of lack of understanding of case status. (See Appendix $D$ for listings of the items in each domain.) Two items added, numbers 2 and 9, were suggested by 
staff in the Family-Based Services Unit in CSD. These items were:

2. I am not satisfied with my family life. (added to the Satisfaction domain)

9. Things have not improved with my family life. (added to the Helpfulness domain)

One additional item was added in the area of convenience.

The first section of the Final survey instrument contained 39 items, or satisfaction statements, and attempted to measure five separate aspects of satisfaction. Like the pre-test, these items composed a Likert-type scale; each with five response choices: (a) "strongly agree," (b) "agree," (c) "not sure," (d) "disagree," and (e) "strongly disagree."

To address the questions of potential positive, or, more likely, negative response bias, both of the first two sections of the survey include half of the statements positively-worded and half negatively-worded. These items were then mixed throughout the sections.

The following are two typical scale items: the first is included in Domain 1 (General Satisfaction) and the second in Domain 4 (Partnership).

18. I am displeased with what has happened with CSD and my family.

Strongly Agree
Agree $\quad$ Not
Strongly

Disagree 
33. I was an active participant in the decisions being made concerning my family.

\author{
Strongly \\ Agree \\ Agree \\ Not \\ Disagree \\ Sure \\ Strongly \\ Disagree \\ The five domains were: \\ 1. Service \\ a. General Satisfaction (items \#2, 15, 18, 20, 23) \\ b. Helpfulness (items \#1, 9, 13, 30, 31, 32) \\ 2. Information Sharing (items \#4; $, 11,25,29,34$ ) \\ 3. Client Empowerment \\ a. Partnership (items \#3, 10, 17, 24, 33) \\ b. Choice (items \#6, 16, 22, 26, 36) \\ Five items were also included to address the area of \\ convenience (items \#5, 12, 19, 27, 35). \\ Additionally, seven items were included which were \\ general opinion statements concerning the mission of the \\ agency (items \#7, 14, 21, 28, 37, 38, 39).
}

\title{
Caseworker Descriptions
}

The second section contained 23 descriptors of words and phrases used to describe caseworkers. The respondents were asked to indicate how each term described their caseworker. The response choices were the same five that were used in the first section of the survey. The section of caseworker descriptions retained all 13 original items from the pre-test and added ten additional ones. These descriptions are listed in Table IV. 
referrals that were assessed by the agency over the 12-month period of time from January 1, 1988, through December 31 , 1988, that met two criteria, validity of the referral and level of service received.

The first criterion was that the referral was found to be valid. Reports of possible abuse are "assessed," or investigated, by CSD, a law enforcement agency, or both. At the end of this assessment, a determination is made concerning whether or not abuse occurred.

The terminology and definitions used to describe this determination is similar, but not uniform, across the 50 states. In Oregon, this determination is termed the "Report Disposition" and there are three choices. "Founded" is defined as "abuse occurred." "Unfounded" is defined as "abuse did not occur." "Unable to Determine" is defined as "insufficient evidence exists to indicate whether abuse occurred or not."

Referrals that were investigated and were determined to be either "Unable to Determine" or "Unfounded" (approximately $65 \%$ of the referrals) were not included. While this group of referrals included cases which were opened for service provision and would add an extremely interesting dimension to the study, it also posed a major ethical problem. In many states, the agencies which conduct the child protective services investigations expunge the records of those cases in which the investigation concluded that the abuse did not 
occur.

While Oregon's CSD does not remove these cases from their information system, the problems with identifying and contacting these families for this study seemed to outweigh the empirical considerations for including them. Including them would have also broadened the issues and possible dimensions to be analyzed, thus diluting the focus of the study from those families in which child abuse was found to have occurred.

of the 7,515 Founded referrals assessed in calendar year 1988, 987, or 13\%, involved multiple incidents of abuse or neglect during the year involving the same family. When these duplicate referrals were removed, there were 6,528 individual cases, or families, remaining.

The second criterion used in selecting the population was that the family had to have received some level of service from CSD beyond "information and referral to other agencies" and "assessment" at some time during their relationship with the agency.

Just as services may be provided to families where the suspected abuse was not confirmed, there are also instances when CSD does not provide direct services to families when abuse or neglect has occurred. Families who had no experience with the agency in the areas of service plan development and delivery of services were not included because they could not respond to the range of issues that 
were included in the survey instrument. When the cases were removed that did not include some level of service, 4,455 cases remained as the potential population to be surveyed. The final step was to remove cases that could not be included because an address could not be found for them. The final resulting population for the survey was 4,337. (Refer to Figure 1.)

$$
\begin{aligned}
& 21,822 \text { - total referrals assessed } \\
& 7,515 \text { - 'founded' referrals } \\
& 6,528 \text { - unduplicated families } \\
& 4,455 \text { - families who received services } \\
& 4,337 \text { - families who were mailed surveys } \\
& \text { Figure 1. A funnel of the total number of CPS } \\
& \text { Referrals which were assessed in calendar year } \\
& \text { 1988 to the total number of families who were } \\
& \text { mailed a survey form. }
\end{aligned}
$$

An important consideration in deciding how broadly to generalize the findings of any survey is whether or not those responding are representative of the entire population included in the survey. Four hundred seventy-eight completed surveys were returned, for a response rate of $11 \%$. Is the group of families who responded representative of the entire population?

Half of the survey forms which were mailed to respondents included a form identification number. Upon return, this number could be matched with a separate listing 
of CSD case numbers to identify the respondent. This provided the capability to retrieve data from the CSD automated information system to compare respondents to the entire population. Additionally, a number of respondents included their return address. In total, 353 of the 478 respondents were known.

While $46 \%$ of the unknown population $(\mathrm{N}=4102)$ had an open case at the time of the selection for the survey, $58 \%$ of the known respondents $(\mathrm{N}=353)$ had an open case. Twenty-five percent of the unknown population had only one case opening compared to $30 \%$ of the known respondents.

Another general indication of agency contact is the number of referrals that a family has had to CSD. A referral is a report of an official contact with CSD. Thirty-eight percent of the unknown population had no prior CPS referrals and $45 \%$ of the known respondents had no prior CPS referrals.

A comparison related to the specific CPS issue qualifying a family for the study is the relationship of the alleged perpetrator to the family. While mothers were the perpetrator for $44 \%$ of the unknown population, mothers only comprised $33 \%$ of the the perpetrators for the known respondents. The corresponding figures for fathers were $32 \%$ and $39 \%$.

A final comparison is in the area of the out-of-home placement experience of the two groups. It can be argued that families who have experienced the placement of 
their chlldren into child protective custody will evaluate their experiences with CSD very different1y than families who have not had this experience. Data indicate that $34 \%$ of identified respondents and $34 \%$ of unknown population had no children placed into child protective custody.

Procedure. Two identical computer printouts of the population of 4,455 potential survey respondents were produced. These printouts were in zip code order and contained the following information; the case number for the family, the case name, the case address, the telephone number, the family survey identification number, and a section for remarks.

The first of these printouts was produced on hardcopy paper and the second printout was produced on mailing labels. Prior to sending the mailing labels to a mail service for stuffing, labeling, and bulk mailing, the completeness of the address information was checked. Addresses that were either incomplete or entirely missing were identified.

As many errors were corrected as possible. This process included checking through the computer records of other Department of Human Resources Divisions in attempts to locate more recent or more complete addresses as well as the necessity of correcting or adding a number of zip codes. The result was a sample of 4,337 . Surveys were sent to families in other states, other counties, and those residing in state and county institutions. No surveys were held back 
because of the address.

In the computer system at CSD, a family is listed in a "case" with a unique seven-character number to identify the case and separate one-character "person letters" to identify individual family members. The case is also identified by the "case name," the name of the individual in the case who is identified with the first person letter. The survey envelope was addressed to the member of the family who was listed as this case name. In most instances, this is the mother.

A cover letter was included in the envelope with the survey form. (See Appendix F.) This cover letter expiained the purpose of the survey, explained how and why the family had been included, emphasized the voluntary nature and confidentiality of the survey results, explained what to do with the completed survey, provided the family a name and number to call with any questions or concerns, and instructed the family that they could decide who in the family would. participate in its completion. Also included was a self-addressed, business reply envelope for return of the completed survey.

Within one day of the surveys being sent to the post office, the researcher received the first telephone call from a family member who had received the survey. In total, 35 telephone calls were received. The majority of the calls were to discuss the family situation or current case status. 
In all cases, the researcher explained that the survey was neither able nor intended to address individual case situations. Only two of the calls were from family members who were not aware of any contact with the Division and who, thus, did not understand why they had received a survey. In both instances, the families wished the researcher to investigate the circumstances and report back to them. Also in both cases, both of the criteria to qualify a family for inclusion in the survey had been met and explained to the . families. A few families called to compliment the Division on conducting such a survey of its clients.

Half of the survey forms contained an identifying number that could then be matched upon receipt to identify the family completing the survey. The code which was used to match the form number with the case number was kept in a locked file cabinet.

This system was implemented for three reasons. The first was to be able to comment on the effect of such a numbering scheme on the rate of return of surveys. The second was to be able to know to whom a second, follow-up survey should be sent. The final reason was to be able to add data about families from the agency computer system to the file for further analysis.

Upon receipt of the returned completed survey forms, the forms were checked for errors and completeness. Case numbers were added to those with the identifying number. 
Surveys were batched and sent to a keypunch service used by the Division.

Two months after the surveys were mailed, a second wave was mailed to 2,000 of the families who were known not to have responded to the first survey. The procedures for the second mailing were identical to the first. Four hundred and nine surveys were returned during the first wave and 69 during the second for a total of 478 .

Data Analysis. The purpose of the data analysis was to answer the research questions concerning an instrument to measure client satisfaction among CPS families. The first two research questions directly addressed the development and the structure of the instrument.

These research questions were:

1. Can a client satisfaction instrument be developed for CPS clients largely through the input of the clients?

2. What are the domains of satisfaction that are applicable to CPS families?

The data analysis procedures utilized to address these first two research questions were applied only to the 22 items of the 39 in the first section of the client satisfaction survey. (The remaining 17 items included a five-item general satisfaction scale and 12 items which were only briefly examined and included in the basic descriptive statistics of the entire survey.) The analyses were 
restricted to the 22 items which comprise the four scales of satisfaction.

The 22 questionnaire items were developed to reflect the domains of satisfaction that had emerged as a result of the interviews with the CPS families. These domains were: (a) Helpfulness, (b) Partnership, (c) Choice, and (d) Information Sharing.

The analysis focused on determining the extent to which these domains held up empirically, that is, whether or not the respondents viewed items designed to represent a specific domain in a similar way.

The first set of procedures was performed to analyze whether or not the scale items measure what the scales purport to measure. Two principle methods, correlational analysis and the principle components factor analysis, were used.

The first procedure was to examine the intercorrelational matrix to determine the correlations among the items included in each of the scales. It was expected that some items would not show homogeneity or relationship with the majority of the items. Two criteria, convergent validity and divergent validity, were used to determine which items to retain.

First, analysis of convergent validity was used to examine the correlations of items within each scale. Items that are tapping the expected domain exhibit high 
correlations both with other items within that scale and with its scale. Likert (1932) states that the uncorrected correlations between each item and its scale should be substantial (at least 0.30 ) and positive.

The second criterion, divergent validity or item discriminant validity, examines the correlations of items across the various scales. Item discriminant validity requires that the corrected correlations between an item and its scale be higher than its correlations with other scales. Items that are tapping a single domain should exhibit low correlations with items in other domains. Items that exhibit high correlations with items in one other scale may actually be tapping the issue in that domain. Items that exhibit high correlations with items in many other scales may actually be a general item.

The second procedure used to examine the scales was factor analysis. Principle Components Factor Analysis was applied to the same set of items as a second method to . examine the structure of the client satisfaction scales. Factor analysis procedures are a second approach to determining the presence or absence of unidimensional scales. Two separate factor analysis procedures were run. The first identified factors based upon a minimum eigenvalue of one. The second procedure established the number of factors to be extracted at four. This specification was established to match the number of domains proposed. 
The next set of analyses was performed in order to estimate the internal consistency reliability of the scales. This third procedure was to subject the set of scales which were identified to reliability analysis (Cronback's Alpha) in order to analyze the structure, or internal consistency, of each of the scales. Item to scale correlations were examined in order to determine the existence of the domains and to determine the best items to retain in each scale.

Examination of the internal consistency of scale items . is appropriate for this study since it provides information about the degree to which items thought to belong to one scale are related to one another. Coefficient Alpha, derived by Cronbach (1951) is the preferred method for assessing internal consistency (Carmines \& Zeller, 1979; Nunnally, 1978). This approach treats common item variance as true score, reliable variance, and both unique item variance and random error as error. Coefficient Alpha is based upon the average correlation among items within a scale and on the number of items in the scale (Nunnally, 1978). It is possible, therefore, to increase the reliability of a test or scale by increasing the average correlation or by increasing the number of items measuring the particular attribute of interest.

If Coefficient Alpha is low, there are too few items or the items have very little in common (i.e., they are not viewed in a similar way). According to Nunnally (1978), 
setting standards for a satisfactory level of reliability depends on how a measure is to be used. Alpha levels of .70 or higher generally are sufficient for early stages of research. In applied situations, where major decisions about individuals will be made, reliabilities of .95 may be required.

The last two research questions addressed the relationship between the various domains of satisfaction and their relationship to an overall measure of general satisfaction. The data analysis procedures used to examine those two questions were applied to new composite variables which were created based upon the results of the reliability analyses. Scale correlations among these new variables were then examined. Additionally, the correlations between these new variables and three measures of overall satisfaction were examined:

1. the general satisfaction scale which resulted from the reliability analysis

2. the scores from the single item number 15, "In general, considering all of my contacts with CSD, and all of the services my family received, I am satisfied with CSD."

3. the scores from the content analysis of comments that a number of respondents included in a "comments" section. These comments were placed on a five-point scale of "very satisfied," 
"satisfied," "mixed satisfaction," "dissatisfied," and "very dissatisfied." 
CHAPTER IV

FINDINGS

This chapter presents the findings from the analyses performed to evaluate the proposed structure of the client satisfaction survey instrument. Following a brief presentation of some general descriptive statistics, two major sections address the research questions. The first section examines the construction of the proposed multi-item scales and addresses the first two research questions. The second section addresses the second two research questions by focusing on the relationship between the proposed scales and three measures of general satisfaction.

DESCRIPTIVE STATISTICS

\section{Satisfaction Statements}

The means, standard deviations, and the number of respondents for each of the entire set of 39 items in the first section of the survey are displayed in Table V. The items are presented in the same order as they appeared on the survey instrument. Throughout this chapter, the items have been abbreviated for presentation. 
The final survey instrument with the complete text of each item is presented in Appendix $E$. In the results presented throughout this chapter, all items have been scored so that a high score indicates a more favorable response. (A "one" is the least favorable and a "five" is the most favorable response.) This was accomplished by recoding the responses for some of the items.

The means ranged from a high of 3.67 for item 37 . to a low of 1.55 for item 21. The response distributions for most of the items were skewed. Means for 33 of the 39 items were below 3.00 , on the side of the response scale midpoint indicating a more negative rating. Standard deviations ranged from 0.94 to 1.58 . Missing data in this section of the survey ranged from a high of $36(7.5 \%)$ to a low of five $(1 \%)$.

The means, standard deviations, and the number of respondents for each of the 22 items which comprise the four multi-item scales are presented in Table VI. The items ar.e grouped within their specific scale. The means ranged from a high of 3.55 for item 9 in the "Helpfulness" scale to a low of 2.13 for item 22 in the "Choice" scale. The response distributions for most of the items were skewed. Means for 21 of the 22 items were below 3.00 , on the side of the response scale midpoint indicating a more negative rating Standard deviations were in a tighter range than those for the entire group of items, ranging from 1.35 to 1.53 . 
TABLE V

MEANS AND STANDARD DEVIATIONS FOR 39 ITEMS IN SATISFACTION STATEMENTS

\begin{tabular}{|c|c|c|c|}
\hline Item (in capsule form) & $\begin{array}{r}\text { Number of } \\
\text { Respondents }\end{array}$ & Mean & $\begin{array}{r}\text { Standard } \\
\text { Deviation }\end{array}$ \\
\hline $\begin{array}{l}\text { 1. Services helped deal with } \\
\text { family's problems } \\
\text { 2. Not satisfied with }\end{array}$ & 468 & 2.827 & 1.502 \\
\hline family life & 459 & 3.682 & 1.378 \\
\hline 3. Agreed with CSD's plan & 460 & 2.633 & 1.404 \\
\hline $\begin{array}{l}\text { 4. Not told ways to complain } \\
\text { 5. Same caseworker since first }\end{array}$ & 464 & 2.489 & 1.414 \\
\hline contact & 458 & 2.718 & 1.423 \\
\hline $\begin{array}{l}\text { 6. Choice to use or not use } \\
\text { help }\end{array}$ & 468 & 2.598 & 1.515 \\
\hline 7. CSD lost sight of interests & & & \\
\hline $\begin{array}{l}\text { of my children } \\
\text { 8. Kept well-informed } \\
\text { 9. No improvement with family } \\
\text { 10. Disagreed with caseworker }\end{array}$ & $\begin{array}{l}471 \\
472 \\
457\end{array}$ & $\begin{array}{l}2.688 \\
2.538 \\
3.547\end{array}$ & $\begin{array}{l}1.565 \\
1.458 \\
1.407\end{array}$ \\
\hline $\begin{array}{l}\text { on problems } \\
\text { 11. Caseworker explained case } \\
\text { 12. Hard to contact caseworker } \\
\text { 13. Services received were }\end{array}$ & $\begin{array}{l}461 \\
464 \\
465\end{array}$ & $\begin{array}{l}2.824 \\
2.841 \\
2.929\end{array}$ & $\begin{array}{l}1.438 \\
1.427 \\
1.384\end{array}$ \\
\hline $\begin{array}{l}\text { appropriate } \\
\text { 14. CSD needs to be consistent } \\
\text { 15. Satisfied with CSD } \\
\text { 16. Participation in services }\end{array}$ & $\begin{array}{l}470 \\
460 \\
473\end{array}$ & $\begin{array}{l}2.753 \\
2.322 \\
2.522\end{array}$ & $\begin{array}{l}1.484 \\
1.274 \\
1.487\end{array}$ \\
\hline $\begin{array}{l}\text { forced } \\
\text { 17. Caseworker doing his/her }\end{array}$ & 458 & 2.887 & 1.498 \\
\hline $\begin{array}{l}\text { part } \\
\text { 18. Displeased with what }\end{array}$ & 470 & 2.811 & 1.509 \\
\hline happened & 473 & 2.683 & 1.580 \\
\hline $\begin{array}{l}\text { 19. Not easy getting to CSD } \\
\text { office } \\
\text { 20. Services offered to everyone }\end{array}$ & 456 & 3.456 & 1.261 \\
\hline $\begin{array}{l}\text { needing help } \\
\text { 21. CSD should help solve }\end{array}$ & 461 & 3.067 & 1.398 \\
\hline $\begin{array}{l}\text { problems } \\
\text { 22. Feeling of powerlessness } \\
\text { 23. CSD helped through crisis } \\
\text { 24. Opinions not considered in }\end{array}$ & $\begin{array}{l}468 \\
463 \\
465\end{array}$ & $\begin{array}{l}1.551 \\
2.130 \\
2.643\end{array}$ & $\begin{array}{l}0.944 \\
1.411 \\
1.493\end{array}$ \\
\hline $\begin{array}{l}\text { decisions } \\
\text { 25. Expectations of CSD not }\end{array}$ & 468 & 2.485 & 1.418 \\
\hline $\begin{array}{l}\text { clear } \\
\text { 26. CSD took over } \\
\text { 27. CSD receptionist friendly } \\
\text { 28. CSD should be more }\end{array}$ & $\begin{array}{l}463 \\
463 \\
454\end{array}$ & $\begin{array}{l}2.851 \\
2.570 \\
3.515\end{array}$ & $\begin{array}{l}1.359 \\
1.534 \\
1.201\end{array}$ \\
\hline supportive & 468 & 1.904 & 1.123 \\
\hline
\end{tabular}


TABLE V

MEANS AND STANDARD DEVIATIONS FOR 39 ITEMS IN SATISFACTION STATEMENTS

(continued)

\begin{tabular}{|c|c|c|c|}
\hline Item (in capsule form) & $\begin{array}{l}\text { iber of } \\
\text { indents }\end{array}$ & Mean & $\begin{array}{r}\text { Standard } \\
\text { Deviation }\end{array}$ \\
\hline $\begin{array}{l}\text { 29. Never sure of case status } \\
\text { - open or closed } \\
\text { 30. Improved parenting skil1s } \\
\text { 31. Services not helpful } \\
\text { 32. Services fit individual }\end{array}$ & $\begin{array}{l}457 \\
463 \\
464\end{array}$ & $\begin{array}{l}2.934 \\
2.579 \\
2.869\end{array}$ & $\begin{array}{l}1.378 \\
1.403 \\
1.481\end{array}$ \\
\hline $\begin{array}{l}\text { situation } \\
\text { 33. Actively participated in }\end{array}$ & 465 & 2.708 & 1.431 \\
\hline $\begin{array}{l}\text { decisions } \\
\text { 34. Did not understand what's }\end{array}$ & 466 & 2.652 & 1.465 \\
\hline $\begin{array}{l}\text { going on } \\
\text { 35. CSD office satisfactory for }\end{array}$ & 462 & 2.840 & 1.402 \\
\hline $\begin{array}{l}\text { family visits } \\
\text { 36. Would return to CSD } \\
\text { 37. Agreed CSD mission to }\end{array}$ & $\begin{array}{l}442 \\
468\end{array}$ & $\begin{array}{l}2.434 \\
2.404\end{array}$ & $\begin{array}{l}1.233 \\
1.471\end{array}$ \\
\hline $\begin{array}{l}\text { protect children } \\
\text { 38. CSD needs to punish abusers } \\
\text { 39. CSD not fair in my case }\end{array}$ & $\begin{array}{l}454 \\
448 \\
457\end{array}$ & $\begin{array}{l}3.667 \\
2.647 \\
2.657\end{array}$ & $\begin{array}{l}1.418 \\
1.512 \\
1.483\end{array}$ \\
\hline
\end{tabular}

Caseworker Descriptors

The means, standard deviations, and the number of respondents for each of the 23 caseworker descriptors which comprise the second section of the survey are displayed in Table VII. The descriptors are ranked from most favorable to least favorable. The means ranged from a high of 3.35 for "Concerned" to a low of 2.46 for "Controlling." Iike the items in the first section, the response distributions for most of the items were slightly skewed. However, this time, means for 13 of the 23 items were above 3.00 , on the side of the response scale midpoint indicating a more positive rating. Standard deviations were in a tighter range than 
TABLE VI

MEANS AND STANDARD DEVIATIONS FOR 22 ITEMS IN FOUR DOMAINS OF SATISFACTION

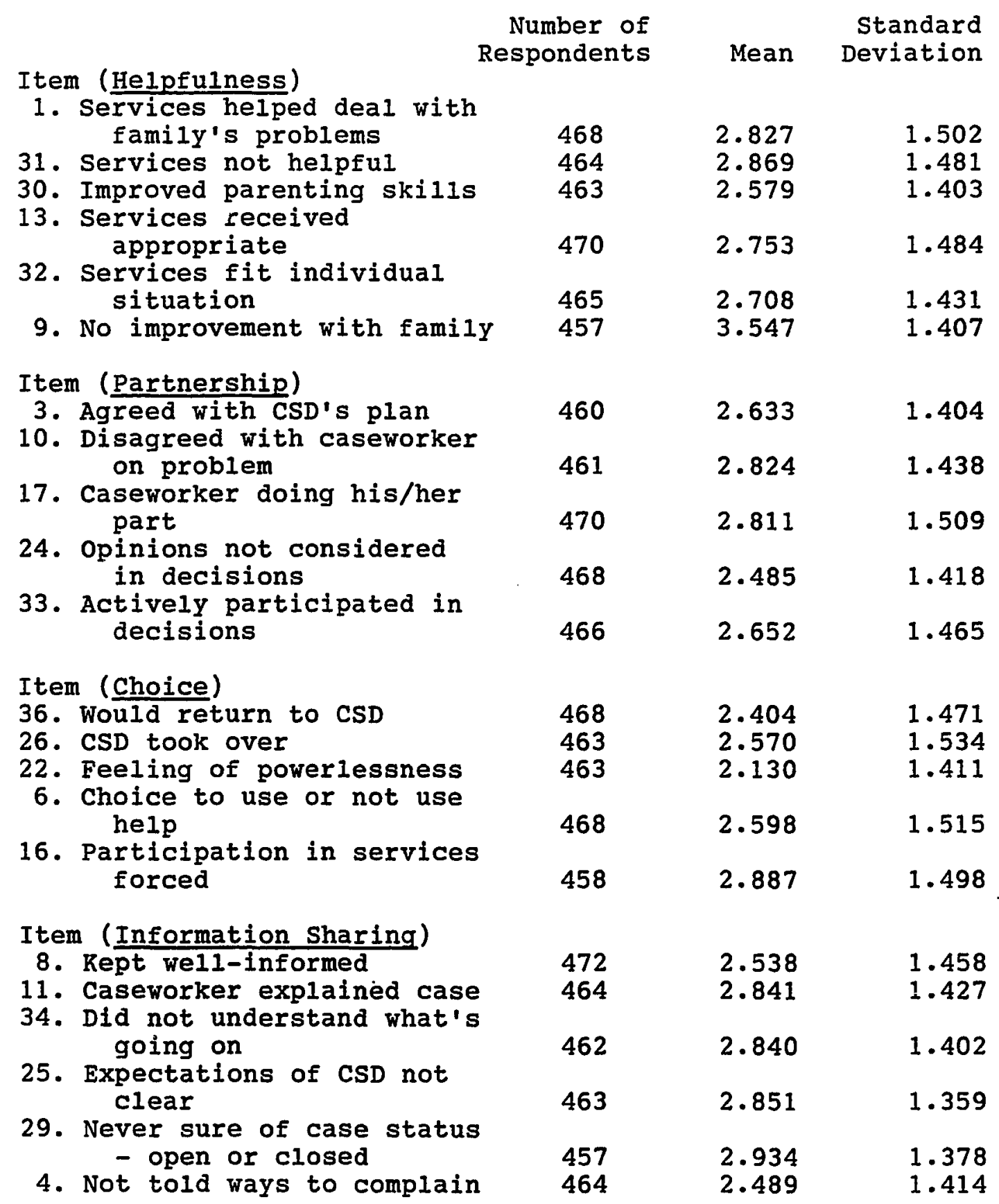


those for the satisfaction statement items, ranging from

1.28 to 1.49 .

Missing data in this section of the survey ranged from a high of $38(7.9 \%)$ to a 1 ow of $23(4.8 \%)$.

TABLE VII

MEANS AND STANDARD DEVIATIONS FOR THE IIST OF 23 CASEWORKER DESCRIPTORS

\begin{abstract}
Caseworker
Descriptor

Concerned

Good listener

Honest

Knowledgeable

Caring

Respectful

Responsive

Dependable

Understanding

Supportive

Inconsistent

Informative

Unavailable

Unfair

Not helpful

open-minded

Sympathetic

Negative

Inflexible

Intimidating

Critical

Judgmental

Controlling
\end{abstract}

$\begin{array}{crr}\begin{array}{c}\text { Number of } \\ \text { Respondents }\end{array} & \text { Mean } & \begin{array}{r}\text { Standard } \\ \text { Deviation }\end{array} \\ 451 & 3.348 & 1.349 \\ 449 & 3.294 & 1.469 \\ 451 & 3.224 & 1.429 \\ 455 & 3.211 & 1.375 \\ 453 & 3.166 & 1.429 \\ 445 & 3.146 & 1.432 \\ 450 & 3.100 & 1.405 \\ 450 & 3.069 & 1.402 \\ 454 & 3.064 & 1.441 \\ 455 & 3.046 & 1.480 \\ 448 & 3.013 & 1.376 \\ 447 & 3.009 & 1.433 \\ 451 & 3.004 & 1.348 \\ 440 & 2.977 & 1.489 \\ 452 & 2.940 & 1.489 \\ 451 & 2.934 & 1.445 \\ 448 & 2.924 & 1.411 \\ 445 & 2.899 & 1.488 \\ 440 & 2.836 & 1.401 \\ 444 & 2.813 & 1.490 \\ 440 & 2.643 & 1.285 \\ 452 & 2.509 & 1.381 \\ 448 & 2.455 & 1.357\end{array}$

\section{List of Services}

The means, standard deviations, and the number of

respondents for each of the 13 services which comprise the

third section of the survey are displayed in Table VIII. The

items are ranked from most favorable to least favorable. The 
means ranged from a high of 3.67 for "Parent Training/Parenting Classes" to a low of 2.54 for "Out-of-Home Placement." The response distributions for most of the items were skewed. Means for 11 of the 13 items were above 3.00 , on the side of the response scale midpoint indicating more positive rating. Standard deviations were again in a tighter range than those for the satisfaction statements, ranging from 1.36 to 1.59 . Missing data in this section conveys additional information from that in the other two sections of the survey. Missing data in this section of services also includes respondents who did not receive a specific service. Missing data ranged from a high of 423 (88.5\%) for "Shelter for Battered Women" to a low of 53 (11.1\%) for "Direct Caseworker Contact."

TABLE VIII

MEANS AND STANDARD DEVIATIONS FOR THE 13 SERVICES

Service

$\begin{array}{lr}\text { Parent Training/Parenting Classes } & 183 \\ \text { Alcohol/Drug Counseling } & 104 \\ \text { Homemaker Services } & 98 \\ \text { Mothers' Sex Abuse Support Group } & 120 \\ \text { Victims' Counseling } & 217 \\ \text { Family Counseling/Intensive } & \\ \text { Family Services } & 224 \\ \text { Direct Caseworker Contact } & 425 \\ \text { Nurse to Instruct Newborn } & \\ \text { Baby Care } & 56 \\ \text { Victims' Sex Abuse Support Group } & 145 \\ \text { Housekeeper Services } & 64 \\ \text { Shelter for Battered Women } & 55 \\ \text { Psychological Evaluation } & 207 \\ \text { Out-of-Home Placement } & 247\end{array}$
Standard Mean Deviation

Number of Respondents

3.672

3.433

3.398

3.325

3.318

3.272

3.259

3.196

3.193

3.109

3.109

2.633

2.539
1. 359

1.538

1.448

1.445

1.523

1.577

1.590

1.470

1.487

1.382

1.370

1.442

1.587 
SCALE CONSTRUCTION

The data presented in this section address the first two research questions concerning the construction and structure of the client satisfaction instrument. The content analysis of the interviews and the literature review proposed that client satisfaction among CPS clients was comprised of four domains. These domains are: (a) Helpfulness, (b) Partrership, (c) Choice, and (d) Information Sharing. The research questions were:

1. Can a client satisfaction instrument be developed for CPS clients largely through the input of the clients?

2. What are the domains of satisfaction that are applicable to CPS families?

Throughout this chapter, the term "domain" will be used to refer to an underlying construct and the term "scale" will be used to refer to the empirical indicator of that construct.

\section{Analysis of Item Convergent Validity}

The first data on the issue of the convergent validity of the scales are displayed in Table IX. This table presents the correlation coefficients for the 22 items grouped in each of their domains. The table only includes correlations which are greater than .50. (Appendix G displays all of the correlations among these 22 items.) 
TABLE IX

CORREIATIONS AMONG 22 CLIENT SATISFACTION ITEMS GROUPED BY DOMAIN

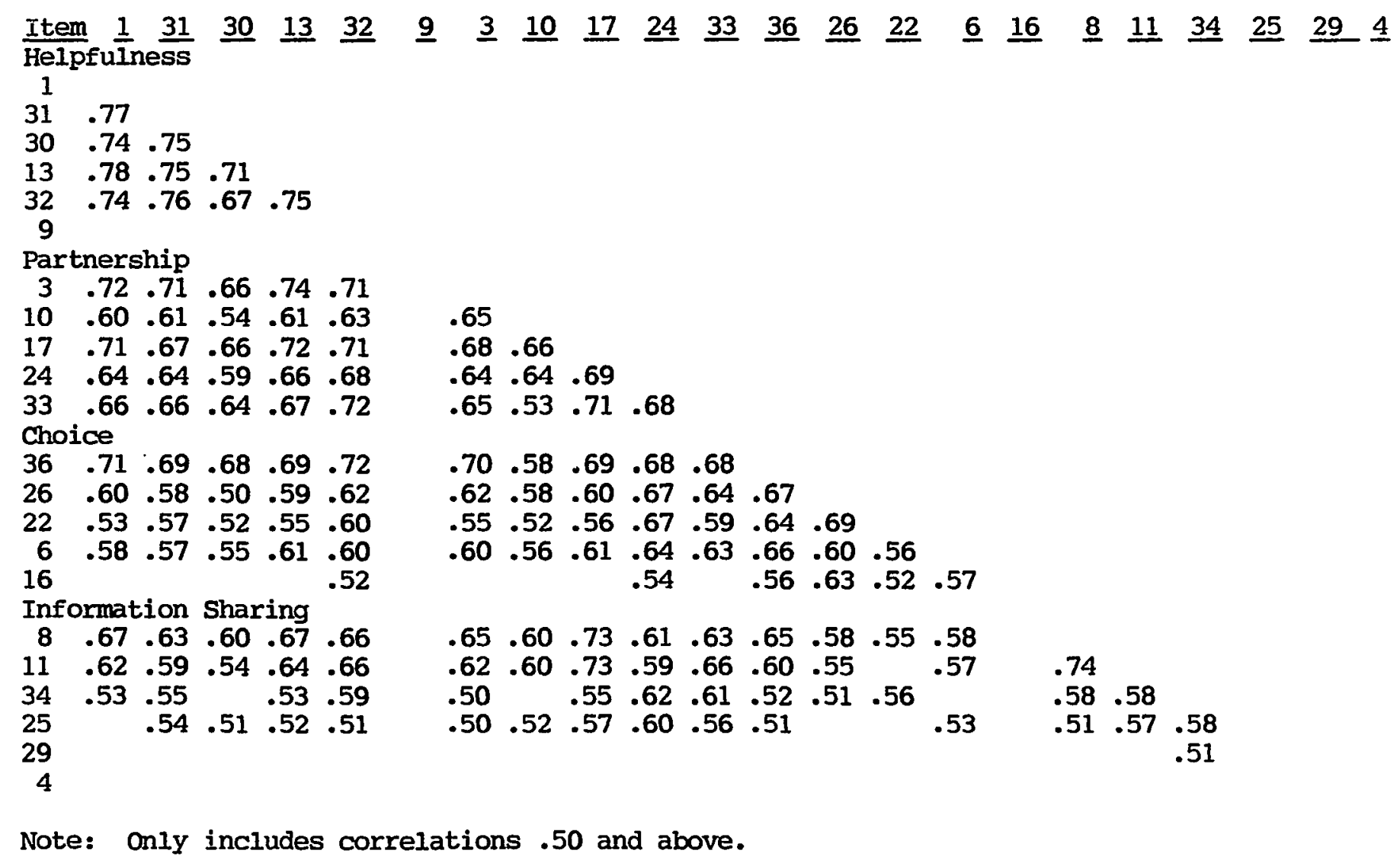


With the exception of item number 9 in "Helpfulness" and items 4 and 29 in "Information Sharing," the correlations among most of the items exceed .50, many above .60 .

A clearer focus upon the question of the convergent validity within each of the four proposed domains is displayed in Tables $\mathrm{X}$-XIII. These tables display the correlations among the items in each scale separately. With the exception of the items mentioned above, the correlations are all above .50 .

Within the "Helpfulness" domain, the correlations range between .29 and .78 . When item 9 is removed, the correlations range between .67 and .78 . Within the "Partnership" domain, the correlations range between .53 and .71. Within the "Choice" domain, the correlations range between .52 and .69. Within the "Information Sharing" domain, the correlations range between .23 and .74 . This lower value rises to .42 by removing item 4 and .51 by also removing item 29 .

TABLE X CORRELATTIONS AMONG THE SIX ITEMS IN THE HELPFULNESS DOMAIN

\begin{tabular}{lcccccc}
$\frac{1}{31}$ & 1 & $\underline{31}$ & $\underline{30}$ & $\underline{13}$ & $\underline{32}$ & 9 \\
$\frac{30}{30}$ & .769 & & & & \\
$\frac{13}{32}$ & .740 & .754 & & & \\
$\frac{.779}{9}$ & .741 & .746 & .713 & & \\
\hline
\end{tabular}


TABLE XI

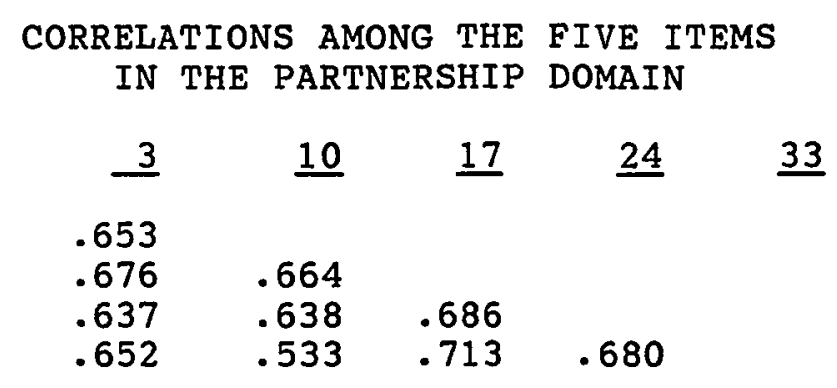

TABLE XII

CORRELATIONS AMONG THE FIVE ITEMS

IN THE CHOICE DOMAIN

$\begin{array}{llllll}\frac{36}{26} & \frac{36}{22} & \underline{26} & \underline{22} & \underline{6} & \underline{16} \\ \frac{26}{6} & .666 & & & \\ \underline{16} & .640 & .690 & & \\ & .659 & .599 & .557 & \\ & .561 & .634 & .521 & .575\end{array}$

TABLE XIII

CORRELATIONS AMONG THE SIX ITEMS

IN THE INFORMATION SHARING DOMAIN

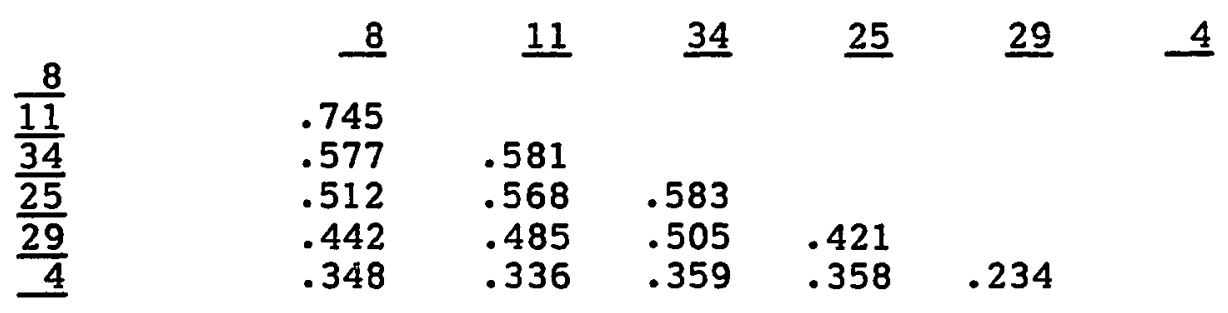

Analysis of Item Discriminant Validity

The next area to examine is the discriminant validity of the scales. Three approaches will be examined to address this issue. The first is to re-examine the correlations displayed in Table IX. The correlations between items within a scale should be greater than the correlations between 
items across scales. While this is generally the case, the differences are not striking.

The correlations between each of the 22 items and the four scales are displayed in Table XIV. If a scale has discriminant validity, the correlation between an item and its own scale should be higher than the correlation between the item and other scales. (The scales have been constructed by only including those items which did not diminish the internal consistency reliability of the scale. This will be discussed further in the next section.)

As with the correlations among individual items, the item-to-scale correlations also provide some support for divergent validity for the scales.

The correlations which have been correlated for overlap between each of the 22 items and the four scales are presented in Table XV. The corrected item-scale correlation has removed each item individually from the scale prior to calculating the correlation between that item and the scale. Although the weakest evidence, the corrected item-to-scale correlations also provide some support for divergent validity for the scales.

\section{Principle Components Analysis}

Principle components analysis was then applied to the 22 items to further examine the structure of the proposed scales. The question being addressed is whether or not there is evidence to support the existence of the four proposed 
TABLE XIV

\section{CORRELATIONS AMONG ITEMS \\ AND PROPOSED SCALES}

(Scale: *)

Info

Item Grouping/Item

Help Part Choi Shar

Helpfulness

1. Services helped deal with

$$
\text { family's problems }
$$

31. Services not helpful

30. Improved parenting skills

13. Services received appropriate

32. Services fit individual

$$
\text { situation }
$$

9. No improvement with family

Partnership

3. Agreed with CSD's plan

10. Disagreed w/caseworker on

$$
\text { problem }
$$

17. Caseworker doing his/her part

24. Opinions not considered in decisions

33. Actively participated in decisions

$\begin{array}{llll}91 & 80 & 70 & 69 \\ 91 & 78 & 70 & 70 \\ 87 & 73 & 64 & 63 \\ 90 & 81 & 69 & 70 \\ 88 & 82 & 75 & 72 \\ 38 & 36 & 25 & 32 \\ & & & \\ 80 & 85 & 71 & 67 \\ 67 & 82 & 65 & 65 \\ 79 & 89 & 70 & 76 \\ 72 & 86 & 78 & 72 \\ 76 & 85 & 74 & 71 \\ & & & \\ 79 & 78 & 86 & 67 \\ 66 & 74 & 88 & 62 \\ 61 & 68 & 83 & 62 \\ 66 & 72 & 82 & 62 \\ 52 & 57 & 80 & 45 \\ & & & \\ 73 & 76 & 68 & 83 \\ 69 & 76 & 63 & 85 \\ 61 & 66 & 57 & 82 \\ 58 & 65 & 57 & 78 \\ 46 & 45 & 39 & 71 \\ 39 & 46 & 41 & 41\end{array}$

\section{Choice}

36. Would return to CSD

26. CSD took over

22. Feeling of powerlessness

6. Choice to use or not use help

16. Participation in services forced

Information sharing

8. Kept well-informed

11. Caseworker explained case

34. Did not understand what's going on

25. Expectations of CSD not clear

29. Never sure of case status

$$
\text { - open or closed }
$$

39

46

41

* Note: All item-total correlations uncorrected for overlap. 
TABLE XV

CORRELATIONS AMONG ITEMS AND PROPOSED SCALES

Item Grouping/Item

Help Part Choi Shar

Helpfulness

1. Services helped deal with family's problems

31. Services not helpful

30. Improved parenting skills

13. Services received were appropriate

32. Services fit individual situation

9. No improvement with family

Partnership

3. Agreed with CSD's plan

10. Disagreed w/Caseworker on problem

17. Caseworker doing his/her part

24. Opinions not considered in decisions

33. Actively participated in decisions

$\begin{array}{llll}83 & 80 & 70 & 69 \\ 83 & 78 & 70 & 70 \\ 77 & 73 & 64 & 63 \\ 82 & 81 & 69 & 70 \\ 81 & 82 & 75 & 72 \\ 38 & 36 & 25 & 32\end{array}$

Choice

36. Would return to CSD

26. CSD took over

22. Feeling of powerlessness

6 . Cholce to use or not use help

16. Participation in services forced

80

76

71

67

67

72

65

65

79

81

70

76

$\begin{array}{llll}72 & 77 & 78 & 72\end{array}$

76

75

74

71

Information Sharing

8. Kept wel1-informed

11. Caseworker explained case

34. Did not understand what's going on

25. Expectations of CSD not clear

29. Never sure of case status

- open or closed

4. Not told ways to complain

79

$78 \quad 77$

67

66

74

79

62

61

68

73

62

66

72

71

62

52

57

68

45

Note: For each scale, item-total correlations are corrected for overlap. 
domains of satisfaction. Two applications of principle components analysis were used.

The first analysis simply applied the default for the number of factors to be extracted. This procedure extracted any factors which exceeded the minimum eigenvalue of 1. The first unrotated factor accounted for $58.3 \%$ of the common variance.

The correlations between the 22 items and the three rotated principle components extracted are presented in Table XVI. Items are listed in the table in order of their highest factor correlation with the factor that they are most highly correlated with, starting with Factor I. Correlations below 0.40 are not included.

The three factors provided evidence for the existence of three of the four proposed domains. The first factor included all five items which comprised the "Choice" scale. It also included an item from the "Partnership" scale, number 24, "MY opinions were not considered in making decisions." At this point, the distinction between these two domains appears fuzzy and this item could easily be placed in either domain.

The second factor generally combines the items from two of the scales, "Helpfulness" and "Partnership." It includes all six of the items from "Helpfulness" and four of the five items from "Partnership." (Item 24 is included in the first factor.) This second factor also includes item number 8 from 
TABIE XVI

CORRELATIONS AMONG 22 CLIENT SATISFACTION ITEMS AND THREE ROTATED PRINCIPLE COMPONENTS

Item

Rotated Components

Factor Factor Factor

16. (c) Participation in services

$\begin{array}{ll}\text { forced } & .82 \\ 26 \text {. (C) CSD took over } & .7\end{array}$

$82 \quad .69$

6. (C) Choice to use or not use help

.71

.67

.67
.61

36. (C) Would return to CSD

.64

.76

22. (C) Feeling of powerlessness

.61

$.48 \quad .74$

1. (H) Services helped deal with family's problems

$\begin{array}{lll}.44 & .75 \quad .81\end{array}$

13. (H) Services received were appropriate

30. (H) Improved parenting skills

31. (H) Services not helpful

32. (H) Services fit individual situation

$.45 \quad .71 \quad .79$

$.71 \quad .70$

$\begin{array}{lll}.44 & .70 & .76\end{array}$

9. (H) No improvement with family

$.49 \quad .66$

.79

3. (P) Agreed with CSD's plan

17. (P) Caseworker doing his/her part

8. (I) Kept well-informed

$\begin{array}{lll}.55 & .63 & .45 \\ .52 & .62 & .74\end{array}$

33. (P) Actively participated in decisions

10. (P) Disagreed with caseworker on problems

$.47 \quad .61 \quad .76$

$\begin{array}{llll}.41 & .54 & .46 & .67\end{array}$

$\begin{array}{lll}.51 & .53 & .69\end{array}$

$\begin{array}{lll}.48 & .48 & .58\end{array}$

29. (I) Never sure of case status - open or closed

34. (I) Did not understand what's going on

25. (I) Expectations of CSD not clear

11.(I) Caseworker explained case

4. (I) Not told ways to complain

$.48-.58$

Abbreviations in parentheses indicate the proposed domain for each item: $H=$ Helpfulness; $P$ = Partnership; $C$ = Choice; $I=$ Information sharing. 
the "Information Sharing" scale. This item is, "Overall, CSD kept me well informed."

The third factor is comprised of four of the five items in the "Information Sharing" scale. The exception is item 8 which has very similar correlations with all three factors; .41 with I, .54 with II, and .46 with III.

Many of the items had secondary correlations of at least .44 with one other factor. Eleven of the 22 items had these correlations with one other factor and one item, 8, had correlations of at least .40 with all three factors.

The second analysis specified the number of factors to be extracted. This procedure extracted four factors, . regardless of the value of the eigenvalue. Four factors were selected based upon the proposed existence of four domains of satisfaction.

The correlations between the 22 items and the four rotated principle components extracted are presented in Table XVII. Items are again listed in the table in order. of their highest factor correlation with the factor that they are most highly correlated with, starting with Factor I. Correlations below 0.40 are not included.

The four factor solution again provided evidence for the existence of three of the four proposed domains. The first factor generally combines the items from two of the scales, "Helpfulness" and "Partnership." It includes five of the six items from "Helpfulness" and four of the five 
TABLE XVII

CORRELATIONS AMONG 22 CLIENT SATISFACTION ITEMS AND FOUR ROTATED PRINCIPLE COMPONENTS

Rotated Components

Item

\begin{tabular}{|c|c|c|c|c|}
\hline $\begin{array}{r}\text { Factor } \\
I\end{array}$ & $\begin{array}{r}\text { Factor } \\
\text { II }\end{array}$ & $\begin{array}{r}\text { Factor } \\
\text { III }\end{array}$ & $\begin{array}{r}\text { Factor } \\
\text { IV }\end{array}$ & $h^{2}$ \\
\hline
\end{tabular}

1. (H) Services helped deal

w/family's problems.81 88

30. (H) Improved parenting

skills 130

$80 \quad .73$

were appropriate $\quad .79 \quad .80$

31. (H) Services not helpful $.78 \quad .77$

3. (P) Agreed W/CSD's plan $.74 \quad .75$

32. (H) Services fit indi-

17. (P) vidual situation .72

his/her part $\quad .68 \quad .77$

36. (C) Would return to CSD $.65 \quad 054 \quad .76$

8.(I) Kept well-informed $.63 \quad .45 \quad .69$

33. (P) Actively participa$\begin{array}{lll}\text { ted in decisions } & .61 & .69\end{array}$

10. (P) Disagreed with caseworker on problems $.48 \quad .46 \quad .61$

16. (C) Participation in

services forced

26. (C) CSD took over

$.78 \quad .70$

$.73 \quad .76$

6.(C) Choice to use or not use help

22. (c) Feeling of

powerlessness
24. (P) Opinions not consid-

$\begin{array}{ll}.65 & .67\end{array}$ ered in decisions

29. (I) Never sure of case status - open or closed

$.59 \quad .75$

34. (I) Did not understand what's going on

25. (I) Expectations of CSD

11. (I) Caseworker

.81

.71

explained case

9. (H) No improvement with

family

$\begin{array}{ll}.81 & .71 \\ .67 & .71 \\ .63 & .63 \\ .56 & .71\end{array}$

.56

.71

4. (I) Not told ways to complain

Analysis specified four factors. 
items from "Partnership." (Item 9 is included in the fourth factor and item 24 is included in the second factor.) This first factor includes item number 8 from the "Information Sharing" scale. This item is, "Overa11, CSD kept me well informed." It also includes item number 36 from the "Choice" scale. This item is, "If my family needed help in the future, I would return to CSD."

The second factor included four of the five items which comprised the "Choice" scale. (Item number 36 was included in the first factor.) It also included an item from the "Partnership" scale, number 24, "My opinions were not considered in making decisions."

The third factor is comprised of four of the five items in the "Information Sharing" scale. The exception is item 8. Fewer of the items had secondary correlations with other factors. Only six of the 22 items had these correlations with one other factor.

Internal Consistency Reliability of the Scale Scores

The next analysis is to examine the structure of the four proposed scales of satisfaction through the application of internal consistency reliability analysis. The reliability of each of the four scales was estimated with Cronbach's (1951) Alpha coefficients.

The results of the initial reliability estimates for each of the four scales are displayed in Tables XVIII-XXI. 
TABLE XVIII

\section{RELIABILITY ANALYSIS FOR THE HELPFULNESS SCALE}

$(N=433)$

$\begin{array}{cccc}\text { Item } & \begin{array}{r}\text { Corrected } \\ \text { Item-Total } \\ \text { Correlation }\end{array} & \begin{array}{r}\text { Squared } \\ \text { Multiple } \\ \text { Correlation }\end{array} & \begin{array}{r}\text { Alpha } \\ \text { if Item } \\ \text { Deleted }\end{array} \\ \text { 1. Services helped deal with } & & & \\ \begin{array}{c}\text { family's problems } \\ \text { 9. No improvement with family }\end{array} & .83 & .72 & .87 \\ \text { 13. Services received were } & .38 & .15 & .94 \\ \begin{array}{c}\text { appropriate } \\ \text { 30. Improved parenting skills }\end{array} & .72 & .71 & .87 \\ \text { 31. Services not helpful } & .83 & .65 & .88 \\ \text { 32. Services fit individual } & .72 & .87 \\ \text { situation } & .81 & .69 & .88 \\ \text { Alpha }=.90 & & & \end{array}$

TABLE XIX

RELIABILITY ANALYSIS FOR THE

PARTNERSHIP SCALE

$(N=444)$ Item

Corrected Squared Item-Total Multiple

Alpha Correlation Correlation Deleted

3. Agreed with CSD's plans

.76

.59

.88

10. Disagreed with caseworker on problems

.72

.55

.89

17. Caseworker doing his/her part

.81

.66

.87

24. Opinions not considered in decisions

.77

.60

.88

33. Actively participated in decisions

Alpha $=.91$ 
TABLE XX

RELIABILITY ANALYSIS FOR THE

CHOICE SCALE

$(\mathrm{N}=431)$

Item

\begin{tabular}{rrr} 
Corrected & Squared & Alpha \\
Item-Total & Multiple & if Item \\
Correlation Correlation & Deleted \\
\hline
\end{tabular}

6. Choice to use or not use help

16. Participation in services

$$
\text { forced }
$$

.71

.51

.87

22. Feeling of powerlessness

$$
.68
$$

.73

.79

.77

.48

.88

.87

.85

36. Would return to CSD

.56

.64

.86

$$
\text { Alpha }=.89
$$

TABLE XXI

$$
\begin{aligned}
& \text { RELIABILITY ANALYSIS FOR THE } \\
& \text { INFORMATION SHARING SCALE } \\
& (\mathrm{N}=432)
\end{aligned}
$$

Item

Corrected Item-Total Correlation Correlation

Alpha if Item Deleted
4. Not told ways to complain
.41
.18
.86
8. Kept well-informed .71
11. Caseworker explained case .73
.60
.80
25. Expectations of CSD not clear
.66
.62
.80
29. Never sure of case status
- open or closed
.55
.45
.81
34. Did not understand what's going on
.80

$$
\text { Alpha }=.84
$$

The results of the final reliability estimates for the two scales which required that items be removed to increase the scale reliability are displayed in Tables XXII and XXIII. Item number 9 was removed from the "Helpfulness" scale. Item 
number 4 was removed from the "Information Sharing" scale.

TABLE XXII

RELIABIIITY ANALYSIS FOR THE

HELPFULNESS SCALE

AFTER CORRECTION

$$
(\mathrm{N}=444)
$$

Item

$\begin{array}{rrr}\text { Corrected } & \text { Squared } & \text { Alpha } \\ \text { Item-Total } & \text { Multiple } & \text { if Item } \\ \text { Correlation Correlation } & \text { Deleted }\end{array}$

1. Services helped deal with

$$
\begin{array}{lllll}
\text { family's problems } & .85 & .72 & .92
\end{array}
$$

13. Services received were appropriate

$.84 \quad .71 \quad .92$

30. Improved parenting skills $.78 \quad .65 \quad .93$

31. Services not helpful

$.85 \quad .72 \quad .92$

32. Services fit individual situation

$$
\text { Alpha }=.94
$$

TABLE XXIII

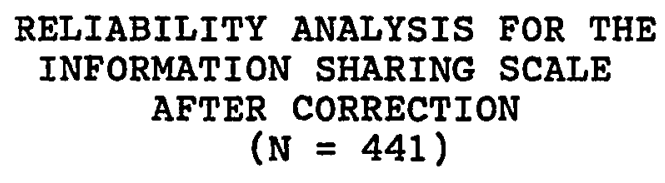

Item

Corrected Item-Total Correlation

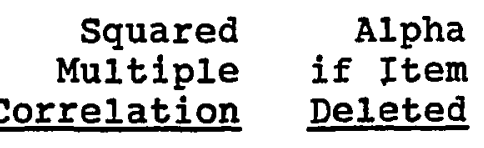

8. Kept we11-informed

.72

.60

.82

.75

.63

.81

25. Expectations of CSD not clear

.65

.45

.84

29. Never sure of case status - open or closed

.56

.32

.86

.70

.50

.82

$$
\text { Alpha }=.86
$$

The Cronbach Alpha reliability coefficients after removing items from the scales of "Helpfulness" (item number 
9), "Information Sharing" (item number 4), and "General Satisfaction" (items number 2 and 20) are displayed in Table XXIV. Among the four scales, after the items were removed, the reliability coefficients ranged from 0.86 for "Information Sharing" to 0.94 for "Helpfulness." The removal of items 4 and 9 is consistent with the performance of these items in the four-factor principle components analysis. These two items comprised the fourth factor with low correlations with any of the first three.

TABLE XXIV

RELIABILITY ESTIMATES FOR CLIENT SATISFACTION SCALES

Domain

Helpfulness (1)

Partnership

Choice

Information Sharing (2)

General Satisfaction (3)
Alpha

.94

.91

.89

.86

.88
No. of Items

5

5

5

5

3

(1) After removing item number 9 .

(2) After removing item number 4 .

(3) After removing items number 2 and 20.

The value of alpha, or the internal consistency reliability, is related both to the average interitem correlation and the number of items in the scale, or the scale length. The reliabilities which were associated with the scales are quite high, particularly given the small numbers of items within each scale (five and six).

\section{Relationships Among the Four Scales}

The next area to address is the relationship among the 
four scales of satisfaction. The correlations between the four scales of satisfaction are displayed in Table XXV.

TABLE XXV

CORRELATIONS AMONG THE FOUR SCALES OF CIIENT SATISFACTION

$\begin{array}{lcccc}\text { Scale } & \text { Helpfulness } & \text { Partnership } & \text { Choice } & \begin{array}{c}\text { Information } \\ \text { Sharing }\end{array} \\ \text { Helpfulness } & .88 & & .78 & .78 \\ \text { Partnership } & & .84 & .83 \\ \text { Choice } & & & .72\end{array}$

The estimated domain correlations which have been corrected for unreliability among the four scales of satisfaction are displayed in Table XXVI. The correlations among the scales have been corrected for unreliability due to random measurement error. Using the alpha for each of the scales as an estimate of the reliability of the scale, the estimate can be used to determine what the correlations would be if they were perfectly reliable. The higher the reliability for the domains, the less that the corrected correlation differs from the observed correlation (Carmines and Zeller, 1981).

The squares of the corrected domain correlations between the four scales of satisfaction are displayed in Table XXVII. Thus, this table displays the amount of shared variance that is explained.

Across all three approaches to examining the relationships between the four scales, the strongest relationship is between "Helpfulness" and "Partnership." This comes as no 
TABLE XXVI

DOMAIN CORRELATIONS AMONG THE FOUR SCALES OF CLIENT SATISFACTION*

Scale Helpfulness

Partnership

Choice Information

Helpfulness

Partnership .96 .85 .93 Sharing Choice

* These correlations have been corrected for attenuation.

TABLE XXVII

SHARED VARIANCE EXPLAINED AMONG THE FOUR SCALES OF CLIENT SATISFACTION

\section{$\underline{\text { Scale }}$}

Helpfulness

Partnership

Choice

Information

Helpfulness

Partnership .92

.72 .86

Sharing

Choice

surprise since the principle components analysis combined these two scales into one factor. Also consistently, the weakest relationship is between "Choice" and "Information Sharing."

SCALES OF SATISFACTION AND GENERAL SATISFACTION

The data presented in this section address the final two research questions concerning the relationship between the four domains of satisfaction and general satisfaction. The content analysis of the interviews and further research proposed that client satisfaction among CPS clients was comprised of four domains. These domains are: 
(a) Helpfulness, (b) Partnership, (c) Choice, and

(d) Information sharing.

This section presents results which attempt to answer the basic questions, "What is the relationship between the four domains of satisfaction and overall satisfaction?" and "Which domain is most highly related to general satisfaction?"

This analysis examines the relationships between the four scales of satisfaction and three measures of general satisfaction. The first measure of general satisfaction is the general satisfaction scale. The general satisfaction scale was proposed to consist of five items: numbers 2, 15 , 18,20 , and 23 . Items number 2 and 20 were removed from this scale. The results of the inftial and adjusted reliability estimates are displayed in Tables XXVIII and XXIX. This scale consists of three items: numbers 15,18 , and 23 . The reliability coefficient for the "General Satisfaction" scale increased from 0.77 to 0.88 after items number 2 and 20 were removed.

The second measure of general satisfaction is the single 1tem, number 15. This item is, "In general, considering all of my contacts with CSD, and all of the services my family received, I am satisfied with CSD."

The third measure of general satisfaction is the five-point rating of comments which some respondents included on the survey form. Of the total of 478 respondents, 269 , or 
TABLE XXVIII

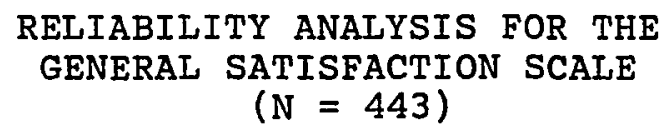

Item

$\begin{array}{rrr}\text { Corrected } & \text { Squared } & \text { Alpha } \\ \text { Item-Total } & \text { Multiple } & \text { if Item } \\ \text { Correlation Correlation } & \text { Deleted }\end{array}$

2. Not satisfied with

$$
\text { family life }
$$

15. Satisfied with CSD

18. Displeased with what

happened
20. Services offered to everyone needing help

23. CSD helped through crisis

$\begin{array}{lll}.08 & .01 & .86 \\ .76 & .68 & \\ .66 & .53 & \\ .66 & .69 \\ .54 & .34 & .73 \\ .74 & .67 & .65\end{array}$

$$
\text { Alpha }=.77
$$

TABLE XXIX

$$
\begin{aligned}
& \text { RELIABILITY ANALYSIS FOR THE } \\
& \text { GENERAL SATISFACTION SCALE } \\
& \text { AFTER CORRECTION } \\
& (N=464)
\end{aligned}
$$

Corrected

Squared

Item-Total

Multiple

Alpha

Item

Correlation Correlation

15. Satisfied with CSD

.81

.68

Deleted

18. Displeased with what happened

23. CSD helped through crisis .78

$$
\text { Alpha }=.88
$$

$56.3 \%$, included comments in the section for comments or returned letters with the survey. These comments were content analyzed and were then rated on a five-point scale. The five points were: (a) very dissatisfied,
(b) dissatisfied,
(c) mixed satisfaction,
(d) satisfied, and

(e) very satisfied. 
Not unexpectedly, most of the comments which were added were rated as negative comments. The comments were rated in the following groups: (a) very dissatisfied - 116, or 43.1\%; (b) dissatisfied - 54, or $20.1 \%$; (c) mixed satisfaction - 39, or $14.5 \%$; (d) satisfied - 20 , or $7.4 \%$; and (e) very satisfied - 40 , or $14.9 \%$.

The correlations among the three measures of general satisfaction are displayed in Table Xxx. The correlation between the single item number 15 and the general satisfaction scale is .81 when corrected for overlap. The correlation between the "Comments" variable and the other two measures are .78 with the scale and .76 with the single item.

TABLE XXX

CORRELATION AMONG THE THREE MEASURES

OF GENERAI SATISFACTION

\begin{tabular}{|c|c|c|c|c|}
\hline $\begin{array}{l}\text { Measure } \\
\text { Generai }\end{array}$ & $\begin{array}{l}\text { of } \\
\text { Satisfaction }\end{array}$ & $\begin{array}{r}\text { General } \\
\text { Satisfaction } \\
\text { Domain }\end{array}$ & $\begin{array}{r}\text { Item } \\
\underline{15} \\
\end{array}$ & Comments \\
\hline $\begin{array}{l}\text { Genera1 } \\
\text { Item } 15\end{array}$ & Satisfaction & Scale & $.92 *$ & $\begin{array}{l}.78 \\
.76\end{array}$ \\
\hline
\end{tabular}

The correlations between the four scales of satisfaction and the three measures of general satisfaction are displayed in Table XXXI. The scales of "Helpfulness" and "Partnership" have very similar correlations with the three measures of general satisfaction. "Choice" and "Information Sharing" both have lower correlations with the three general 
satisfaction measures.

TABLE XXXI

CORRELATIONS AMONG THE FOUR SCALES OF SATISFACTION AND THREE MEASURES OF GENERAL SATISFACTION

\section{Measures of General Satisfaction}

\begin{tabular}{|c|c|c|c|}
\hline Scale & $\begin{array}{r}\text { General } \\
\text { Satisfaction } \\
\text { Scale }\end{array}$ & $\begin{array}{r}\text { Item } \\
15 \\
\end{array}$ & Comments \\
\hline $\begin{array}{l}\text { Helpfulness } \\
\text { Partnership } \\
\text { Choice } \\
\text { Information Sharing }\end{array}$ & $\begin{array}{l}.89 \\
.90 \\
.83 \\
.78\end{array}$ & $\begin{array}{l}.85 \\
.85 \\
.77 \\
.74\end{array}$ & $\begin{array}{l}.74 \\
.76 \\
.72 \\
.67\end{array}$ \\
\hline
\end{tabular}

The corrected correlations between the four scales of satisfaction and the three measures of general satisfaction are displayed in Table XXXI. Both of the scales of "Helpfulness" and "Partnership" again have very similar correlations with the three measures of general satisfaction. The scale of "Partnership" has a slightly stronger relationship with all three measures when examining the corrected correlations.

"Choice" and "Information Sharing" again have lower correlations with the three general satisfaction measures. The correlations between these two scales and the three measures of general satisfaction are more similar with the corrected correlations. 
TABLE XXXII

CORRELATIONS AMONG THE FOUR SCALES OF SATISFACTION AND THREE MEASURES OF GENERAL SATISFACTION

\section{Measures of General Satisfaction}

$\begin{array}{rrr}\begin{array}{r}\text { General } \\ \text { Satisfaction }\end{array} & \text { Item } \\ \text { Scale } & \underline{15} \quad \text { Comments }\end{array}$

Helpfulness

Partnership
.98
1.00
.94

.91

.94

.86

.79

.86

.84

.81

Information Sharing

These correlations have been corrected for attenuation. a This calculated corrected correlation was greater than 1.00 ( 1.01$)$ and it has been set to the maximum possible value of 1.00 . 
CHAPTER V

SUMMARY AND CONCLUSIONS

SUMMARY

The purpose of this study was to develop and test an instrument to measure client satisfaction among families who are clients of a child protective services agency. A second purpose was to identify the various domains of satisfaction that apply to CPS clients. A third was to analyze the relationship between these domains and measures of the clients' overall level of satisfaction. Finally, it was proposed that the most important domain of client satisfaction for CPS families was the domain of "Partnership."

Two rounds of interviews were held with families who had been clients of the CPS agency serving the state of oregon. These interviews served as the major source of information for domain identification and item development. The responses to the interviews were content analyzed and four specific domains of client satisfaction were identified. These were: (a) Helpfulness, (b) Partnership, (c) Choice, and (d) Information Sharing. Items were developed for each of these domains. Items were also developed to comprise a 
"General Satisfaction" domain.

An instrument was constructed and pre-tested in two

Branch offices of the agency. This instrument included five

items to address the issue of "convenience." It also

included seven items to gather information concerning the

opinions of clients on the agency mission and goals. Results

of the pre-test were analyzed and the instrument revised.

The final instrument was mailed to a population of $4,337 \mathrm{CPS}$

families.

RESEARCH IMPLICATIONS OF THE STUDY

CPS clients, as the consumers of child protective services, offer a unique and valuable vantage point from which to assess these child welfare services and programs. Yet clients of child protective services have been largely neglected as a possible source of information.

The rarity of this approach in child protection seems due both to a tendency to see the parents involved as less capable, articulate, and objective than other human service recipients and to the considerable difficulties of gaining the confidence of these parents for research interviews. Yet there are important advantages to actively soliciting parents' views and placing more trust in their responses. (Magura \& Moses, 1984, p. 100)

Shireman, Grossnickle, Hinsey, and White (1990) conducted a study which compared information provided by CPS families during interviews with information from CPS agency 
case records. The authors were seeking information to determine the best source of data for measurements of outcome in evaluations of child welfare services. They concluded, "The willingness with which the parents talked with the interviewer, and the high congruence of their reports and those recorded by the caseworker, indicate that these mandated clients are indeed a valuable source of data." (p. 178)

\section{The Research Questions}

The first research question posed was, "Can a client satisfaction instrument be developed for CPS clients largely through the input of the clients?"

The preliminary answer to this question is positive. Interviews with 27 families served as the primary source of data for the identification of the domains of satisfaction and the development of the specific items within each domain. Correlations among the items which originated from the interviews were above 0.40 . Two of the four items with the owest correlations with all other items and which were removed from the scales based upon the internal consistency reliability analyses were items which were added by the agency •

The second research question was, "What are the domains of satisfaction that are applicable to CPS families? The analyses of the interview responses identified four 
four domains of client satisfaction. These were:

(a) "Helpfulness," (b) "Partnership," (c) "Choice," and (d)

"Information Sharing." Thus, four domains were identified

from the open-ended interviews and the analysis of the

closed-ended instrument provided support for their existence.

The correlational and factor analyses provided evidence

for the existence of the domains proposed: "Choice,"

"Information Sharing," "Helpfulness," and "Partnership;" the

latter two possibly combined. The internal consistency

reliability analysis of the four scales identified alphas .

which ranged from .86 for "Information Sharing" to .94 for

"Helpfulness."

\section{Areas for Future Research}

This study began with a caution against the development of new instruments to measure client satisfaction. The review of the client satisfaction literature concluded that an exception to this caution should be made in the arena of families who were clients of CPS agencies.

There are a number of areas in which future research is warranted. First, the instrument that has been developed needs further testing. The final instrument consisted of 23 items and five scales, including "General satisfaction." Will the basic structure and relationship between the scales be replicated in future testing? Do the scales of "Helpfulness" and "Partnership" comprise two aspects of one 
broader domain, or are they distinct aspects of client satisfaction?

A second area of testing relates to the generalizability of the instrument. With a return rate of $11 \%$, questions need to be asked concerning the applicability of the results to the entire population of CPS families served by CSD. Additionally, are the issues most germane to a mixed population of CPS clients equally important among sub-populations? Are there a series of specific issues which relate more directly to families who have experienced sexual abuse? Are these different for neglectful families? Another area of testing would address the question of the applicability of the instrument to CPS populations in other states. Are there unique aspects of the CPS philosophy, approach, procedures, and services as they are provided in Oregon? A final area would address the question, are the domains and items generalizable to the families who will be served by CPS agencies five years from now?

A third question concerns to what respect the instrument. can be applied to clients of other types of agencies. Are these domains applicable to the entire population of families which CSD currently serves as a broad child welfare agency? To address this issue, a second application of a revised instrument will be implemented with a general population of CSD clients. Are these domains applicable to other populations of involuntary clients? In what respects 
are CPS clients different from clients of other social service agencies?

Tanner (1982) developed a multi-dimensional measure of client satisfaction with mental health services. His analysis identified dimensions of client satisfaction which are very similar to those proposed and tested in this study. The dimensions which Tanner identified were:

(a) Satisfaction, (b) Helpfulness, (c) Accessibility,

(d) Respect, and (e) Partnership. The major difference between the domains in the current study and those identified by Tanner and elsewhere is the domain of "accessibility" or "convenience." Is this domain an important aspect of client satisfaction for CPS clients? There is little evidence in the current study to support it.

Many times, the interpretation of the results from client satisfaction surveys needs to be tempered by the compounding effects of positive response bias. In such cases, the most important information may be in the minority of items and among the specific issues which reflect lesser degrees of satisfaction.

It was anticipated that the responses from a survey of CPS clients would potentially be subject to a negative response bias. This was the case. Overall, respondents rated services the most favorably, followed by descriptors of caseworkers, and statements concerning the agency were the least favorable. Means for 33 of the 39 satisfaction 
statements were on the negative side of the response scale midpoint. On the other hand, means for 13 of the 23 caseworker descriptors were on the positive side of the response scale midpoint. Means for 11 of the 13 services were also on the positive side of the response scale midpoint.

In Tanner's study, the total factor for the scale had a mean of 22 out of a maximum score of 25 (1982). Given the similarity of the aspects of client satisfaction that these two instruments were attempting to measure, the differences in the overall levels of satisfaction is evidence that the difference may be attributable to the difference in client group.

Information from clients can serve three important purposes. First, it can be an important, but certainly not the only, measure of agency effectiveness. Secondly, it can serve as an explanatory variable to help an agency understand the level of utilization of services - why and when services are used. Finally, information on client satisfaction can be used to help an agency predict future client behavior. In gathering this information from CPS clients, important issues such as compliance with service agreements, decisions to place children in foster care, and when to return children to their families can be better understood.

To this point, the instrument developed in this study has only been tested to examine its structure. Initially, 
the data should be analyzed further to describe the clients. The characteristics of those clients who are satisfied should be compared to those of clients who are not satisfied across the four domains. Populations of particular interest should be examined. Specifically, the population of families who have experienced the out-of-home placement of one of their children should be compared to the population who have not had that experience.

A next major step would be to examine the value of the instrument as a measure of satisfaction and as a predictor of future behavior. Specifically, data could be gathered from the CSD automated information system on the families who responded to the survey. At this writing, eighteen months have passed since the survey. Data could be obtained in the following areas: (a) the current status of the case for the family, (b) any subsequent CPS referrals and victims, (c) any subsequent placements or reunifications of children with their families.

The instrument could be used to test a series of hypotheses related to client behavior. One could hypothesize that satisfied clients are more likely to comply with service plans than clients who are not satisfied.

If there is evidence to support its predictive value, the next step might then be to conduct an intervention study to determine whether a particular intervention, for example, enhancing client empowerment by involving clients more in 
decision-making, would result in higher levels of satisfaction which would then result in increased levels of compliance.

\section{POLICY AND PRACTICE IMPLICATIONS OF THE STUDY}

Few 2 thempts have been made to gather information from CPS clients; to gain an understanding of the impact of the protective service experience upon them. Yet the child welfare agencies that conduct child abuse investigations and provide protective social services strive to keep these families united, either by providing family-based services prior to the removal of a child or by providing family reunification services in those cases when a child is removed. (The issue of the relationship between CPS referrals and placement into foster care is one with widespread misunderstanding. Only 10 percent of CPS referrals result in the removal and placement of a child. When focusing on referrals which have been determined to be valid, this percent increases to between $20 \%$ and $25 \%$. Thus, in over three-quarters of the situations in which a victim of abuse has been identified, the victim remains in the care of the family.)

Over the past ten years, many changes have impacted the ability of CPS agencies to perform their functions. The percent of the families served by child welfare agencies who 
have issues of child abuse and neglect has risen. The numbers and seriousness of the child abuse and neglect situations confronting these agencies has increased. Both of these conditions have led to increasing numbers of children being placed into protective custody. The related numbers of children residing in foster care have shown the same increases. The availability of resources to serve these families has declined. Average caseloads have increased as funding has not kept pace with the increasing numbers of children and families requiring service. State legislatures are requiring more accountability for the expenditure of funds that they authorize.

Child protective service agencies and staff grapple daily with a range of critical issues. They are asked to make difficult, vital decisions concerning the level of risk and degree of safety of some of society's most vulnerable citizens. CPS staff are asked to perform two highly professional, and potentially conflicting, tasks. The first is to investigate possible situations of child abuse, to assess complex intrafamily situations, and to determine the level of risk and safety to a child. Secondly, they are asked to develop a service plan to address the factors and issues related to the risk and safety questions. They are then asked to implement the service plan to improve the condition or conditions related to the abuse. This may require the sanctions of the court in order to monitor 
and evaluate the level of compliance with the service plan by the family.

Why should anyone care to measure the satisfaction among CPS clients? What is the importance of knowing the areas and issues which are important to this group of clients?

As mentioned previously, information from clients can serve three important purposes. These are: (a) as a measure of agency effectiveness, (b) as an explanatory variable to help an agency understand the level of utilization of services - why and when services are used, and (c) to help an agency predict future client behavior.

One of the reactions to the increasing number of children being placed into foster care has been the implementation of family-based treatment approaches to working with abusive families. Family-based treatment programs, such as Homebuilders and intensive family services, attempt to intercede in "imminent risk" situations at the outset to try to prevent placement. In cases in which a placement has already occurred, these programs try to become involved early in order to enhance the chances of reunification.

In a study of its current foster care situation, oregon CSD (CSD Research, 1989) estimated that 50\% of the children currently in care would not be returning home. One of the major contributing factors to these estimates was the 10w rate of compliance with service plan agreements by the 
families with children in foster care. The need to engage these families in the CPS casework decisions may be the key to reversing these trends.

One of the key ingredients to a successful outcome in any casework situation, including protective services, lies in the ability of the caseworker to engage the client in the treatment process of problem identification, case plan development, and participation in services to successfully complete the plan. The possibility of successful engagement and service provision to these families can be enhanced by knowing what families in similar situations valued, what caseworker attributes they found positive, and what services they found helpful.

Shireman et al. (1990) concluded that,

There is little in the literature concerning client satisfaction for mandated clients. Yet, if we are to reach out and engage these troubled individuals and families, we must take into account the perspective from which they see our service. (p. 178)

Twenty-seven of the 31 families who agreed with the caseworker on the definition of the family's problem were satisfied with caseworker services, as were only ten of the 22 who disagreed, reinforcing the practice proposition that effective work is not possible until worker and client agree on the problem that is the subject of their work together. (p. 175)

Magura and Moses (1984) concluded that,

Areas of successful collaboration with clients should be identified and enhanced. Where problems in collaboration exist, the client's perspective must be 
understood so that appropriate modification in policies and practices can be made. (p. 100)

How did the families who responded to the survey view their contact with CSD? As mentioned above, overall the most favorably rated group of items was the services that the families received. The only two services which were rated below the response scale midpoint were "psychological evaluation" and "out-of-home placement." The service which was rated the most favorably was "parent training." Not . including those who responded "Not Sure," $81 \%$ of the respondents indicated that this service was either "helpful" or "very helpful."

Overa11, caseworker descriptions were rated somewhat less favorably than services. The wording of these items clearly had some effect on the responses. The ten items rated most favorably were worded positively. The six items rated least favorably were worded negatively.

The two positive descriptors that were rated most favorably were "concerned" and "good listener." Not including those who responded "Not Sure," $54 \%$ of the respondents indicated that these terms described their worker. The two positive items that were rated the least favorably were "sympathetic," with 40\%, and "open-minded," with $42 \%$, of the respondents indicating that these terms described their worker.

The two negative descriptors that were rated most 
favorably were "not helpful" and "unfair." Not including those who responded "Not Sure," 51\% and 53\% of the respondents respectively indicated that these terms described their worker. The negative items that were rated the least favorably were "controlling," with 78\%, "judgmental" and "critical," with $69 \%$ each, of the respondents indicating that these terms described their worker.

The Role of Empowerment

Rappaport (1981) discussed the paradoxical conflict between two models for viewing people in trouble and the need to move to a new model. One of the current models, the "needs" model, relies on notions of protection and dependency. It suggests the role of the caseworker as one of a professional expert who holds the solution to the problem. The second model, the "rights" model, emphasizes the legal rights of the individual and presents a position of advocacy for those rights.

Rappaport suggests an empowerment model which would blend the positive aspects of the other two models which are seemingly in conflict. It proposes a collaborative relationship between the caseworker and the client.

The general theme which runs through the entire client satisfaction instrument is that of empowerment. Three of the four domains of satisfaction which were identified in this study were: (a) "Partnership," (b) "Choice," and 
(c) "Information Sharing." But how does a CPS agency incorporate these issues into its mandate?

Kopp (1989) commented that most of the discussions of the empowerment model are focused in the area of advocacy. She discusses the need for practical ideas on how to implement specific techniques for enhancing empowerment. She places particular emphasis upon engaging in such work during the assessment phase of a case. The possibilities are there to build a collaborative, complementary relationship between the caseworker and the client.

Kopp feels that one very useful technique is that of self-observation, self-recording, or self-monitoring. This allows clients to become active participants in their cases from the outset. They would be used to gather information about themselves that would be used in the initial phases of problem-definition and planning formulation.

The researcher is not immune from these issues. Guba and Lincoln (1991) discuss an approach to evaluation, the constructivist paradigm, which proposes the empowerment and enfranchisement of all of the stakeholders in an evaluation. One of the most satisfying aspects of the present study was the feeling that the interviews were meaningful to the families. It gave them an opportunity to express their feelings openly and freely concerning their contact with CSD. Rooney (1988) discusses socialization strategies for caseworkers to use in working with involuntary clients. He 
discusses reactance theory and strategies to avoid the possible negative outcomes of working with these clients. He states that more successful interventions are usually related to establishing congruence during the initial stages of treatment between the caseworkers and the clients on the goals and the methods to be pursued. Rooney feels that even more important than the voluntary-involuntary nature of the client is the interaction which takes place between the worker and the client in the initial stages of the treatment. The Child Welfare League of America recently (1989) stated,

The social worker's ability to engage the family during the initial intake contacts is an important determinant of the success of the service. The process of empowerment should begin with the first contact with the family, whether by phone or in person, by asking the family when and where a visit would be most convenient and by encouraging them to define their own problems, needs, strengths, and service priorities. (p.32)

Currently, CSD is taking some very positive, concrete steps in this direction. The agency's Family-Based Services Unit is implementing a Family Unity Model in a number of Branch offices. This model attempts to institute two major practices.

The first is to empower the family by asking them to suggest ways in which the current situation of concern can be addressed. In some Branches, this specifically involves asking the family to develop its own plan to present to court. 
The second is to invite the family to a meeting very early in the life of the case and to ask the family to bring with them anyone they feel can help articulate and support a plan for the family. These are very positive signs and demonstrate an agency open to new approaches to difficult practice issues.

Hegar and Hunzeker (1988) discuss how the entire history of the child welfare movement is within the paternalistic tradition. Focusing on the area of CPS, they describe how the entire process is one of disempowerment. They describe three practice principles to empower clients:

1. Families with similar problems may require different solutions.

2. The need to recognize strengths in families.

3. The need to view the worker-client relationship as a collaboration among peers to try to solve a problem.

Gold (1990) discusses the notion of motivation as a key, unexplored component of social work practice. She discusses the importance of the concept of "locus of control" and the important differences of viewing events as being of either internal or external origin. She discussed helplessness as being caused by believing that one's actions do not have any influence on the ultimate outcomes.

She also discussed the distinction between two kinds of communication events as proposed by Deci and Ryan (1980). 
The first, "controlling," pressures another toward specific outcomes. The second, "informational," provides meaningful feedback to another in the context of an actual choice. This second signifies to the other person a feeling of competence.

The Child Welfare League of America recently (1989) stated,

These standards articulate CWLA's belief that strengthening families is a major factor in properly serving children. These standards view families as participants and partners in service and envision good practice as the means to build families' own capabilities rather than merely "doing for" them. (Forward, p. viii)

The following quotes from two respondents to the client satisfaction survey illustrate two poles of perceptions from their experiences with CSD:

The CSD office does not at all give me the impression they were here to help us as a (different) family, they go by their rules on cases somewhat like ours. It was very bothersome to deal with people that when they talk you listen, when I talk they plain out say I can't help you you have to do it my way or there's consequences. You ask a question and get 3 different answers from 3 different people. You never know what to do.

My worker has been supportive of me all along the way. My life has changed drastically in the last year for the better. On August $8 \mathrm{I}$ will have one year clean. And I can't say I would be there if it hadn't been for CSD. If they had taken my children I don't know if I'd have cooperated because I'd have been angry. But because they let me keep them and worked out a program for me to follow. I am grateful and we are happy. 
REFERENCES

Allen, M. J. and W. M. Yen 1979. Introduction to Measurement Theory. Monterey, CA: Brooks/Cole Company.

American Association for Protecting Children, The 1989. Highlights of Official Aggregate Child Neglect and Abuse Reporting 1987. (Grant No. 90-CA-1262.) The American Humane Association.

American Humane Association, The 1979. Child Protective Services Entering the 1980's. Englewood, Colorado: The American Humane Association.

Andrews, F. M. and S. B. Withey 1976. Social Indicators of Well-Being. New York: Plenum Press.

Attkisson, C. C. and R. Zwick 1982. The client satisfaction questionnaire: psychometric properties and correlations with service utilization and psychotherapy outcome. Evaluation and Program Planning, 5: 233-7.

Blythe, B. J. 1983. A critique of outcome evaluation in child abuse treatment. Child Welfare, LXII, 4: 325-36.

Bush, M. and A. C. Gordon 1982. The case for involving children in child welfare decisions. Social Work, 27(4): 309-14.

Bush, M., A. C. Gordon and R. LeBailly 1977. Evaluating child welfare services: a contribution from clients. Social Service Review, 51: 491-501.

Campbell, A., P. E. Converse and W. L. Rodgers 1976. The Quality of American Life. New York: Russell Sage Foundation.

Carmine, E. G. and R. A. Zeller 1981. Reliability and Validity Assessment. Beverly Hills, CA: Sage.

Chapko, M. K., M. Bergner, K. Green, B. Beach, P. Milgram, and N. Skalabrin 1985. Development and validation of a measure of dental patient satisfaction. Medical Care, 23(1): 39-49. 
Child Welfare League of America 1989. Standards for Services to Strengthen and Preserve Families with Children. Washington, DC: The Child Welfare League of America.

Cronbach, L. J. 1951. Coefficient alpha and the internal structure of tests. Psychometrika, 16: 294-334.

Davies, A. R. and J. E. Ware, Jr. undated. Development of a dental satisfaction questionnaire for the health insurance experiment. Rand Health Insurance Experiment Series.

Dillman, D. A. 1978. Mail and Telephone Surveys: Total Design Method. New York: John Wiley and Sons.

Drews, K. 1980. The role conflict of the child protective service worker: investigator-helper. Child Abuse and Neglect, 4: 247-54.

El1sworth, Robert B. 1975. Consumer feedback in measuring the effectiveness of mental health programs. Handbook of Evaluation Research Vol. 2, ed. M. Guttentag and E. L. Struening, 239-74. Beverly Hills, CA: Sage Publications.

Fanshel, D. 1976. Status changes of children in foster care: final results of the Columbia University longitudinal study. Child Welfare, LV, 3:

Flynn, T. C., P. Balch, S. B. Lewis, and B. Katz 1981. Predicting client improvement from and satisfaction with community mental health center services. American Journal of Community Psychology, 9(3): 339-46.

Fryer, G. E., D. C. Bross, R. D. Krugman, D. B. Denson, and D. Baird 1990. Good News for CPS Workers. Public Welfare, $27-2$ : $38-41$.

Garabino, James and Deborah Sherman 1980. Protecting Children from Abuse and Neglect: Developing and Maintaining Effective Support Systems for Families. San Francisco, CA: Jossey-Bass, Inc.

Giordano, Peggy C. 1977. The client's perspective in agency evaluation. Social Work, 22: 34-9.

Gold, N. 1990. Motivation: the crucial but unexplored component of social work practice. Social Work, 35(1): 49-55. 
Greenley, J. R. and R. A. Schoenherr 1981. Organization effects on client satisfaction with humaneness of service. Journal of Health and Social Behavior, 22: $2-18$.

Grossnickle, D., C. Hinsey, J. White, and J. Shireman 1986. An outcome Study of Child Protective Services. Salem, OR: Department of Human Resources, State of Oregon, Children's Services Division.

Gruber, A. R. 1978. Children in Foster Care. New York: Human Sciences press.

Guba, E. G. and Y. S. Lincoln 1991. Fourth Generation Evaluation. Beverly Hills, CA: Sage Publications.

Hartman, Ann and Joan Laird 1983. Family Centered Social Work Practice. New York: The Free Press.

Hasenfeld, Y. andM. A. Chesler 1989. Client empowerment in the human services: personal and professional agenda. The Journal of Applied Behavioral Science, 25(4): 499-521.

Hegar, R. L. 1989. Empowerment-based practice with children. Social Service Review, 63(3): 372-83.

Hegar, R. I. and J. M. Hunzeker 1988. Moving toward empowerment-based practice in public child welfare. Social Work, 33(6): 499-502.

Holder, W. M. and C. Mohr 1981. Helping in Child Protective Services. Englewood, CO: The American Humane Association.

Hulka, B. S., S. J. Zyzanski, and J. L. Cassell 1970. Scale for the measurement of attitudes toward physicians and primary medical care. Medical Care, 8: 429.

Kadushin, A. 1974. Child Welfare Services. New York: McMilian Co.

Kadushin, A. 1980. Child Welfare Services. 3rd ed. New York: McMillan Co.

Kopp, J. 1989. Self-observation: an empowerment strategy in assessment. Social Casework, 70(5): 276-84.

Koss, M., H. Hatry,A. Millar, and T. Van Houten 1980. Social Services: What Happens to the Clients. Washington, DC: The Urban Institute. 
Larsen, D. I., C. C. Attkisson, W. A. Hargreaves, and T. D. Nguyen 1979. Assessment of client satisfaction: Development of a general scale. Evaluation and Program Planning, 2: 197-207.

Lebow, J. L. 1974. Consumer assessments of the quality of medical care. Medical Care, 12: 328-37.

Lebow, J. L. 1983. Client satisfaction with mental health treatment: methodological considerations in assessment. Evaluation Review, $7(6)$ : 729-52.

Lewis, C. C., D. E. Scott, R. H. Pantell, and M. H. Wolf 1986. Parent satisfaction with children's medical care. Medical Care, 24(3): 209-15.

Linder-Pelz, S. 1982. Toward a theory of patient satisfaction. Soc Sci Med, 16(5): 577-82.

Linn, L. S. 1975. Factors associated with patient evaluation of health care. Health and Society: 531-48.

Loff, C. D., L. J. Trigg, and C. Cassels 1987. An evaluation of consumer satisfaction in a child psychiatric service: viewpoints of patients and parents. American Journal of Orthopsychiatry, 57(1): $132-4$.

Maas, H. and R. Engler 1959. Children in Need of Parents. New York: Columbia University Press.

Magura, Stephen 1982. Clients view outcomes of child protective services. Social Casework, 63: 522-31.

Magura, Stephen and Beth S. Moses 1984. Clients as evaluators in child protective services. Child Welfare, LXIII, 2: 99-112.

Magura, Stephen and Beth S. Moses 1986. Outcome Measures for Child Welfare Services. Washsington, DC: Child Welfare League of America.

Maluccio, A. N. 1979. Perspectives of social workers and clients on treatment oucome. Social Casework, 60: 394-401.

Maluccio, A. N. 1979. Promoting competence through life experience. Social Work Practice: People and Environments, ed. C. B. Germain. New York: Columbia University Press.

Maluccio, A. N. (ed.) 1981. Promoting Competence in Clients. New York: The Free Press. 
Maluccio, A. N. and P. A. Sinanoglu (ed.) 1981. The Challenge of Partnership: Working with the Parents of Children in Foster Care. New York: Child Welfare League of America.

McIver, J. P. and E. G. Carmines 1979. Unidimensional Scaling. Beverly Hills, CA: Sage Publications.

MCWilliams, S. A., S. B. Lewis, P. Balch, and J. Ireland 1979. Sample bias in questionnaire completion at a community mental health center. American Journal of Community Psychology, 7(1): 107-10.

Millar, A., H. P. Hatry, and M. Koss 1977. Monitoring the outcomes of Social Services, Vols. 1 and 2 . Washington, DC: The Urban Institute.

Murdach, A. D. 1980. Bargaining and persuasion with nonvoluntary clients. Social Work, 25(6): 458-61.

National Association of Public Child Welfare Administrators 1988. A Model System of Protective Services for Abused and Neglected Children and Their Families. Washington, DC: American Public Welfare Association.

National Commission on Child Welfare and Family Preservation 1991. A Commitment to Change. Washington, DC: American Public Welfare Association.

National Commission on Child Welfare and Family Preservation 1990. A Commitment to Change. Washington, DC: American Public Welfare Association.

Nugent, W. R. and J. A. Hankins 1989. The use of itemresponse theory in social work measurement and research. Social Service Review 63(3): 447-73.

Nunnally, J. C. 1978. Psychometric Theory, 2nd ed. New York: McGraw-Hill.

Oxley, G. B. 1966. Caseworkers' expectations and client motivation. Social Casework, 47: 432-7.

Patton, M. Q. 1980. Qualitative Evaluation Methods. Beverly Hills, CA: Sage Publications.

Poertner, J. 1986. The use of client feedback to improve practice: defining the supervisor's role. The clinical Supervisor, 4(4): 57-67.

Poertner, J. and R. Wintersteen undated. Measurement of Client Satisfaction with Social Work Services. 
Rappaport, J. 1981. In praise of paradox: a social policy of empowerment over prevention. American Journal of Community Psychology, 9(1): 1-25.

Robinson, J. P. and P. B. Shaver 1969. Measures of Social Psychological Attitudes. Survey Research Center Institute for Social Research.

Rooney, R. H. 1988. Socialization strategies for involuntary clients. Social Casework, 69(3): 131-40.

Rummel, R. J. 1969. Understanding factor analysis. Journal of Conflict Resolution, Vol. II: 444-80.

Shireman, J., D. Grossnickle, C. Hinsey, and J. White 1990. Outcome study of protective services: comparison of interviews and records as data sources. Child Welfare, LXIX, 2: 167-79.

Spector, W. D. and M. L. Drugovich 1989. Reforming nursing home quality regulation. Medical Care, 27(8): 789-801.

Stamps, P. I. and J. B. Finkelstein 1981. Statistical analysis of an attitude scale to measure patient satisfaction with medical care. Medical Care, 19(11): $1108-35$.

State of Oregon, Department of Human Resources, Children's Services Division 1989. A Study of Foster Care in oregon. (PAM 1557)

Stewart, M. A. and J. Wanklin 1978. Direct and indirect measures of patient satisfaction with physicians' services. Journal of Community Health, 3: 195 .

Stipak, B. 1980. Using clients to evaluate programs. Computers, Environment, and Urban Systems, 5: 137-54.

Study Findings: Study of National Incidence and Prevention of Child Abuse and Neglect: 1988 . (Contract No. 105-85-1702). Washington, DC: National Center on Child Abuse and Neglect.

Sue, D. W. 1981. Counseling the Culturally Different: Theory and Practice. New York: John Wiley and Sons

Tanner, B. A. 1979. Assessing client satisfaction with direct services. News, I: $15-6$. 
Tanner, B. A. 1981. Factors influencing client satisfaction with mental health services: A review of quantitative research. Evaluation and Program Planning, 4(314): 279-86.

Tanner, B. A. 1982. A multi-dimensional client satisfaction instrument. Evaluation and Program Planning, 5: 161-7.

U. S. Department of Health and Human Services 1981. Study Findings: National Study of the Incidence and Severity of Child Abuse and Neglect. DHHS Publication No. (OHDS) $81-30325$.

Ware, J. 1978. Effects of acquiescent response set on patient satisfaction ratings. Medical Care, 16(4): 327-336.

Ware, J., A. Davies-Avery, and A. L. Stewart 1978. The measurement and meaning of patient satisfaction. Hea1th and Medical Care Services Review, 1(1): 1-15.

Ware, J. E., Jr., and R. D. Hays 1988. Methods for measuring patient satisfaction with specific medical encounters. Medical Care, 26(4): 393-402.

Ware, J. E., Jr., and M. K. Snyder 1975. Differences in satisfaction with health care services as a function of recipient: self or others. (Contract No. HSM 110-72-299) Research Methods Branch, National Center for Health Services Research, DHEW.

Ware, H. E., Jr., and M. K. Snyder 1975. Dimensions of patient attitudes regarding doctors and medical care services. (Contract No. HSM 110-72-299) Research Methods Branch, National Center for Health Services Research, DHEW.

Ware, J. E., Jr., and M. K. Snyder 1975. Dimensions of patient attitudes regarding doctors and medical care services. Medical Care, 13: 669.

Ware, J. E., Jr., M. K. Snyder, and W. R. Wright 1976. Development and validation of scales to measure patient satisfaction with health care services: Vol. I of a final report, Part B: Results regarding scales constructed from the patient satisfaction questionnaire and measures of other health care perceptions. Southern Illinois University School of Medicine, Carbondale, IL. 
Ware, J. E., Jr., M. K. Snyder, and W. R. Wright 1977. Some issues in the measurement of patient satisfaction with health care services. Presented at Statistics section, 105th Annual Meeting of the American Public Health Association, Washington, DC, November 1977.

Wartman, S. A., L. L. Morlock, F. E. Malitz, and E. Palm 1981. Do prescriptions adversely affect doctor-patient interactions? American Journal of Public Health, 71(12): 1358-61.

Zastowny, T. R., K. J. Roghman, and A. Hengst 1983. Satisfaction with medical care: replications and theoretical re-evaluation. Medical Care, 21(3): 294-322

Zimmerman, R. S. 1988. The dental appointment and patient behavior. Medical Care, 26(4): 403-14.

Zyzanski, S. J., B. S. Hulka, and J. C. Cassell 1974. Scale for the measurement of "satisfaction" with medical care: modifications in content, format and scoring. Medical Care, 12(7): 611-20. 
APPENDIX A

DIMENSIONS OF SATISFACTION

FROM LITERATURE REVIEW 
DIMENSIONS OF SATISFACTION FROM LITERATURE REVIEW

I. Medical Care

(Anderscis, 1971)

1. Cost

2. Accessibility

3. Courtesy

4. Information

5. Coordination

III. Doctors and Medical Care (Ware, 1975)

1. Physician conduct

2. Availability of services

3. Continuity/convenience

4. Access mechanisms

V. Medical Care

(Langston, 1971)

1. Humaneness

2. Convenience

3. Technical aspects
II. Mental Health Treatment (Lebow, 1983)

1. Clinician

2. Outcome

3. Access

4. Confidentiality

5. Medicines

IV. Mental Health Services (Murphy, 1979)

1. Relationship

2. Goal achievement

3. Amount of advice

4. Satisfaction

VI. General Social Services

(Reid \& Gundlach, 1983)

1. Relevance

2. Impact

3. Gratification

VII. Mental Health Services (Larsen, 1979)

1. Physical surroundings

2. Support staff

3. Kind/type of service

4. Treatment staff

5. Amount, length, quantity of
6. Quality of service

7. Outcome of service

8. General satisfaction

9. Procedures

VIII. Medical Care (Hulka et al., 1970)

1. Personal qualities of physicians

2. Professional qualities/competence

3. Cost and convenience of services

IX. General Health and Human Services

(Greenley \& Schoernherr, 1981)

1. Humaneness of staff

2. Technical competence

3. Verbal Instructional behavior

X. Mental Health Services (Tanner, 1982)
1. Satisfaction
2. Helpfulness
4. Respect
3. Accessibility
5. Partnership 
APPENDIX B

CLIENT SATISFACTION INTERVIEW SCHEDULE 


\section{CLIENT SATISFACTION INTERVIEW SCHEDULE}

1. Can you tell me a little about your experiences with CSD/the situations which opened your case?

\section{$\underline{\text { Services }}$}

2. Were you offered any services by CSD? Any by referral?

3. Were these services simply offered to you voluntarily, or did you feel forced or told that you must participate? Was this good or bad? (How did you feel about this?

4. Do you feel that the services you received contributed to making things (better or worse)?

4a. What services do you feel have been most helpful/ useful? How - be specific.

4b. What services do you feel have been least helpful/ useful? How - be specific.

5. What services/help should CSD be offering or providing that they are not? Do you feel they are unable or unwilling to do these things?

6. Overall, how satisfied are you with the services you received from CSD?

Caseworker (If more than one, please discuss a11.)

7. What did your caseworker do to make things better? What was helpful? What did you like most about your caseworker?

8. What did your caseworker do to make things worse? What wasn't helpful? What did you like least about your caseworker?

9. What would you like to see changed about your caseworker? (What should your caseworker have done differently?) What should remain the same? 
Process/Communication

10. What did you like/find helpful about the process/ communication of keeping you informed?

11. What didn't you like/find helpful about the process/ communication of keeping you informed?

12. In general, how well do you feel that you were kept informed concerning the various legal and other processes involved in your case? (Do you feel that you understood what was going on or were you generally confused?)

13. Do you have any suggestions for improving communications between parents/clients and CSD?

14. To what extent do you feel that you were included in, or that you participated in, the planning and decisionmaking concerning your case/family? How did you feel about this?

15. To what extent do you feel that you understood what was expected of you; what you needed to do?

\section{General}

16. What did you like the most about CSD? (What do you think helped you the most?)

16a. Was there anything that you liked about CSD; was anything helpful?

17. What didn't you like about CSD? (What were you unhappy with about the agency?)

17a. Was there anything that you didn't like about CSD; was anything not helpful?

18. What changes would you recommend for CSD to make in its Protective Services Program?

19. Do you have any further comments or concerns, either positive or negative, about CSD that we haven't covered?

20. If the situation that we have been discussing hadn't come to the attention of some agency, what do you think would have happened? 
21. Either at the time that you were actively involved with CSD or in looking back, did you feel isolated/that you were the only person going through that sort of situation?

22. In general, how satisfied are you with your relationship with CSD? 


\section{APPENDIX C}

CLIENT SATISFACTION SURVEY

PRE-TEST 


\section{CLIENT SATISFACTION SURVEY}

Please respond to each of the statements found on the next two pages by choosing one of the following six choices and marking the appropriate box:

$\begin{array}{ll}\text { Strongly Agree } & \text { Agree } \\ \text { Disagree } & \text { Strongly Disagree }\end{array}$

1. CSD offered help that I could either decide to use or decide not to use - the choice was mine.

2. I was under pressure from CSD to participate in the programs that they were offering.

3. Overall, the services I received were helptul.

4. Services were offered to everyone in my family that I felt needed help.

5. What was done for my family situation seemed to be chosen specifically to fit our individual circumstances.

6. Overall, CSD kept me well informed.

7. CSD was clear in stating their expectations of me.

8. My opinions were taken into consideration in making decisions.

9 I understood what was going on.

10. I was an active participant in the decisions being made concerning my family.

11. CSD was not fair in their handling of my situation.

12. The overall feeling that $I$ had in dealing with CSD was one of powerlessness.

13. CSD came into my tife in a time of crisis and helped me through it.

14. CSD came into my life and took over.

15. In my panticular case, CSD lost sight of what was in the best interest of my children.

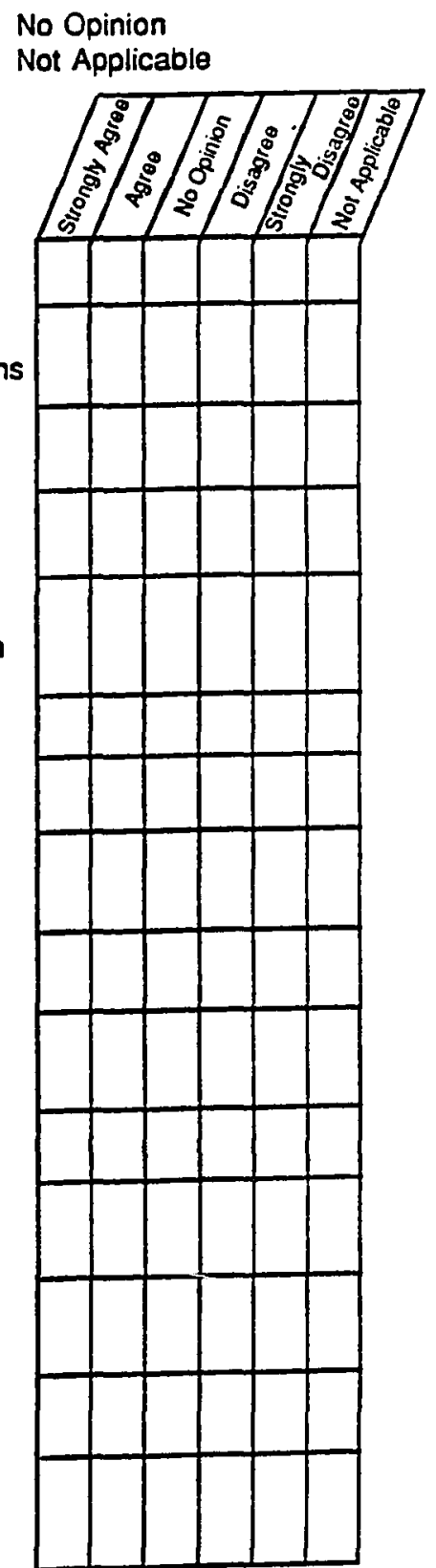


Please respond to each of the following statements by choosing one of these six choices and marking the appropriate box:

$\begin{array}{ll}\text { Strongly Agree } & \text { Agree } \\ \text { Disagree } & \text { Strongly Disagree }\end{array}$

16. CSD needs to follow a consistent set of policies and procedures for handling situations like mine.

17. CSD needs to stop processing people and, instead, provide individual support and help to individual situations.

18. CSD should be an agency you go to for help in solving a problem - not to get investigated and treated like a criminal.

19. CSD should treat families who want to work with CSD differently from families who do not want to cooperate.

20. CSD should be more supportive and less controlling.

21. I agree with what CSD is trying to do - to protect children from harm.

22. In order to protect children from harm, CSD needs to be controlling and punitive toward those accused of abuse.

23. I had trouble finding the local CSD office.

24. I had to wait too long for my appointment.

25. It was easy finding transportation to the local CSD office.

26. The recontionist was friendly and easy to talk to.

27. I find the local CSD office to be a satistactory place to visit my children.

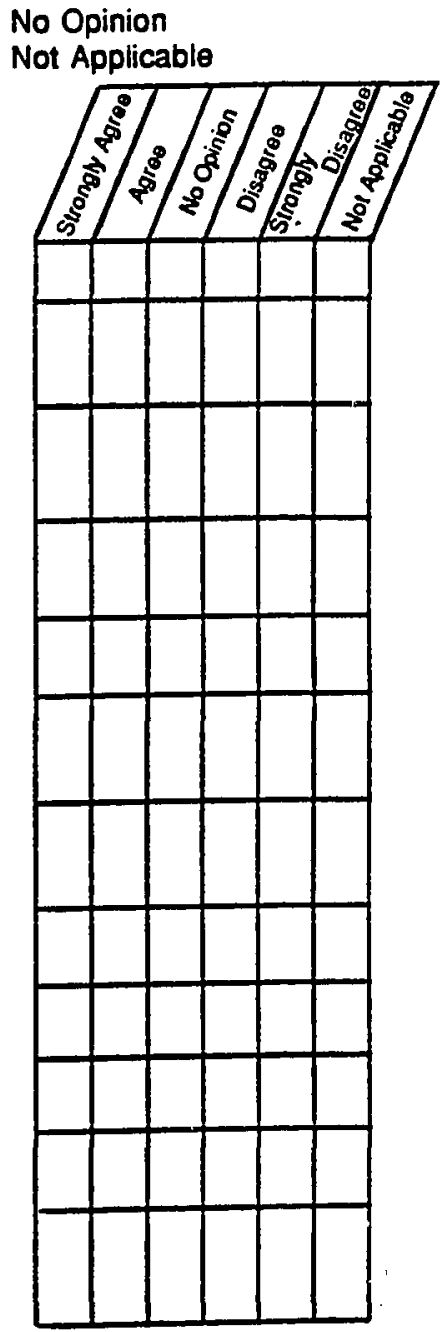


Below is a list of words that have been used to describe some caseworkers. Please check whether you agree or disagree that these words describe your caseworker.

Strongly
Good Listener
Critical
Supportive
Unavailable
Honest
Controlling
Open-minded
Knowledgeable
Judgemental
Understanding
Caring
Not Helptul
Unfair




\section{LIST OF SERVICES}

For each of the services below that you received, please indicate how helpful you feel the service was in dealing with your individual or family situation.

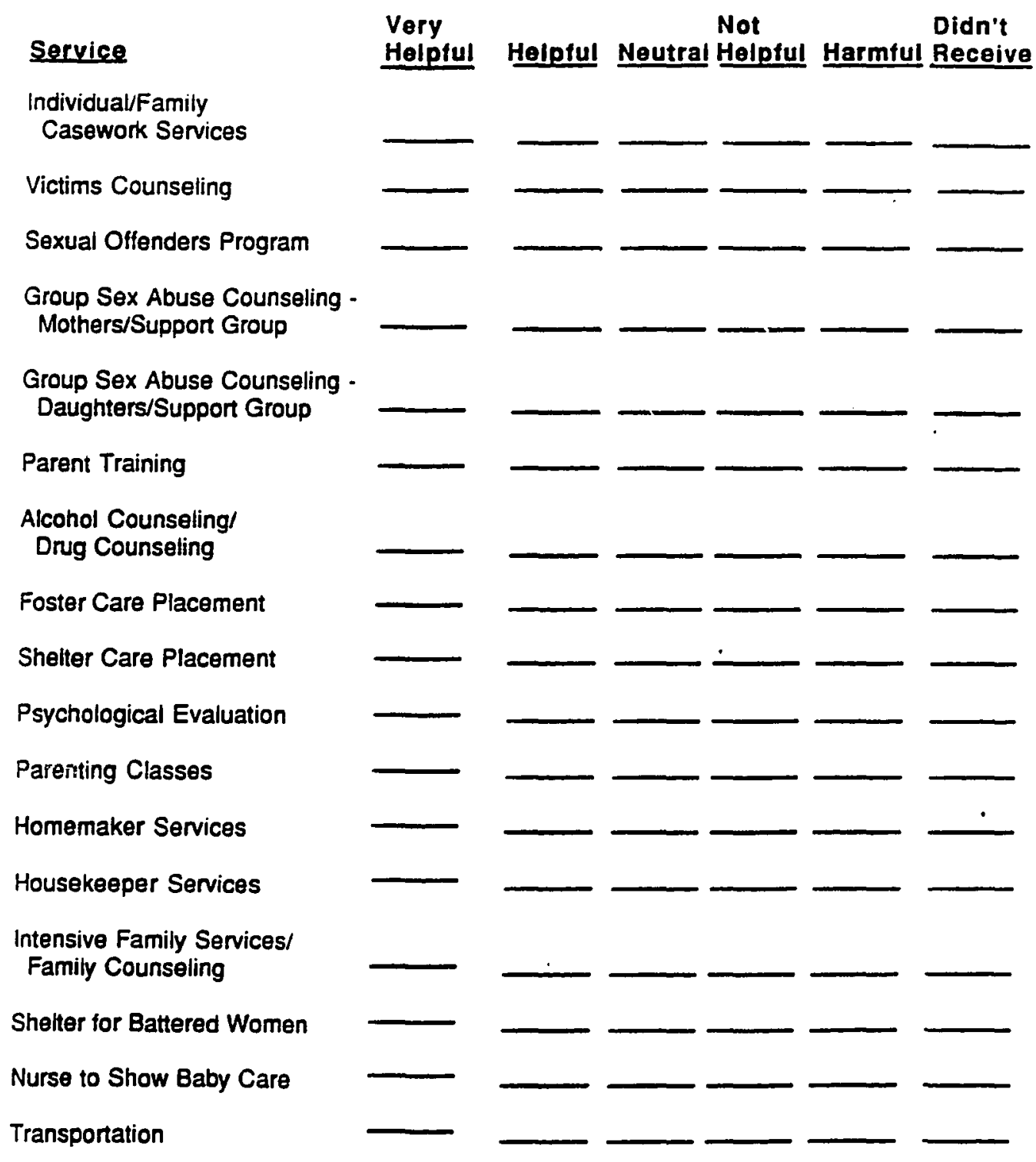

Thank you for your help! 


\section{APPENDIX D}

CLIENT SATISFACTION SURVEY ITEMS

ILISTED BY DOMAIN 


\section{CLIENT SATISFACTION SURVEY ITEMS}

\section{LISTED BY DOMAIN}

Items in the Helpfulness Domain

1. The services I received helped me deal more effectively with my family's problems.

9. Things have not improved with my family life.

13. Considering my particular needs, the kinds of services I received were appropriate.

30. CSD has helped me improve my skills as a parent.

31. Overall, the services I received were not helpful.

32. What was done for my family fit our individual situation.

\section{Items in the Partnership Domain}

3. I agreed with CSD's plan for my family.

10. My caseworker and I did not agree on what problems needed to be worked on.

17. I felt that my caseworker was doing his/her part to help resolve my family's problems.

24. My opinions were not considered in making decisions.

33. I was an active participant in the decisions being made concerning my family.

\section{Items in the Choice Domain}

6. CSD offered help that I could either decide to use or decide not to use - the choice was mine.

16. CSD forced me to participate in the services that they offered.

22. The overall feeling that $I$ had in dealing with CSD was one of powerlessness. 
Items in the Choice Domain (continued)

26. CSD came into my 1 ife and took over against my wishes.

36. If my family needed help in the future, I would return to CSD.

Items in the Information Sharing Domain

4. I was not told about ways that I could complain about my contact with CSD.

8. Overall, CSD kept me well informed.

11. My caseworker explained what was happening with my case.

25. CSD was not clear in stating their expectations of me.

29. I was never sure whether my case was open or closed.

34. I did not understand what was going on with my case.

Items in the General Satisfaction Domain

2. I am not satisfied with my family life.

15. In general, considering all of my contacts with CSD, and all of the services my family received, I am satisfied with CSD.

18. I am displeased with what happened with CSD and my family.

20. Services were offered to everyone in my family who needed help.

23. CSD helped me through a time of crisis. 
APPENDIX E

\section{CLIENT SATISFACTION SURVEY}

FINAL INSTRUMENT 
19. It was not easy getting to the local CSO office.

$$
\text { _Strongly Agree _- Agree _ Nol Sure__Disagree__Srongly Disagree }
$$

20. Services were offered to everyone in my family who needed help.

$$
\text { —Strongly Agree _Agree _-Not Sure _- Disagree _ _trongly Disagrea }
$$

21. CSD should be an agency you go to for help in solving a problem - not to get investlgated and treated like a criminal.

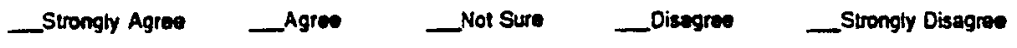

22. The overall teeling that $I$ had in dealing with CSD was one of powerlessness.

_Strongty Agree _-Agree - Not Sure _Oisagree _Strongly Disagree

23. CSD helped me through a time of crisis.

$$
\text { _strongly Agres _-Agres_-Not Sure _ Disagree - Strongly Disagres }
$$

24. My opinions were not considered in making decisions.

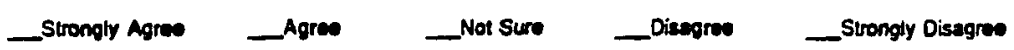

25. CSD was not clear in stating their expectations of me.

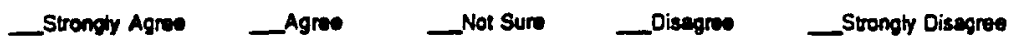

26. CSD came into my life and tsok over against my wishes.

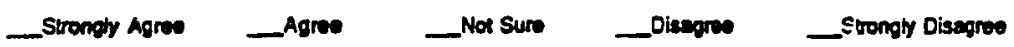

27. The receptionist at the CSD office was friendly and made me feel comfortable.

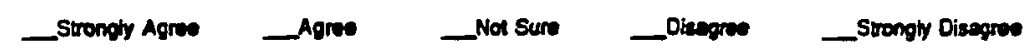

28. CSD should be more supportive and less controlling.

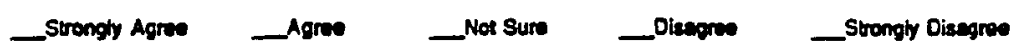

29. I was never sure whether $\mathrm{my}$ case was open or closed.

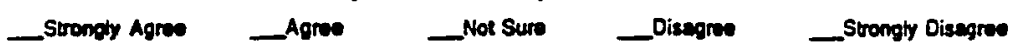

30. CSD has helped me improve my skills as a parent.

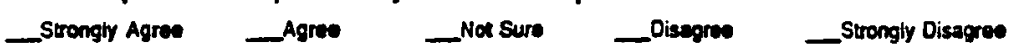

31. Overall, the services I receiyed were not helpful.

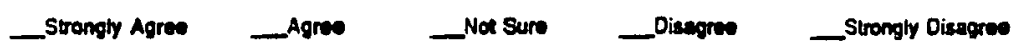

32. What was done for my family fit our individual situation.

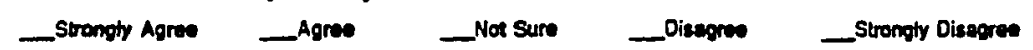

33. I was an active participant in the decisions being made conceming my family.

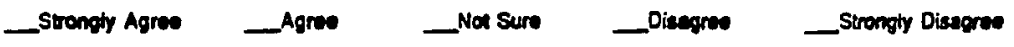

34. I did not understand what was going on with my case.

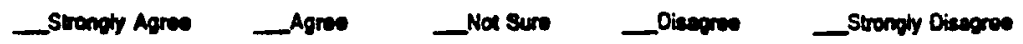

35. The local CSD office is a satlafactory place for parents to visit their children.

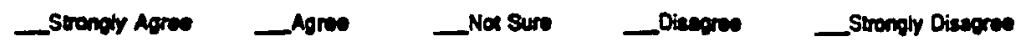

36. If my family needed help in the future, I would return to CSD.

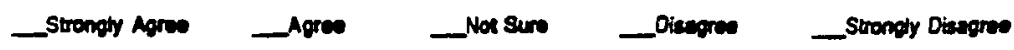

37. I agree with what CSD is trying to do - to protect children from harm.

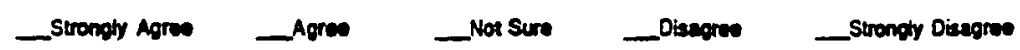


38. To protect children from harm, CSD needs to punish those accused of abuse.

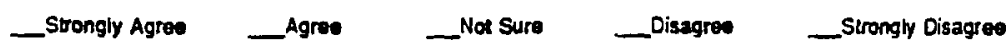

39. CSD was not fair in handling my situation.

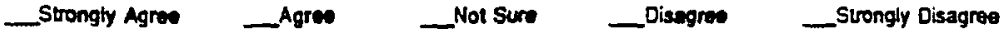

Below is a list of words that have been used to describe caseworkers. Please check whether you agree or disagree that these words describe your caseworker.

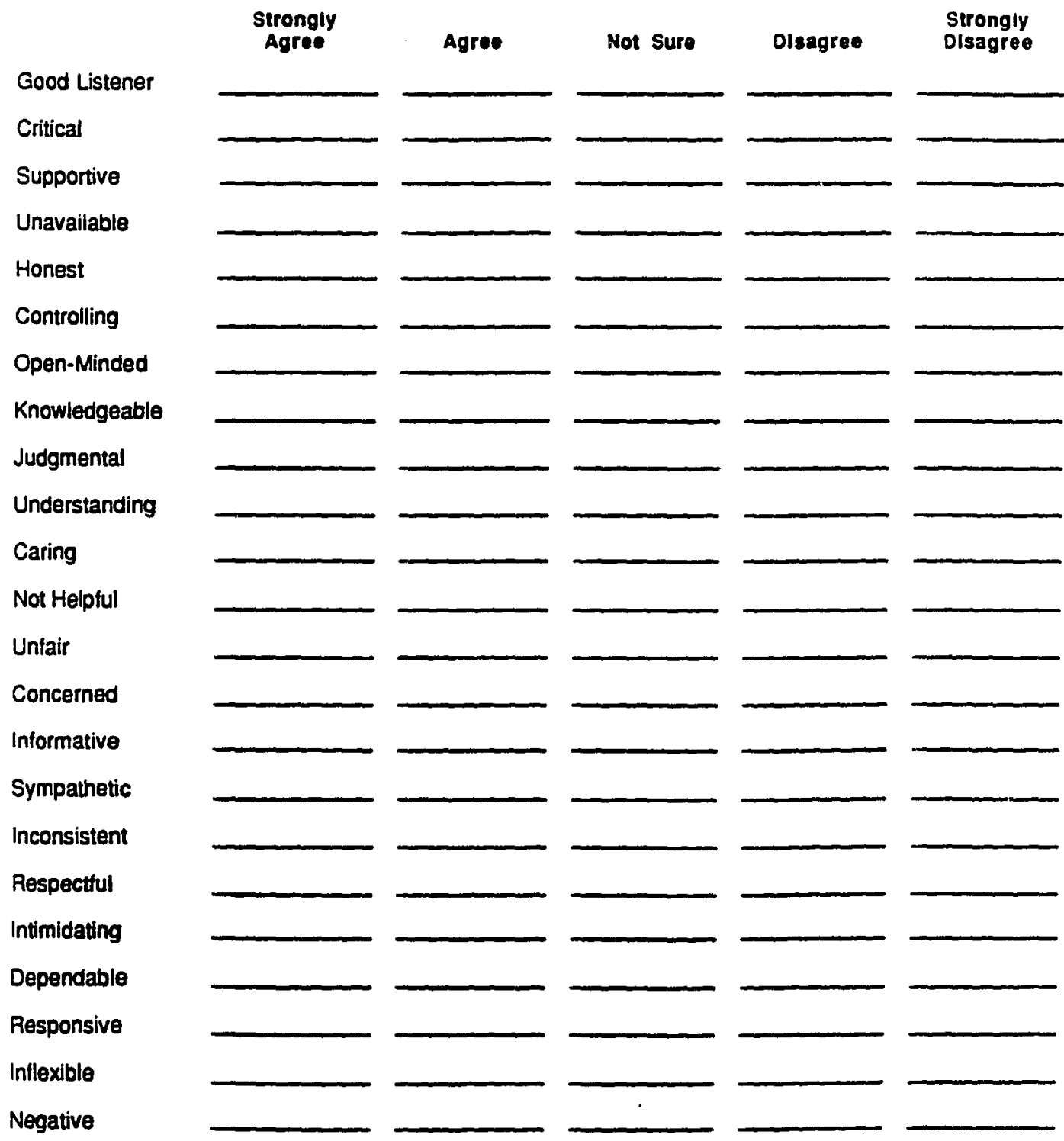


Cor each of the services below. please indicate how helpful you feel the service was in dealing with your individual or family situation. Please note any services which your family did not receive by checking the appropriate response.

$\begin{array}{cccc}\text { Vory } & \text { Somewhat Not Somewhat } & \text { Very } & \text { Did not } \\ \text { Helptul } & \text { Helpful Sure Unhelpful Unhelptul Receive }\end{array}$

Direct Caseworker Contact

Victims' Counseling

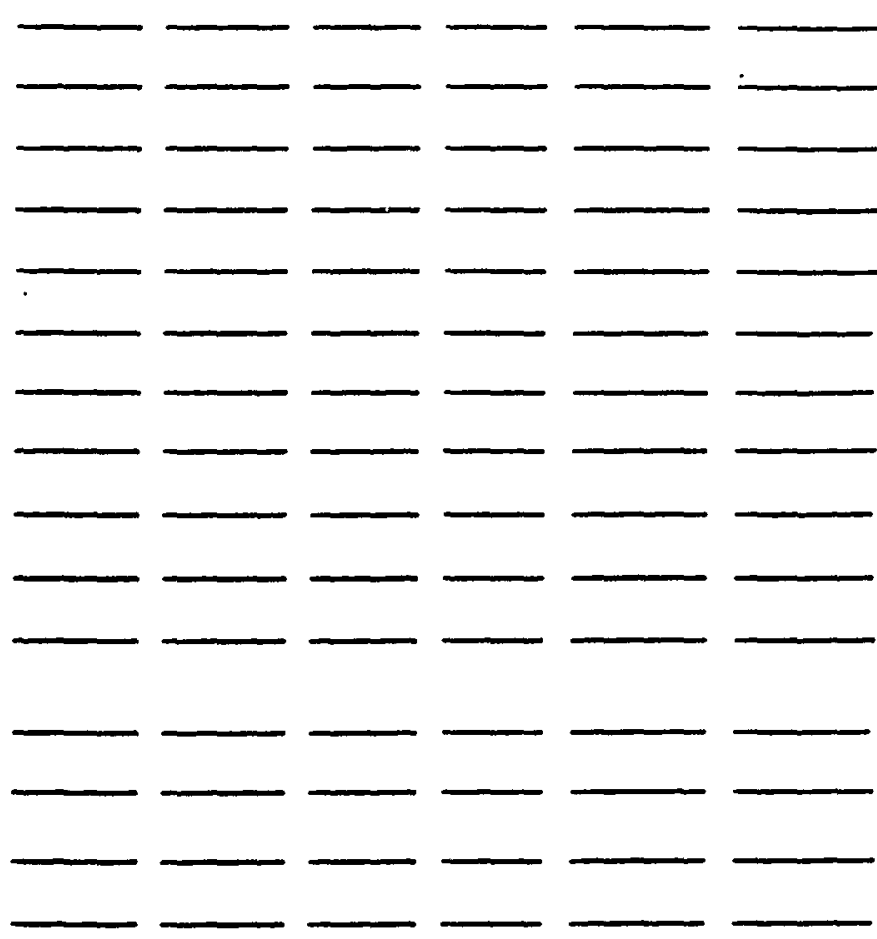

Thank You For Your Helpl!

Mothers' Sex Abuse Support Group

Victims' Sex Abuse Support Group

Parent Training/Parenting Classes

Alcohol /Drug Counseling

Out-of-home Placement

Psychological Evaluation

Homemaker Services

Housekeeper Services

Family Counseling/Intensive Family Services

Shelter for Battered Women

Nurse to Instruct Newbom Baby Care

Other (list):

Person(s) responding to this survey:

_Mother

Father

Both Other:

Please use this space If you have additional comments. 
APPENDIX F

CLIENT SATISFACTION SURVEY

COVER LETTER 


\section{CLIENT SATISFACTION SURVEY}

Children's Services Division is gathering information from its clients concerning its programs and services. The purpose is to determine where the agency is doing a good job and were improvements are needed.

You have been asked to participate because your family has been involved with CSD. All of the information that you provide will be kept confidential. Tour identity will be kept anonymous. Your answers will not be shared with your caseworker or anyone else connected with your individual case. Your honest opinions on these questions will help CSD make decisions about how to improve its services.

To repeat: Your participation is voluntary -- it is entirely your choice to answer the questions or not answer them. By agreeing to participate, you will be giving CSD important information about your contact with the agency.

Please place the completed form in the pre-addressed envelope provided and mail to the CSD Research and Statistics Section; no stamp is needed.

If you have any questions or concerns, please call Jim White in Salem at 1-503-378-4513 or 1-800-556-6616. 
APPENDIX G

CORRELATIONS AMONG 22 CLIENT SATISFACTION ITEMS

GROUPED BY DOMAIN 
CORRETATIONS AMONG 22 CLIENT SATISFACTION ITEMS GROUPED BY DOMAIN

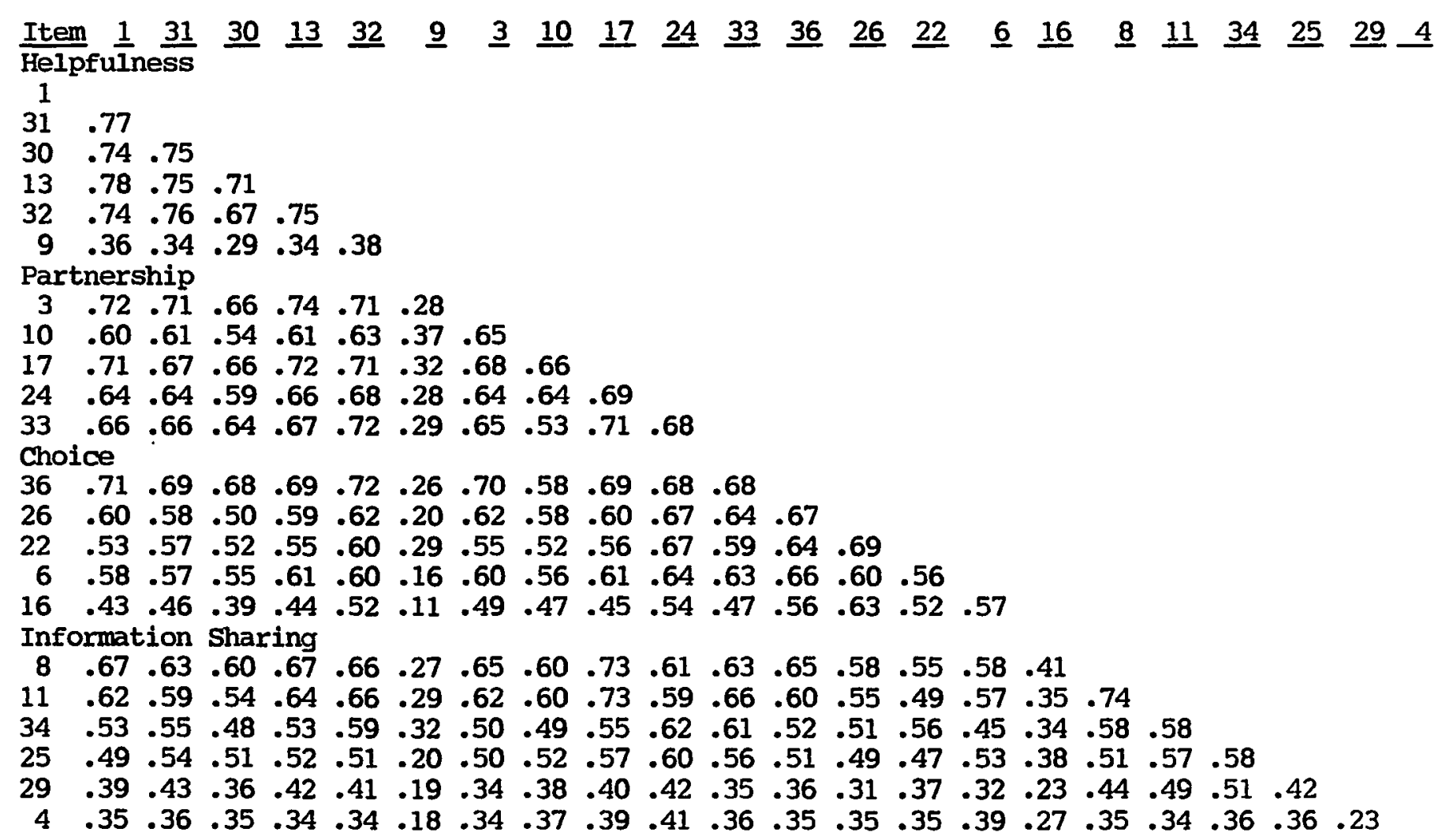

